\title{
Auxílio na Prevenção de Doenças Crônicas por meio de Mapeamento e Relacionamento Conceitual de Informações em Biomedicina
}

\section{Juliana Tarossi Pollettini}

\author{
DISSERTAÇÃO APRESENTADA \\ $\mathrm{AO}$ \\ PROGRAMA INTERUNIDADES EM BIOINFORMÁTICA \\ DA \\ UNIVERSIDADE DE SÃO PAULO \\ PARA \\ OBTENÇÃO DO GRAU DE MESTRE \\ EM \\ CIÊNCIAS \\ Área de Concentração: Bioinformática \\ Orientador: Profa. Dra. Alessandra Alaniz Macedo
}

Durante a elaboração deste trabalho a autora recebeu apoio financeiro da FAPESP

- Ribeirão Preto, novembro de 2011 - 


\title{
Auxílio na Prevenção de Doenças Crônicas por meio de Mapeamento e Relacionamento Conceitual de Informações em Biomedicina
}

\author{
Este exemplar corresponde à redação final \\ da dissertação de mestrado devidamente \\ corrigida e defendida por \\ Juliana Tarossi Pollettini \\ e aprovada pela comissão julgadora.
}

Ribeirão Preto, 28 de novembro de 2011.

\section{Banca Examinadora:}

- Profa. Dra. Alessandra Alaniz Macedo (Orientadora) - FFCLRP-USP

- Prof. Dr. Evandro Eduardo Seron Ruiz - FFCLRP-USP

- Profa. Dra. Viviane Cunha Cardoso - FMRP-USP 
Dedico esta dissertação à minha família, por sua grande contribuição em minha formação como pessoa. Em especial a meus pais, Geronymo Junior e Eliana, pelo amor incondicional, carinho e atenção, assim como por todo o apoio provido para a concretização de meus sonhos. 


\section{Agradecimentos}

A Deus, que ao longo de toda minha vida caminhou a meu lado e que, nos momentos mais difíceis de minha caminhada, não me abandonou, mas me "carregou no colo".

À Fundação de Amparo à Pesquisa do Estado de São Paulo (FAPESP) por ter apostado em minha capacidade para desenvolver o projeto e financiado esta pesquisa. Sem este apoio, o desenvolvimento do trabalho não seria possível.

À Universidade de São Paulo, pela oportunidade de nela estudar e a todos os contribuintes do estado de São Paulo, que indiretamente colaboraram para minha formação através do pagamento de seus impostos, dos quais esta universidade depende.

À minha orientadora, Profa. Dra. Alessandra Alaniz Macedo, que muito me ensinou em todos esses anos de convivência, contribuindo para meu crescimento científico e intelectual. Por ter me orientado com muita competência, paciência e disposição, inclusive incorporando papel de psicóloga em momentos nos quais situações cotidianas abalaram meu equilíbrio emocional.

À Profa. Dra. Sandra Grisi, por suas contribuições para o contexto de aplicação do presente trabalho. Às Dras. Filumena Maria da Silva Gomes e Maria Helena Valente, por todas as suas colaborações para o desenvolvimento do trabalho, como o preenchimento da coleção de referência para avaliação do trabalho e considerações importantes para o entendimento do contexto de aplicação. A Sílvia Y. Bando, pela análise da lista de conceitos sobre mecanismos epigenéticos. Aos demais membros da equipe do departamento de Pediatria da FM-USP que, direta ou indiretamente, contribuíram para o presente trabalho. À Equipe KEDRI da Auckland University of Technology, pela disponibilização da Chronic Disease Ontology.

Aos Profs. Drs. Carlos A. Moreira-Filho e Thiago A. S. Pardo pela contribuições na banca de qualificação. Ao Prof. Dr. Evandro E. S. Ruiz, pelas contribuições dadas ao trabalho e pelos diversos conselhos que me deu durante minha vida acadêmica, desde os primeiros anos de graduação em Informática Biomédica. Esses conselhos foram muito importantes para algumas decisões que tomei nesse período. Ao Prof. Dr. Benito F. Pires, pela ajuda com relação à simulação de casos para a coleção de referência e com o 
software Mathematica. Ao Prof. Dr. Ricardo Z. N. Vêncio que colaborou bastante no início do desenvolvimento do projeto, pela identificação de que o trabalho pertencia à área de Bioinformática Translacional e artigos relacionados.

À Patrícia Martorelli, por toda a ajuda que me deu durante esse período de mestrado, principalmente por estar sempre disponível para atender solicitamente cada pedido e cada trâmite burocrático necessários para que eu pudesse concluí-lo. Aos secretários e técnicos do Departamento de Computação e Matemática, antigo Departamento de Física e Matemática e seção de pós-graduação da FFCLRP, pela ajuda com questões burocráticas que deveriam ser resolvidas em Ribeirão Preto. Aos membros da Comissão de PósGraduação do programa Interunidades em Bioinformática, pelas decisões que afetaram direta ou indiretamente este trabalho.

À Flávia Pena Nicolas que desenvolveu seu Trabalho de Conclusão de Curso (TCC) no contexto do tema deste trabalho e a Equipe da Universidade de Michigan que colaborou para seu projeto de TCC. Aos alunos de pós-graduação do Departamento de Computação e Matemática, principalmente a Daniane Silva de Paula, Gisele H. B. Miranda, Flávia A. Miyasaki, Lariza L. de Oliveira e Hugo C. Pessotti, que estiveram presentes em muitos momentos importantes do desenvolvimento deste trabalho e estavam sempre disponíveis para um conselho, uma conversa ou um café. Aos amigos do curso de Informática Biomédica, do Vita et Pax e de Mogi Mirim, que estiveram presentes em muitos momentos importantes de minha vida. A Thiago Martini da Costa, por tudo o que me ensinou no tempo em que esteve fisicamente neste mundo e pela promessa de ajuda na revisão desta dissertação, a qual tenho certeza de que só não foi cumprida por ele ter sido chamado para outras moradas antes da conclusão deste mestrado.

À minha família que sempre me apoiou e me deu forças para realizar cada atividade em minha vida. Principalmente, a meus pais e a meus irmãos, Lucas e João Paulo, que proporcionaram a concretização de tudo o que conquistei em minha vida, foram os principais responsáveis pela formação de meu caráter e sempre demonstraram muito amor, carinho e compreensão.

Ao meu namorado, Newton Shydeo Brandão Miyoshi, por ter auxiliado na revisão desta dissertação, ouvido pacientemente todas as minhas preocupações e me ajudado em praticamente todos os momentos. Por sua paciência, apoio e companheirismo inestimáveis!!!

Enfim, a todos os que contribuíram, direta ou indiretamente, para mais essa conquista em minha vida, MUITO OBRIGADA. 
"Ninguém é tão grande que não possa aprender, nem tão pequeno que não possa ensinar." Autor desconhecido 


\section{Resumo}

Pesquisas recentes em medicina genômica sugerem que fatores de risco que incidem desde a concepção de uma criança até o final de sua adolescência podem influenciar no desenvolvimento de doenças crônicas da idade adulta. Artigos científicos com descobertas e estudos inovadores sobre o tema indicam que a epigenética deve ser explorada para prevenir doenças de alta prevalência como doenças cardiovasculares, diabetes e obesidade. A grande quantidade de artigos disponibilizados diariamente dificulta a atualização de profissionais, uma vez que buscas por informação exata se tornam complexas e dispendiosas em relação ao tempo gasto na procura e análise dos resultados. Algumas tecnologias e técnicas computacionais podem apoiar a manipulação dos grandes repositórios de informações biomédicas, assim como a geração de conhecimento. O presente trabalho pesquisa a descoberta automática de artigos científicos que relacionem doenças crônicas e fatores de risco para as mesmas em registros clínicos de pacientes. Este trabalho também apresenta o desenvolvimento de um arcabouço de software para sistemas de vigilância que alertem profissionais de saúde sobre problemas no desenvolvimento humano. A efetiva transformação dos resultados de pesquisas biomédicas em conhecimento possível de ser utilizado para beneficiar a saúde pública tem sido considerada um domínio importante da informática. Este domínio é denominado Bioinformática Translacional (BUTTE, 2008). Considerando-se que doenças crônicas são, mundialmente, um problema sério de saúde e lideram as causas de mortalidade com $60 \%$ de todas as mortes, o presente trabalho poderá possibilitar o uso direto dos resultados dessas pesquisas na saúde pública e pode ser considerado um trabalho de Bioinformática Translacional. 


\section{Abstract}

Genomic medicine has suggested that the exposure to risk factors since conception may influence gene expression and consequently induce the development of chronic diseases in adulthood. Scientific papers bringing up these discoveries indicate that epigenetics must be exploited to prevent diseases of high prevalence, such as cardiovascular diseases, diabetes and obesity. A large amount of scientific information burdens health care professionals interested in being updated, once searches for accurate information become complex and expensive. Some computational techniques might support management of large biomedical information repositories and discovery of knowledge. This study presents a framework to support surveillance systems to alert health professionals about human development problems, retrieving scientific papers that relate chronic diseases to risk factors detected on a patient's clinical record. As a contribution, healthcare professionals will be able to create a routine with the family, setting up the best growing conditions. According to Butte, the effective transformation of results from biomedical research into knowledge that actually improves public health has been considered an important domain of informatics and has been called Translational Bioinformatics. Since chronic diseases are a serious health problem worldwide and leads the causes of mortality with $60 \%$ of all deaths, this scientific investigation will probably enable results from bioinformatics researches to directly benefit public health. 


\section{Sumário}

\section{Lista de Figuras}

Lista de Tabelas

1 Introdução $\quad$ p. 13

1.1 Contextualização . . . . . . . . . . . . . . . . . . p. 13

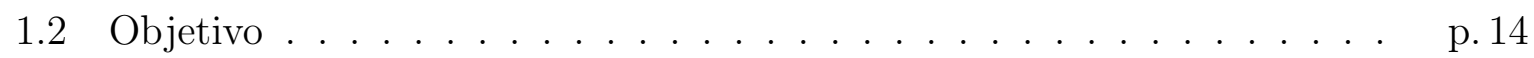

1.3 Metodologia e Resultados . . . . . . . . . . . . . . p. 15

1.4 Organização do Documento . . . . . . . . . . . . . p. 15

2 Doenças Crônicas e Fatores Epigenéticos $\quad$ p. 17

2.1 Doenças Crônicas . . . . . . . . . . . . . . . p. 17

2.2 Fatores de Risco Genéticos e Epigenéticos . . . . . . . . . . . . . p. 19

2.3 Considerações do Capítulo . . . . . . . . . . . . . . . . p. 23

3 Tratamento de Informações em Texto Livre para Biomedicina p. 24

3.1 Recuperação de Informação . . . . . . . . . . . . . . . . p. 25

3.1.1 Modelos Clássicos para Representação de Documentos . . . . p p. 27

3.1.2 Expansão de Consultas . . . . . . . . . . . . . . . . p. 28

3.2 Mineração de Texto para Literatura e Registros Clínicos . . . . . . . . p. 29

3.3 Processamento de Linguagem Natural . . . . . . . . . . . . . . p. 31

3.4 Artefatos Linguísticos . . . . . . . . . . . . . . . p. 32

3.4 .1 Ontologia . . . . . . . . . . . . . . . p. 32 


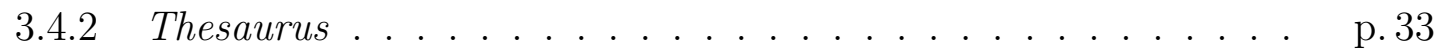

3.4.3 Unified Medical Language System (UMLS) . . . . . . . . . . . p. 34

3.4.4 Chronic Disease Ontology (CDO) . . . . . . . . . p. 37

3.5 Terminologia Computacional . . . . . . . . . . . . . . p. 38

3.6 Inteligência Artificial e Aprendizado de Máquina . . . . . . . . . . . p. 38

3.7 Relacionamentos Textuais Semânticos em Biomedicina . . . . . . . p. p. 40

3.8 Considerações do Capítulo . . . . . . . . . . . . . . . . p. 44

4 Sistema de Vigilância para Doenças Crônicas (SisViDas) p. 46

4.1 Projeto e Criação do SisViDas . . . . . . . . . . . . . p. p. 46

4.1.1 Criação e Atualização da Coleção de Artigos Científicos . . . . . p p.50

4.1.2 Processamento Textual e Armazenamento de Informações . . . . p.51

4.1.3 Identificação de Conceitos Médicos: Interação com o UMLS p.52

4.1.3.1 Abordagem 1: UTS Web Service API . . . . . . . p. 52

4.1.3.2 Abordagem 2: MetaMap ........... p. . 53

4.1.3.3 Resultados Comparativos do Uso do UMLS . . . . . p. 53

4.1.4 Processamento de Similaridade entre Documentos . . . . . . . p. 55

4.1.5 Expansão de Consultas . . . . . . . . . . . . . . p. 55

4.1 .6 Interface com o Usuário . . . . . . . . . . . . . . p. 56

4.1.7 Classificação de Pacientes em Grupos de Risco . . . . . . . . . . p.57

4.2 Exemplo de Uso e Resultados . . . . . . . . . . . . . . . . p. 59

4.3 Considerações do Capítulo . . . . . . . . . . . . . . . p. 60

5 Arcabouço de Software para Sistemas de Vigilância Epidemiológica apoiados por Relacionamentos Textuais Semânticos p. 63

5.1 Exemplos Utilizados para Abstração do Arcabouço . . . . . . . . . . p. p. 64

5.1 .1 GV-Automático . . . . . . . . . . . . p. 64

5.1.2 Sistema de Vigilância para Outras Enfermidades . . . . . . . . p. 66 
5.2 Identificação de Pontos Fixos e de Flexibilização . . . . . . . . . . . p. 66

5.3 Projeto do Arcabouço . . . . . . . . . . . . . . . . . p. 67

5.4 Diagrama de Classes . . . . . . . . . . . . . . . . p. 68

5.5 Considerações do Capítulo . . . . . . . . . . . . . . . . . p. 69

6 Avaliação e Resultados para o Caso de Uso SisViDas p.71

6.1 Simulação de Prontuários . . . . . . . . . . . . . . . . . . p. 72

6.2 Criação de Coleção de Referência . . . . . . . . . . . . . . . . . . p.73

6.3 Avaliação de Precisão e Revocação . . . . . . . . . . . . . . . . p.75

6.3.1 Precisão e Revocação com Coleção de Referência . . . . . . . . . p p.76

6.3.2 Precisão e Revocação com Termos MeSH . . . . . . . . . . . . p. p8

6.4 Resultados para Ferramentas de Busca . . . . . . . . . . . . . p. 79

6.4.1 Busca por Prontuário . . . . . . . . . . . . p. 80

6.4 .2 Busca por Expressão . . . . . . . . . . . . . . . . p. 81

6.5 Considerações do Capítulo . . . . . . . . . . . . . . . . . p. 88

7 Conclusão $\quad$ p. 90

7.1 Contribuições . . . . . . . . . . . . . . . . . p. 90

7.2 Dificuldades e Limitações . . . . . . . . . . . . . . . . . . . . p. p1

7.3 Trabalhos Futuros e em Andamento . . . . . . . . . . . p. 91

$\begin{array}{ll}\text { Referências } & \text { p. } 94\end{array}$

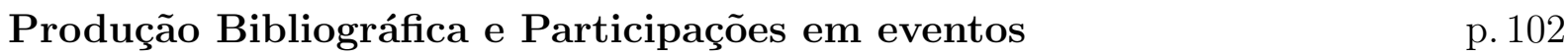

Apêndice A - Mecanismos Epigenéticos $\quad$ p. 106

$\begin{array}{lr}\text { Apêndice B - Consulta PubMed } & \text { p. } 107\end{array}$ 


\section{Lista de Figuras}

1 Etiologia multifatorial de doenças. Fonte: Cecil Medicine (KORF, 2008).

p. 21

2 Número de artigos do MEDLINE através dos anos. Fonte dos dados: http://www.nlm.nih.gov/bsd/medline_cit_counts_yr_pub.html. Acessado em 04/02/2011. p. 25

3 O processo de recuperação de informação. Fonte: (BAEZA-YATES; RIBEIRONETO, 1999) . . . . . . . . . . . . . . . . . . p. 26

4 Diagrama de Casos de Uso . . . . . . . . . . . . . . . . . p. 47

5 Requisitos para caso de uso de atualização da coleção de artigos científicos . $\quad$ p. 47

6 Requisitos para caso de uso de recuperação de artigos para um registro clínico p. 48

7 Infraestrutura do SisViDas com processos e repositório. . . . . . . . . . p. 50

8 Interface Gráfica de Usuário para submissão de consultas por fatores potenciais ou registros clínicos em formato texto . . . . . . . . . . . . . p. 58

9 Interface Gráfica de Usuário para exibição de resultados para uma consulta submetida . . . . . . . . . . . . . . . . . . p. 58

10 Infraestrutura, com processos e repositório, do arcabouço. . . . . . . . . p. 68

11 Diagrama de classes . . . . . . . . . . . . . . . . . p. 70

12 Página para preenchimento de relacionamentos entre caso simulado e artigos científicos para criação de coleção de referência . . . . . . . . . . . . . . p.74

13 Exemplo de Precisão x Revocação para um caso da coleção de referência . . p. 78

14 Precisão x Revocação médias para coleção de referência $\quad$. . . . . . . . . . p. 79

15 Precisão x Revocação médias para coleção de referência $\quad \ldots$. . . . . . . . . p. 79

16 Página de retorno do Google Acadêmico para consulta submetida no campo para expressão na própria página do Google Acadêmico . . . . . . . . . . p p.82 


\section{Lista de Tabelas}

1 Síntese UMLS (elaborada de acordo com (CHEN; FULLER; FRIEDMAN, 2005)) p. 35

2 Termos e conceitos inseridos no banco de dados após processamento _ . . . p. p.54

3 Resumo sobre os 5 primeiros documentos recuperados para um registro clínico fictício contendo os termos "subnutrição materna ou stress" e "baixo peso ao nascer", utilizando a abordagem UTS para reconhecimento de conceitos . . p.61

4 Resumo sobre os 5 primeiros documentos recuperados para um registro clínico fictício contendo os termos "subnutrição materna ou stress" e "baixo peso ao nascer", utilizando a abordagem MetaMap para reconhecimento de conceitos

5 Resumo sobre os 5 primeiros documentos recuperados para a expressão "Doenças atuais: Pré-natal com intercorrências como Hipertensão arterial” . . . . . . p p.82

6 Resumo sobre os 5 primeiros documentos recuperados para a expressão " $F a$ tores de Risco (Riscos e proteção familiares relacionados à saúde): Peso de nascimento $<2.500$ grs" . . . . . . . . . . . . . . . . p. 84

7 Resumo sobre os 5 primeiros documentos recuperados para a expressão " $D i$ agnóstico nutricional: excesso de massa corporal" . . . . . . . . . . . . . . p. p.86 


\section{Introdução}

\subsection{Contextualização}

Doenças crônicas têm sido consideradas um sério problema de saúde em todo o mundo, liderando as causas de mortalidade entre homens e mulheres, com aproximadamente $60 \%$ de todas as mortes (OMS, 2009a). Indica-se que as transformações socioeconômicas vivenciadas pelas sociedades nas últimas décadas e consequentes alterações de estilo de vida colaboraram para o aumento da incidência dessas doenças multifatoriais. Dietas não saudáveis, sedentarismo e fumo, fatores modificáveis, relacionados ao estilo de vida, são os principais fatores para doenças crônicas. Por exemplo, cerca de $80 \%$ das doenças cardíacas, acidentes vasculares cerebrais e diabetes tipo 2 poderiam ser evitados se esses riscos majoritários fossem eliminados (OMS, 2010c).

Pesquisas recentes em medicina genômica sugerem que a exposição a fatores de risco ao desenvolvimento humano pode estar relacionada a doenças crônicas da idade adulta, principalmente considerando-se que esses fatores incidem desde a concepção de uma criança até o final de sua adolescência. Essa afirmação é apoiada por evidências de que esses fatores de risco influenciam a expressão gênica e, consequentemente, induzem o desenvolvimento das doenças crônicas. David Barker (2001) menciona, por exemplo, que muitos bebês e fetos humanos são obrigados a se adaptar a uma oferta limitada de nutrientes, o que influencia mudanças permanentes em sua fisiologia e metabolismo. Essas mudanças podem dar origem a uma série de doenças na vida adulta, como diabetes e doenças coronárias (BARKER, 2001). De acordo com Wadhwa et al. (2009), a "Hipótese de Barker" surgiu há aproximadamente 25 anos e estimulou o interesse de pesquisadores pelas origens fetais das doenças dos adultos, levando à formação de uma sociedade internacional para estudar o tema (WADHWA et al., 2009). A International Society for Developmental Origins of Health and Disease (DOHaD) concentra seus estudos nos primeiros estágios do desenvolvimento humano e provê um novo paradigma de prevenção para doenças crônicas comuns (GILLMAN et al., 2007). 
Artigos científicos com descobertas e estudos inovadores no domínio de atuação da DOHaD indicam que a epigenética ${ }^{1}$ deve ser explorada para prevenir doenças de alta prevalência (como doenças cardiovasculares, diabetes e obesidade). Estudos científicos geram conhecimento que pode ser utilizado para benefício da população. Essas informações normalmente estão apresentadas em vastos repositórios de artigos científicos, que podem ser consultados por profissionais de diversas áreas. A grande quantidade de artigos, todavia, dificulta a atualização de profissionais, uma vez que buscas por artigos científicos com a informação exata que se deseja tornam-se complexas e dispendiosas em relação ao tempo gasto na procura e análise dos resultados. Algumas tecnologias e técnicas computacionais podem apoiar o gerenciamento dos grandes repositórios de informações biomédicas e a geração de conhecimento, por exemplo, pelo relacionamento de resultados de pesquisas de diferentes pesquisadores, institutos ou até mesmo áreas. Processamento semântico e mapeamento de documentos para estruturas conceituais, por exemplo, podem ser tecnologias úteis para a identificação de conceitos e relações e, consequentemente, para facilitar a descoberta do conhecimento. Tecnologias como essas podem, portanto, ser usadas para facilitar a prática da medicina atual, a qual é apoiada pela descoberta de evidências.

De acordo com Butte (2008), a efetiva transformação dos resultados de pesquisas biomédicas em conhecimento possível de ser utilizado para beneficiar a saúde pública tem sido considerada um domínio importante da informática. Esse domínio é chamado de Bioinformática Translacional e foi definido pela AMIA (Associação Americana de Informática em Saúde, do inglês American Medical Informatics Association) como: “... o desenvolvimento de métodos de armazenamento, analíticos e interpretativos para otimizar a transformação de dados biomédicos cada vez mais volumosos em saúde pró-ativa, preditiva, preventiva e participativa" (AMIA, 2006) (BUTTE, 2008).

\subsection{Objetivo}

O presente trabalho tem como objetivo relacionar semanticamente informações textuais biomédicas e de saúde, como artigos científicos e dados textuais de registros clínicos de pacientes, considerando suas estruturas conceituais e de linguagem para auxiliar na prevenção de doenças crônicas.

\footnotetext{
1 "Estudo de características herdáveis do genitor para a prole que não resultam de uma mutação no DNA" (PASTERNAK, 2007)
} 


\subsection{Metodologia e Resultados}

Durante o desenvolvimento do trabalho, foi criado um sistema de vigilância (SisViDas - Sistema de Vigilância para Doenças Crônicas) apoiado por relacionamentos textuais semânticos para alertar os profissionais de saúde sobre os fatores de risco em três doenças crônicas: doenças cardiovasculares, diabetes mellitus e obesidade. Um arcabouço de software (ASSim-VigiE - Arcabouço de Software para Sistemas de Vigilância Epidemiológica) foi criado a partir da generalização de dois exemplos concretos e das abstrações que seriam necessárias para o desenvolvimento de um terceiro exemplo.

Para o relacionamento de informações entre registros clínicos e artigos científicos foram explorados processamento de linguagem natural e artefatos linguísticos como ontologias e dicionários controlados da área de saúde, com o objetivo de identificar e relacionar conceitos médicos e biomédicos presentes nos artigos científicos e registros clínicos de pacientes. Abordagens de recuperação de informação inter-lingual se tornaram necessárias, pois os artigos científicos encontram-se em inglês e os registros clínicos de pacientes em português, uma vez que o trabalho tem sido desenvolvido principalmente para o contexto do sistema de saúde brasileiro. A solução desenvolvida utiliza o Metathesaurus do UMLS (Unified Medical Language System).

A recuperação de artigos científicos que relacionem fatores de risco genéticos e epigenéticos encontrados em registros clínicos de pacientes a doenças crônicas auxiliará o uso de resultados da medicina genômica na saúde pública. Como resultado espera-se que, recebendo alertas sobre possíveis problemas no desenvolvimento de um paciente, o profissional de saúde esteja habilitado para criar com a família uma rotina protetora que estabeleça as melhores condições de crescimento e torne o meio ambiente um protetor e não um deflagrador de doenças. Dessa forma, pretende-se também contribuir para o desenvolvimento da Bioinformática Translacional, que, de acordo com a AMIA, inclui pesquisas relacionadas ao desenvolvimento de novas tecnologias para a integração de dados clínicos e biológicos e à evolução das metodologias de informática clínica para englobar observações biológicas (AMIA, 2006).

\subsection{Organização do Documento}

A presente dissertação está organizada da seguinte forma: no Capítulo 2 são apresentados doenças crônicas e fatores de risco para o desenvolvimento das mesmas; no Capítulo 
3 são discutidos fundamentos teóricos da área da computação e trabalhos relacionados que dão suporte ao presente trabalho; no Capítulo 4 o sistema de vigilância SisViDas é detalhado; no Capítulo 5 é apresentado o arcabouço de software ASSim-VigiE; no Capítulo 6 são apresentados a avaliação e os resultados para o sistema SisViDas; e, finalmente, no Capítulo 7 são apresentadas algumas conclusões. 


\section{Doenças Crônicas e Fatores Epigenéticos}

Pesquisadores de medicina genômica, em estudos científicos recentes, têm encontrado fortes evidências de que a exposição a fatores de risco em fases cruciais do desenvolvimento humano (principalmente na infância) pode estar relacionada a doenças crônicas do adulto. Isso acontece devido à possibilidade de a presença de fatores de risco precoces ocasionar alterações na expressão de uma série de genes. Nesse contexto, foi criada a $\mathrm{DOHaD}^{1}$, que visa promover pesquisas sobre modelos de causalidade e mecanismos associados ao desenvolvimento das doenças, agregando cientistas de diversas localidades e diferentes áreas do conhecimento. No Brasil, o Laboratório de Genômica Pediátrica na Faculdade de Medicina da Universidade de São Paulo (FM-USP), primeiro laboratório de genômica instalado em um departamento de pediatria brasileiro, foi criado com o auxílio da FAPESP para estudar as origens da saúde e da doença².

O presente capítulo apresenta conceitos relacionados a doenças crônicas, com destaque para doenças cardiovasculares, diabetes tipo 2 e obesidade, assim como fatores de risco para o desenvolvimento dessas doenças.

\subsection{Doenças Crônicas}

Doenças crônicas consistem em enfermidades causadas por fatores múltiplos, como genéticos, ambientais e relacionados ao estilo de vida (por exemplo, fumo, insuficiência de atividades físicas e maus hábitos alimentares). Essas doenças, em geral, não podem ser prevenidas por vacinas, nem curadas por medicação, mas podem ser modificadas, prevenidas ou até curadas por mudanças no estilo de vida. Em países desenvolvidos, as doenças crônicas de maior incidência são doenças cardiovasculares, diabetes tipo 2,

\footnotetext{
${ }^{1}$ Página Oficial DOHaD: www.mrc.soton.ac.uk/dohad/

${ }^{2}$ Agência FAPESP: Novo paradigma da pediatria (www.agencia.fapesp.br/materia/9042/noticias/novoparadigma-da-pediatria.htm)
} 
obesidade, artrite e câncer. Essas enfermidades, especialmente doenças cardiovasculares, diabetes tipo 2 e obesidade, possuem etilogia multifatorial e alta prevalência no mundo, sendo causadas principalmente pela interação de fatores que incluem genes, nutrição e estilo de vida (VERMA et al., 2009).

Doenças cardiovasculares (CVDs) consistem na principal causa de mortes no mundo. Elas compõem um grupo de enfermidades dos vasos sanguíneos e coração que inclui: doença arterial coronariana, doença cerebrovascular, doença arterial periférica, cardiopatia reumática, cardiopatia congênita, trombose venosa profunda e embolia pulmonar. Dentre suas principais consequências pode-se mencionar ataques cardíacos e acidentes vasculares cerebrais (AVCs), que consistem em eventos agudos (OMS, 2009a).

Diabetes Mellitus é outra doença crônica de alta prevalência que preocupa milhares de pessoas ao redor do mundo. No mundo, mais de 220 milhões de pessoas são afetadas por essa enfermidade, cujos casos são caracterizados por insuficiência na produção de insulina ${ }^{3}$ pelo pâncreas, ou, apesar de o pâncreas continuar produzindo insulina, o corpo tornar-se incapaz de utilizá-la eficientemente. Em 2005, a diabetes mellitus foi causa de aproximadamente 1,1 milhão de mortes e o impacto total da doença é ainda maior que esse número, pois, apesar de as pessoas viverem por anos com diabetes, suas causas de morte são normalmente registradas como doenças cardíacas ou insuficiência renal, as quais são consequências da diabetes adquirida em uma grande porcentagem dos casos (OMS, 2009b). As consequências mais comuns dessa doença são danos ao coração, aos vasos sanguíneos, aos olhos, aos rins e às fibras nervosas. Devido à falta de sensibilização sobre a diabetes e seus riscos e também devido à insuficiência de acesso aos serviços de saúde, essa doença pode levar a complicações graves como insuficiência renal, amputações e cegueira (OMS, $2009 b)$.

Obesidade e sobrepeso são definidos como acúmulo anormal ou excessivo de gordura que pode prejudicar a saúde. Esses distúrbios são diagnosticados pelo Índice de Massa Corporal (IMC), um índice simples que mede o peso em quilogramas dividido pelo quadrado da altura em metros $(\mathrm{kg} / \mathrm{m} 2)$. A Organização Mundial de Saúde (OMS ou WHO, do inglês World Health Organization) define sobrepeso como IMC igual ou superior a 25 e obesidade como IMC igual ou superior a 30, todavia há evidências de que o risco para um indivíduo desenvolver outras doenças crônicas aumenta progressivamente a partir do IMC igual a 21 (OMS, 2010b). A obesidade já atingiu globalmente proporções epidêmicas, com pelo menos 2,6 milhões de pessoas morrendo a cada ano devido a con-

\footnotetext{
${ }^{3}$ Hormônio regulador do açúcar no sangue.
} 
sequências do sobrepeso. Esse problema, que já foi exclusivo de países ricos, é atualmente prevalente também em países de baixa e média renda (OMS, 2010a). Como fatos mundiais relevantes sobre esse problema, pode-se mencionar que, em 2008, aproximadamente 1,5 bilhão de adultos (20 anos ou mais) estavam acima do peso e, desses, ao menos 500 milhões de adultos eram obesos. Calcula-se que, em 2010, aproximadamente 43 milhões de crianças até 5 anos de idade estavam acima do peso (OMS, 2010b). Algumas consequências comuns da obesidade e do sobrepeso são doenças cardiovasculares (especialmente doenças cardíacas e AVC), diabetes, distúrbios osteomusculares e alguns canceres (OMS, 2010b). A obesidade infantil tem sido considerada um dos mais sérios desafios da saúde pública no século XXI, pois crianças obesas tendem a ser adultos obesos e estão mais propensas a desenvolver diabetes e doenças cardiovasculares em uma idade mais jovem (levando a uma maior probabilidade de morte prematura e deficiências) (OMS, 2010a).

\subsection{Fatores de Risco Genéticos e Epigenéticos}

Seres humanos e demais mamíferos são organismos multicelulares especialmente complexos e, por esse motivo, são necessários vários mecanismos reguladores para manter a ampla diversidade da expressão gênica nesses organismos. A regulação gênica pode ser considerada em três amplos níveis de operação: regulação da expressão gênica simultânea à transcrição; regulação da expressão gênica posterior à transcrição; e mecanismos epigenéticos e controle da expressão gênica de longo alcance (STRACHAN; READ, 1999).

Enquanto fatores genéticos consistem em registros biológicos carregados por genes ao longo das gerações, fatores epigenéticos são fatores não diretamente atribuíveis às sequências de DNA, mas que também podem ser herdados do genitor para a prole (PASTERNAK, 2007). Assim, apesar de não consistirem em alterações na sequência do DNA, esses mecanismos podem ser transmitidos à progênie de células após a divisão celular. Desde o seu surgimento até o presente, a definição de epigenética mudou um pouco, mas sempre houve o entendimento de que ela controla a expressão de um gene ou as propriedades de seu produto de maneira estável e essas modificações, chamadas epigênicas, ou epigenéticas, são transmitidas durante divisões celulares (STRACHAN; READ, 1999)(ISLES; WILKINSON, 2008). As modificações epigenéticas podem ser, por exemplo, mediadas por marcação química da sequência de DNA em si (metilação do DNA) e/ou marcação química de proteínas histonas que se ligam ao DNA e são ferramentas moleculares pelas quais os níveis de expressão de genes são controlados (ISLES; WILKINSON, 2008). Uma lista contendo conceitos relacionados a mecanismos epigenéticos obtidos a partir da análise de 
vocabulários controlados do domínio de saúde pode ser encontrada no Apêndice A.

A presença de fatores de risco incidentes desde a concepção até o final da adolescência pode ocasionar alterações na expressão de uma série de genes. Como doenças complexas, além de serem caracterizadas pela influência de vários genes em sua origem e desenvolvimento, interagem fortemente com fatores externos provenientes do ambiente, um relacionamento entre exposição a fatores de risco no período de desenvolvimento e doenças crônicas do adulto é evidenciado. Barker (2001) apresenta uma analogia simples que explica de maneira clara a essência desse processo. Segundo ele, todo ser humano apresenta ao nascer o mesmo número de glândulas sudoríparas, mas nenhuma delas funciona. Nos três primeiros anos de vida, uma parte dessas glândulas se tornam funcionais, dependendo das condições de temperatura do ambiente em que a criança vive. Quanto mais expostos ao calor, maior o número de glândulas que são programadas para funcionar e, após esses três anos, o número de glândulas funcionais é fixado. Dessa forma, a criança exposta a um ambiente mais quente durante esse período estará mais apta a se adaptar a condições semelhantes no futuro (BARKER, 2001).

A partir de uma perspectiva médica, a contribuição genética para uma doença pode ser dividida em três categorias: (i) enfermidades cromossômicas ou monogênicas de alta penetrância; (ii) versões monogênicas de doenças comuns; e (iii) doenças complexas ou multifatoriais (KORF, 2008). No que diz respeito às doenças complexas, Korf (2008) afirma que compreender a genética por trás de doenças comuns consiste em um dos grandes desafios da medicina moderna, e que tal compreensão proverá benefícios em termos de prevenção, diagnóstico e tratamento das doenças. É interessante notar que os genes específicos que são relevantes para essas doenças podem diferir de uma pessoa para outra. A Figura 1 apresenta um modelo de desenvolvimento de doenças multifatoriais. Na figura, é possível observar que, ao nascer, um indivíduo já apresenta suscetibilidade genética para uma doença, mas permanece em um estado pré-sintomático por algum tempo. Após a ocorrência de eventos adicionais, como a exposição a fatores ambientais, um limiar pode ser atingido e, a partir de então, é caracterizada a doença (KORF, 2008).

Os estudos de Barker e outros relacionados sobre as origens fetais das doenças dos adultos influenciaram a formação da DOHaD. Segundo Gillman et al. (2007), áreas emergentes de pesquisa entre pesquisadores dessa sociedade são, por exemplo: (i) o papel controverso do ganho de peso infantil na predição de doenças como obesidade, diabetes e CVDs na vida adulta; (ii) a importância de se prestar atenção, com igual dedicação, a fatores como sobre-nutrição fetal e crescimento retardado; (iii) o efeito duradouro de 


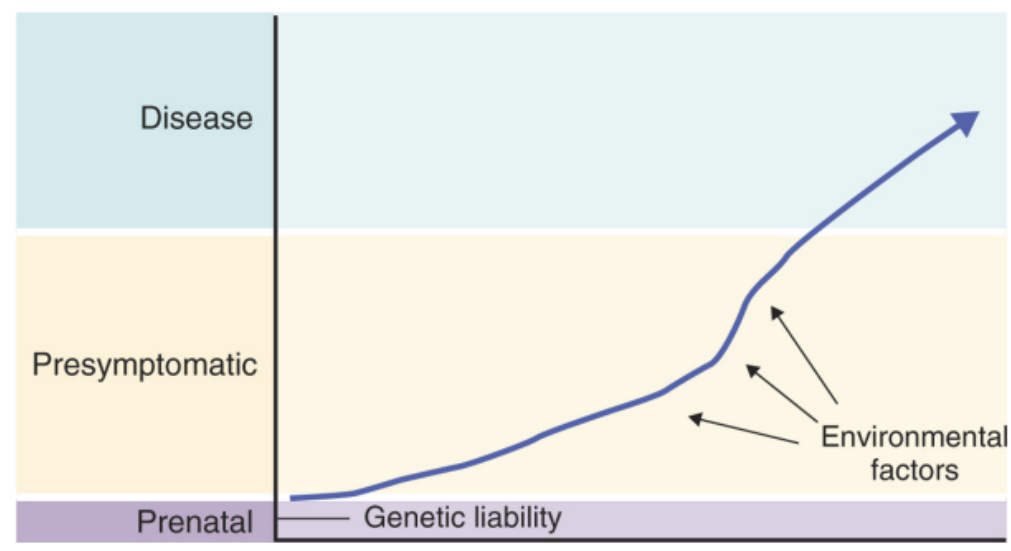

Figura 1: Etiologia multifatorial de doenças. Fonte: Cecil Medicine (KORF, 2008).

toxinas ambientais sobre o desenvolvimento humano; e (iv) os mecanismos epigenéticos como possíveis explicações para indivíduos geneticamente idênticos e criados em ambientes semelhantes serem capazes de desenvolver fenótipos diferentes (GILLMAN et al., 2007). Wadhwa et al. (2009), em sua revisão sobre os principais temas abordados pela DOHaD, discutem, por exemplo, avanços teóricos relacionados a respostas adaptativas dos fetos a estímulos ambientais, observações empíricas relacionadas a efeitos de sobrenutrição e estresse durante a gravidez sobre a infância e vida adulta e mecanismos epigenéticos potencialmente responsáveis por essas observações e teoria (WADHWA et al., 2009). Os autores mencionam, por exemplo, um grupo de pesquisa da Universidade de Duke que usou um modelo de camundongos para investigar os efeitos da dieta materna durante a gravidez sobre o fenótipo dos descendentes. O grupo concluiu que uma dieta materna rica em soja, através de mecanismos epigenéticos, reduz a obesidade na prole e influencia na cor da pelagem. Wadhwa et al. mencionam também trabalhos que relacionam estresse intra uterino causado por suprimento materno-placentário pobre em nutrientes a adversidades na infância e vida adulta, como CVDs, hipertensão e diabetes (WADHWA et al., 2009).

Segundo Pike, Hanson e Godfrey (2008), estudos clínicos e epidemiológicos demonstram que indivíduos pequenos ao nascimento e que apresentaram baixo crescimento durante a infância possuem um risco mais elevado de desenvolverem doenças cardiovasculares e respiratórias, principalmente se esse período de crescimento restrito foi seguido por um ganho acelerado de peso (PIKE; HANSON; GODFREY, 2008). Os autores afirmam ainda que o risco de desenvolvimento de doenças crônicas na idade adulta aumenta se o ambiente no qual a pessoa vive durante a infância e idade adulta difere do previsto durante o desenvolvimento precoce (PIKE; HANSON; GODFREY, 2008). De acordo com Moura e Passos (2005), a programação consiste em um fenômeno epigenético através do qual eventos nutricionais, hormonais, físico-psicológicos, entre outros, incidentes sobre um período crítico da vida de 
um indivíduo, como gestação e lactação, modificam funções fisiológicas (MOURA; PASSOS, 2005). Dessa forma, má-nutrição durante períodos como lactação e gestação ativa genes diferentes que proporcionam ao organismo um fenótipo parcimonioso. Após esse período, caso esses organismos sejam expostos a uma oferta abundante de nutrientes, apresentarão maior risco que os demais para desenvolver doenças metabólicas, como obesidade e diabetes mellitus, uma vez que foram adaptados a um baixo desperdício metabólico e melhor aproveitamento da energia. Algumas mudanças hormonais e metabólicas que ocorrem durante os períodos de gestação e de lactação e que constituem fatores potenciais para a programação são aumento da triiodotironina materna, da leptina e dos glicocorticóides e a diminuição da prolactina (MOURA; PASSOS, 2005). Tosh et al. (2010) também estudaram os efeitos da má-nutrição durante a gravidez e afirmam que a restrição alimentar materna durante esse período pode provocar na prole crescimento intrauterino restrito associado a um rápido crescimento após o nascimento (catch-up growth), assim como desenvolvimento de síndrome metabólica e obesidade na idade adulta. Todavia, uma restrição de nutrientes continuada durante o período de amamentação, em casos de má-nutrição intra-uterina, retarda o crescimento e evita o desenvolvimento da obesidade na idade adulta. Essas alterações podem ser explicadas pelo regulamento epigenético do hormônio IGF1, que é sintetizado pelo fígado e exerce papel modulador do crescimento (TOSH et al., 2010).

De acordo com Schlinzig et al. (2009), crianças nascidas por cesariana apresentam um risco maior de desenvolver doenças como diabetes, alergias e leucemia que crianças nascidas por parto normal devido a alterações epigenéticas. Os autores afirmam que o tipo de parto afeta a metilação do DNA, que é medida em leucócitos é maior em crianças nascidas por cesariana (SCHLINZIG et al., 2009). Margaritte-Jeannin et al. (1995) estudaram a relação entre pacientes com diabetes mellitus insulino-dependentes e o efeito de imprinting parental (ou seja, o papel diferencial de alelos paternos e maternos). Segundo os autores, foi observado nesses pacientes um excesso de alelos maternos DR3 associado ao excesso de alelos paternos DR4 e suas pesquisas levaram à conclusão de que imprinting parental sobre uma combinação específica de alelos pode explicar as observações sobre os genótipos dos pacientes e seus familiares (MARGARITTE-JEANNIN et al., 1995). 


\subsection{Considerações do Capítulo}

De acordo com a Profa. Dra. Sandra Grisi ${ }^{4}$, em (POLIMENo, 2009), na história recente diversos estudos buscaram relações epidemiológicas entre agravos à saúde da vida adulta e velhice e as condições de nascimento e crescimento. Nesse contexto, os estudos de David Barker, professor de epidemiologia clínica da Universidade de Southampton, representam um marco, pois, segundo a Profa. Grisi, "Barker foi pioneiro ao relacionar doença coronariana e hipertensão com baixo peso ao nascer". Com o avanço nas pesquisas das áreas de genética e genômica, foi possível identificar que, na fase de intensa multiplicação celular, o ambiente pode modificar a expressão gênica (POLIMENO, 2009). Como impacto para a prática médica, a Profa. Grisi afirma que, com o conhecimento de que o meio ambiente influencia a expressão gênica, o médico pediatra deve começar a prestar atenção ao histórico familiar (das três últimas gerações) do paciente e avaliar riscos, estando apto então para criar condições de proteção e fazer com que os riscos não se tornem ameaças reais (POLIMENO, 2009). Para atingir tais resultados, o médico deve criar uma rotina com a família para estabelecer boas condições de crescimento e transformar o meio ambiente em um fator protetor e não deflagrador das possíveis doenças. A Profa. Sandra Grisi afirma, entretanto, que, apesar de terem começado a se consolidar na década de 1990, esses conhecimentos são muito recentes e estão chegando à prática médica agora (POLIMENO, 2009). A mestranda e a orientadora pretendem, com o presente trabalho, ajudar na propagação desses conhecimentos entre a comunidade médica.

\footnotetext{
${ }^{4}$ Médica pediatra, professora titular da Faculdade de Medicina da Universidade São Paulo (FMUSP), superintendente do Hospital Universitário da Universidade de São Paulo e especialista no contexto $\mathrm{DOHaD}$
} 


\section{Tratamento de Informações em Texto Livre para Biomedicina}

Os importantes resultados de pesquisas médicas, biomédicas e de bioinformática são usualmente publicados em artigos científicos. Esses artigos são indexados por repositórios de informações como o MEDLINE. O PubMed, que consiste em um recurso desenvolvido e mantido pelo U.S. National Center for Biotechnology Information (NCBI), abrange mais de vinte milhões de citações para a literatura científica do MEDLINE, de periódicos das ciências da saúde e de livros on-line. O volume de literatura científica disponível cresce a cada ano, como pode ser visto na Figura 2. A quantidade crescente de novas informações disponibilizadas a cada ano dificulta que profissionais de saúde interessados em se manter constantemente atualizados consigam fazê-lo apropriadamente. Isso acontece pois, entre outros motivos, quanto maior o número de documentos, mais difícil a tarefa de se encontrar no meio deles a informação exata que se deseja.

Durante o desenvolvimento do presente trabalho, além dos conceitos semânticos da área de saúde relacionados a doenças crônicas e a fatores genéticos e epigenéticos no desenvolvimento dessas doenças, foram estudados fundamentos teóricos relacionados a tecnologias computacionais que poderiam ser utilizadas para atingir o objetivo proposto. No presente capítulo, são apresentados conceitos relacionados ao projeto no âmbito de Mineração de Texto para Literatura e Registros Clínicos, Processamento de Linguagem Natural, Artefatos Linguísticos como ontologias, dicionários e redes semânticas e Recuperação de Informação. Esses conceitos estão relacionados ao processamento textual e semântico de artigos científicos e registros clínicos, assim como ao processamento de similaridade entre documentos. São apresentados também conceitos de Terminologia Computacional e Aprendizado de Máquina. Os trabalhos mais diretamente relacionados ao presente projeto são apresentados na Seção 3.8 


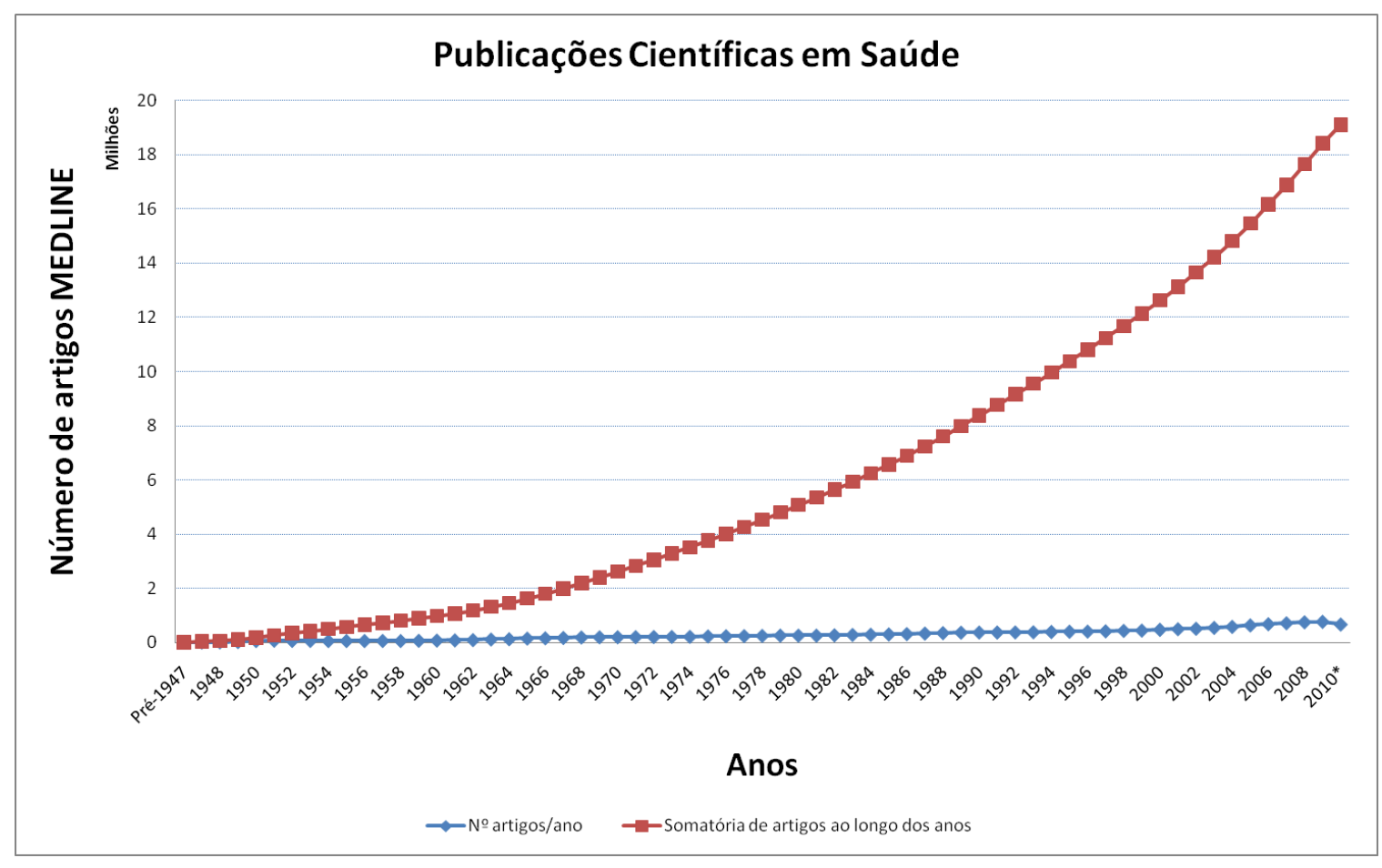

Figura 2: Número de artigos do MEDLINE através dos anos. Fonte dos dados: http://www.nlm.nih.gov/bsd/medline_cit_counts_yr_pub.html. Acessado em 04/02/2011.

\subsection{Recuperação de Informação}

De acordo com Baeza-Yates e Ribeiro-Neto (1999), Recuperação de Informação (IR - do inglês, Information Retrieval) é uma área da ciência que lida com representação, armazenamento, organização e acesso a itens de informação. O objetivo central de um sistema de IR consiste em recuperar informação que seja útil e/ou relevante para o usuário. De fato, é mais que apenas recuperar dados que satisfaçam uma consulta específica, é necessário recuperar informação sobre um assunto. Nos últimos 20-30 anos, a área de IR tem crescido além das metas nos domínios de indexação de textos, busca por documentos úteis em uma coleção, modelagem, classificação e categorização de documentos, entre outros. Essa área está também altamente relacionada à introdução e ao sucesso da World Wide Web (BAEZA-YATES; RIBEIRO-NETO, 1999).

O processo de recuperação de informação, resumido na Figura 3, se inicia com a definição do banco de dados ou repositório de textos a ser utilizado. Essa definição normalmente é realizada pela especificação: (i) dos documentos a serem utilizados; (ii) das operações textuais a serem executadas para transformar os documentos originais e gerar uma visão lógica dos mesmos; e (iii) do modelo de texto, ou seja, a estrutura e elementos do texto que podem ser recuperados. Uma vez que uma visão lógica dos documentos tenha sido definida, um índice (por exemplo, um arquivo invertido) é construído. Com o banco 
de dados de documentos indexado, o processo de recuperação pode então ser iniciado. Quando o usuário especifica sua necessidade, a expressão de consulta elaborada por ele passa por transformações textuais semelhantes às quais os textos passaram previamente. Em seguida, operações de consulta, como retroalimentação de relevância (relevance feedback), podem ser aplicadas para melhorar a representação das necessidades do usuário. Podem existir outras formulações de consulta, uma vez que a primeira consulta elaborada pelo usuário pode não representar suas necessidades adequadamente. A consulta é comparada ao índice para busca dos documentos de interesse. Antes de serem retornados ao usuário, os documentos recuperados são ordenados de acordo com o grau de relevância, atribuído por alguma métrica de similaridade. O usuário pode examinar os documentos ordenados e pode apontar um subconjunto de documentos mais relevantes para iniciar um ciclo de retroalimentação (feedback) de usuário, no qual esse subconjunto de documentos é utilizado para reformular a expressão de consulta (BAEZA-YATES; RIBEIRO-NETO, 1999).

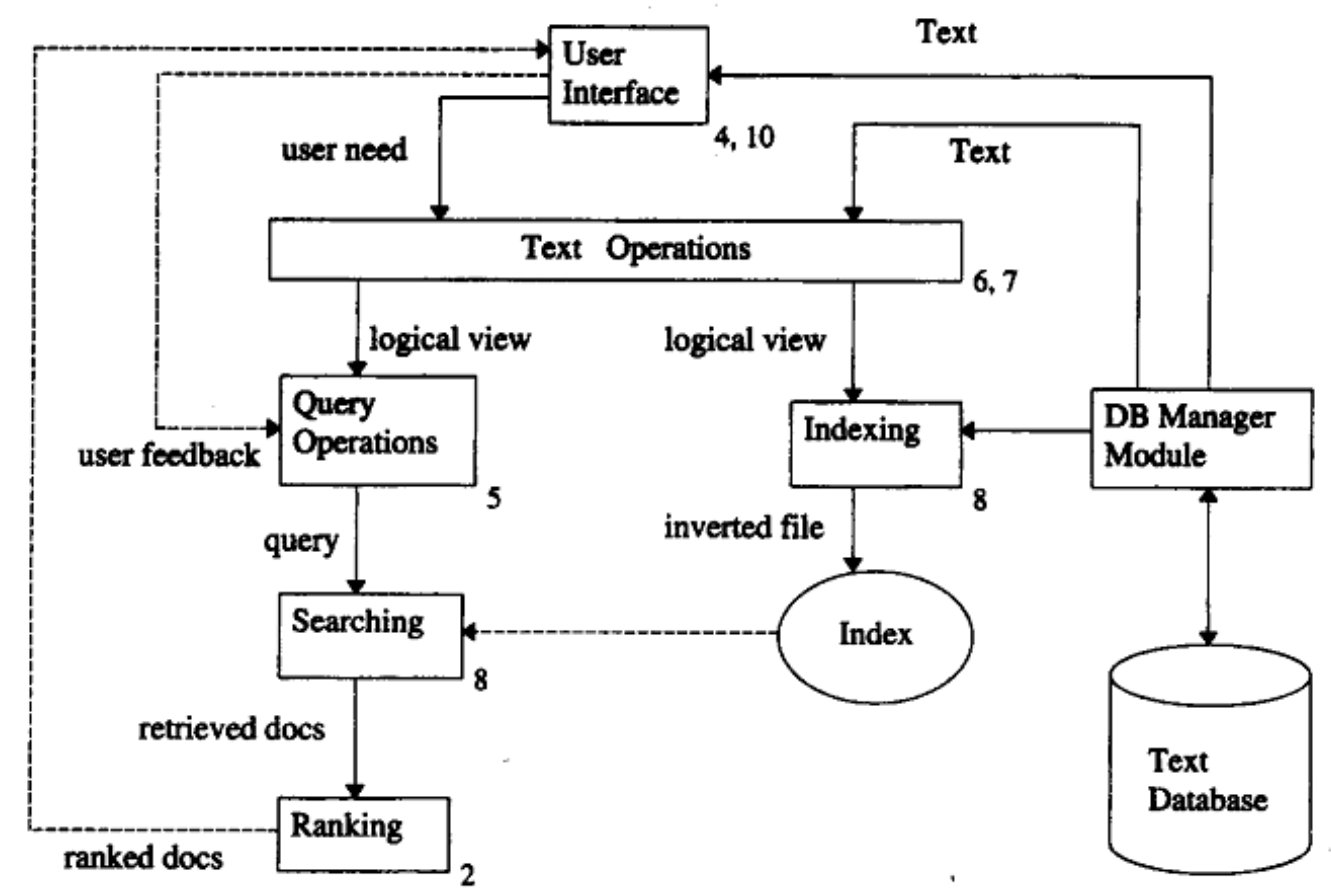

Figura 3: O processo de recuperação de informação. Fonte: (BAEZA-YATES; RIBEIRO-NETO, 1999)

É importante notar que a área de mineração de textos biomédicos evoluiu a partir de IR em conjunto com outras áreas (KRALLINGER; VALENCIA, 2005). Krallinger e Valencia, por exemplo, afirmam que a mineração de de textos para biologia molecular emergiu como uma disciplina híbrida nas fronteiras entre as áreas de ciência da informação, bioinformática e linguística computacional (KRALLINGER; VALENCIA, 2005). Segundo os autores, o processamento de linguagem natural inclui técnicas desenvolvidas para prover 
extração automática de informação funcional a partir de dados não estruturados, como publicações científicas. Eles afirmam também que sistemas de IR e processamento de linguagem natural em breve se tornarão importantes não somente para a extração de informação, como também para assistir a pesquisa em vários aspectos, como o descobrimento de novos fatos e interpretação de descobertas. De acordo com Krallinger e Valencia, um dos primeiros passos no manejo de dados textuais consiste na extração de documentos relevantes de uma grande coleção, ou seja, consiste no processo de recuperação de informação. Os autores afirmam também que o primeiro passo para a mineração desses textos consiste na identificação de entidades biológicas nos textos livres, processo conhecido como namedentity recognition. O passo seguinte consiste na mineração de interações e relacionamentos (KRALLINGER; VALENCIA, 2005).

\subsubsection{Modelos Clássicos para Representação de Documentos}

Três modelos clássicos de IR são: (i) Modelo Booleano; (ii) Modelo de Espaço Vetorial, também conhecido simplesmente como Modelo Vetorial; e (iii) Modelo Probabilístico. Esses modelos consideram cada documento como um conjunto de palavras-chave representativas do mesmo, chamadas termos de índice, os quais consistem em palavras cuja semântica ajuda a representar o conteúdo do documento. Dentre todos os termos de índice de um documento, nem todos são igualmente úteis para representar seu conteúdo, entretanto, decidir a importância de um termo para sumarizar o conteúdo do documento não é uma tarefa trivial. Algumas técnicas e propriedades de um termo de índice, contudo podem auxiliar essa tarefa (BAEZA-YATES; RIBEIRO-NETO, 1999).

O modelo vetorial reconhece as limitações do modelo booleano e propõe resolver seus problemas. Ele atribui pesos não binários para os termos de índice, que são usados para calcular um grau de similaridade entre cada documento armazenado em um sistema e a consulta do usuário. Os documentos e consultas são, portanto, representados como vetores t-dimensionais que armazenam os pesos dos termos de índice. O grau de similaridade entre os documentos e as consultas são avaliados como a correlação entre esses vetores, a qual pode ser quantificada, por exemplo, pelo cosseno do ângulo entre esses vetores. A similaridade intra-cluster no modelo vetorial (Equação 3.1) é calculada medindo-se a frequência bruta de um termo em um documento, o que é chamado de fator $t f$ (term frequency). A dissimilaridade intra-cluster (Equação 3.2) mede o inverso da frequência de um termo entre os documentos da coleção, o que é conhecido como frequência inversa do documento (fator $i d f$, do inglês inverse document frequency). Os esquemas de atribuição 
de pesos para termos de índice mais efetivos em IR buscam balancear os fatores $t f$ e $i d f$. Essas estratégias de ponderação são chamadas de esquemas $t f-i d f$ (BAEZA-YATES; RIBEIRO-NETO, 1999). A similaridade entre dois documentos ${ }^{1}$ é normalmente medida pelo cosseno do ângulo entre os vetores de termos dos dois documentos, conforme Equação 3.3.

$$
\begin{aligned}
t f_{i}, j & =\frac{\text { frequenciaDoTermoNoDocumento }}{\text { frequenciaMaximaDentreOsTermosDoDocumento }} \\
& =\frac{\text { freq } q_{i, j}}{\max \left(\text { freql }_{, j}\right)} \\
i d f_{i} & =\log \frac{\text { numeroDeDocumentosNaBase }}{\text { numeroDeDocumentosComTermo }}+1 \\
& =\log \frac{N}{n_{i}}+1
\end{aligned}
$$

$$
\begin{aligned}
& \operatorname{Sim}\left(d_{i}, d_{j}\right)=\cos (\Theta) \\
& =\frac{\overrightarrow{d_{i}} \bullet \overrightarrow{d_{j}}}{\left|\overrightarrow{d_{i}}\right| \times\left|\overrightarrow{d_{j}}\right|} \\
& =\frac{\sum_{\text {todosTermos }} \text { pesoDoTermoNoDoc } i \text { pesoDoTermoNoDoc } j}{\sqrt{\sum_{\text {todosTermos }} \text { pesoDoTermoNoDoc }}{ }_{i}^{2} \times \sqrt{\sum_{\text {todosTermos }} \text { pesoDoTermoNoDoc }_{j}^{2}}} \\
& =\frac{\sum_{k=1}^{t} w_{i, k} \times w_{j, k}}{\sqrt{\sum_{k=1}^{t} w^{2}{ }_{i, k}} \times \sqrt{\sum_{k=1}^{t} w^{2}{ }_{j, k}}}
\end{aligned}
$$

Apesar de sua simplicidade, o modelo vetorial produz conjuntos de resposta difíceis de serem melhorados sem a utilização, por exemplo, de expansão de consultas (BAEZAYATES; RIBEIRO-NETO, 1999). De acordo com Baeza-Yates e Ribeiro-Neto (1999), muitos métodos de ordenação de documentos alternativos foram comparados ao modelo vetorial. Os autores afirmam haver um consenso de que, além de o modelo vetorial ser simples e rápido, ele, em geral, é superior ou, pelo menos, tão bom quanto as alternativas conhecidas. Por esses motivos, esse é um modelo de recuperação bastante popular (BAEZA-YATES; RIBEIRO-NETO, 1999).

\subsubsection{Expansão de Consultas}

Usuários que não possuem um conhecimento detalhado sobre ambientes de pesquisa com frequência apresentam dificuldades para formular consultas que representem adequadamente suas necessidades (BAEZA-YATES; RIBEIRO-NETO, 1999). Técnicas de expansão de consultas surgiram nesse contexto para melhorar a formulação da consulta inicial. Essas técnicas envolvem dois passos básicos: expansão da consulta com os novos termos e reformulação dos pesos da consulta expandida. Existem diversas abordagens

\footnotetext{
${ }^{1}$ ou entre a expressão de consulta e um documento
} 
para a realização da expansão de consultas e reformulação de pesos, mas elas podem ser agrupadas em três categorias: (i) abordagens de retroalimentação de relevância (relevance feedback), apoiadas por informação de relevância fornecida pelo usuário; (ii) abordagens de análise automática local, apoiadas por informações procedentes do conjunto de documentos recuperados inicialmente; e (iii) abordagens de análise automática global, apoiadas por informações globais procedentes da coleção de documentos (BAEZA-YATES; RIBEIRONETO, 1999). A reformulação de pesos da consulta pode ser realizada por meio da Equação de Rocchio (ROCCHIO, 1971).

\subsection{Mineração de Texto para Literatura e Registros Clínicos}

Técnicas de mineração de texto têm sido aplicadas na análise da literatura da área de bioinformática, de maneira particular, e de informática biomédica, de maneira geral. Devido à grande quantidade de informação científica disponibilizada diariamente, é comum pesquisadores encontrarem informações não muito recentes das quais não tinham conhecimento (ver Figura 2). Desse modo, técnicas de mineração de texto podem ser muito valiosas para descobrir padrões, hipóteses e novos conhecimentos a partir do manejo da grande quantidade de informação na literatura da área de informática biomédica.

Rodriguez-Esteban em (RODRIGUEZ-ESTEBAN, 2009), artigo de revisão sobre o domínio, resume o estado da arte para aplicações de mineração de textos biomédicos. De acordo com o artigo, processar grandes quantidades de texto com o auxílio do computador não é uma tarefa simples, envolvendo muito mais do que "simplesmente equipá-lo com um dicionário e uma gramática". Rodriguez-Esteban caracteriza a área de mineração de textos biomédicos, também conhecida como BioNLP, como uma sub-área do processamento de linguagem natural (apresentado na Seção 3.3) e afirma que, por motivos de disponibilidade e custo, muitas das aplicações, além de serem desenvolvidas para tipos específicos de textos, trabalham apenas com resumos científicos em inglês, extraídos do MEDLINE. Como conceitos principais do domínio, o autor explica o que são "termos" e "relacionamentos", apresenta algumas ferramentas para trabalhar com esses conceitos e disserta sobre descoberta de relacionamentos, qualidade e abrangência da mineração de textos.

De acordo com Holzinger et al. (2008), dados hospitalares em registros médicos, além de crescerem continuamente em quantidade, estão, em sua maior parte, disponíveis apenas em formato texto. Essas características dificultam que esses dados se tornem real- 
mente informação, ou seja, que possam ser utilizados para gerar conhecimento. Textos representam informações em uma maneira complexa, rica e "opaca", difícil de ser analisada por métodos convencionais de mineração de dados. Segundo os autores, esses fatos fazem da mineração de textos uma área essencial no contexto da informática médica, permitindo que dados brutos provenientes de textos sejam minerados, transformando-se em informação (utilizável e útil). Em seu trabalho, os autores descrevem o projeto e o desenvolvimento de uma aplicação para analisar comentários de especialistas em diagnósticos de imagens de ressonância magnética. Essa análise é realizada por meio da aplicação de uma metodologia de mineração de textos que examina diagnósticos à procura de correlações entre termos anatômicos e patológicos. Holzinger et al. (2008) afirmam ainda que, no domínio dos documentos médicos, podem ser delineadas três áreas de aplicação de mineração de textos: (i) aplicação de métodos para construir uma infraestrutura ou modelos para biomedicina, pela descoberta de padrões e relações em textos e da criação de um espaço de características; (ii) observação e recuperação de documentos com novidades da área; e (iii) extração de informação ou de características de um corpus de textos clínicos.

Segundo Matos et al. (2010), no domínio biomédico existem muitos documentos que reportam experimentos envolvendo pacientes com alguma doença. Esses documentos descrevem o tratamento em estudo, o número de pacientes sob esse tratamento, sintomas da doença, fatores de risco e resultados do estudo. Médicos e pesquisadores, por serem humanos, não possuem a agilidade necessária para processar esse grande número de documentos (MATOS et al., 2010). Para transformar esses documentos naturalmente não estruturados para um formato estruturado e permitir descoberta automática de conhecimento, os autores propuseram o ambiente Information Extraction and Decision Support System in Biomedical domain (IEDSS-Bio). Alguns dos desafios enfrentados pelos autores foram: (i) identificar passagens contendo informação relevante; (ii) coletar pedaços de informação relevantes; (iii) popular um banco de dados e um data warehouse; e (iv) minerar esses dados. O ambiente/arcabouço de software foi utilizado em um caso de estudo de artigos sobre anemia falciforme para identificar sentenças sobre a doença, efeitos do tratamento e número de pacientes (MATOS et al., 2010). Os melhores resultados, em experimentos com Aprendizado de Máquina para identificação de passagens relevantes no contexto em estudo, foram obtidos com um método estatístico e com o uso de técnicas de pré-processamento para reamostragem dos exemplos com o objetivo de eliminar ruídos. 


\subsection{Processamento de Linguagem Natural}

A linguagem geral é aquela transferida e assimilada, inicialmente, pelas relações familiares, sendo passada de geração a geração. O processamento automático de linguagem natural (Natural Language Processing - NLP) consiste em uma área da Inteligência Artificial que pretende aprimorar o uso de informação transmitida em linguagem geral por aplicações da área de informática biomédica. Exemplos desse aprimoramento incluem: sumarização, respostas a questionamentos e descobertas científicas a partir da análise da literatura.

Algumas aplicações de NLP são utilizadas no estudo de etiologia de doenças genéticas, por exemplo, com foco em predicações semânticas na literatura científica que caracterizem o relacionamento entre genes e doenças. O programa SemGem, por exemplo, mapeia frases substantivas em conceitos semânticos e utiliza métodos estatísticos e empíricos para identificar nomes de genes que não estão no Metathesaurus do UMLS (ver Seção 3.4). A ferramenta SemGem é utilizada para comparar resultados de uma base de dados de doenças genéticas, a OMIM (Online Mendelian Inheritance in Man) com informações científicas atuais do PubMed sobre determinada doença genética (RINDFLESCH; FISZMAN; LIBBUS, 2005).

Artefatos linguísticos como ontologias e dicionários podem auxiliar no Processamento de Linguagem Natural. Strube de Lima, Nunes e Vieira (2007) apresentam os desafios do processamento de língua natural, principalmente no que se refere ao contexto da língua portuguesa (Strube de Lima; NUNES; VIEIRA, 2007). Ao detalharem alguns entraves tecnológicos da área de NLP, os autores apresentam recursos linguísticos de base, que são criados para aprimorarem o processamento da língua humana, por exemplo, wordnets e treebanks. Strube de Lima, Nunes e Vieira (2007) afirmam, todavia, que, principalmente no que concerne à língua portuguesa, ainda há muito a avançar em relação a recursos necessários para o desenvolvimento da área de NLP. A página Linguateca ${ }^{2}$ reúne hoje a maior parte das ferramentas e corpora disponíveis da língua portuguesa e o PLN-BR ${ }^{3}$ se constitui em um dos projetos para construção de um corpus para processamento de textos em português do Brasil. Para o inglês, algumas ferramentas como o PropBank (KINGSBURY; PALMER, 2002) são usadas para inferência de significados. As ontologias, especificações de conceitos utilizadas em domínios bem definidos, também se constituem como um recurso semântico para auxiliar o processo de NLP de forma que, associadas a

\footnotetext{
${ }^{2}$ http://www.linguateca.pt

${ }^{3}$ http://www.nilc.icmc.usp.br:8180/portal/
} 
thesaurus, podem guiar a coleta e o armazenamento de dados, assim como a codificação da informação. Strube de Lima, Nunes e Vieira mencionam também que o processamento da língua natural tem se relacionado bastante com as ciências da vida e da saúde, como Biologia, Bioinformática e Medicina, sendo frequente a representação de conhecimento na forma de ontologias. De acordo com os autores, a área de NLP, juntamente com áreas como Bioinformática e Visão Computacional, têm sido consideradas como Data Science.

\subsection{Artefatos Linguísticos}

\subsubsection{Ontologia}

O termo ontologia originou-se na filosofia e, naquele campo, está relacionado ao estudo do ser e da existência (GRUBER, 2009). Para o contexto das ciências da computação e da informação, entretanto, ontologia é um termo técnico que denota um artefato projetado para o propósito de permitir a modelagem do conhecimento sobre algum domínio, real ou imaginado, definindo um conjunto de primitivas de representação ${ }^{4}$ (GRUBER, 2009). De acordo com Gruber (1993), as ontologias podem ser definidas como especificações de conceitualizações $^{5}$ (GRUBER, 1993). Elas definem formalmente a relação entre termos em um dado domínio e são frequentemente usadas para facilitar o compartilhamento de conhecimento entre pessoas, processamento de informação, mineração de dados, comunicação entre agentes de software e outros tipos de processamento de conhecimento. Segundo Guarino (1997), as ontologias podem ser classificadas em quatro tipos, de acordo com seu nível de dependência com uma tarefa particular ou ponto de vista (GUARINO, 1997):

Ontologias de alto-nível são genéricas e descrevem conceitos gerais como espaço, tempo, matéria, objeto, evento e ação. Esses conceitos são independentes de um problema ou domínio particular.

Ontologias de domínio descrevem o vocabulário relacionado a um domínio genérico (medicina, por exemplo), especializando termos introduzidos na ontologia de altonível.

Ontologias de tarefas descrevem uma tarefa ou atividade genérica (como diagnosticar ou vender) especializando termos introduzidos na ontologia de alto-nível.

\footnotetext{
4 "Tipicamente classes (ou conjuntos), atributos (ou propriedades), e relacionamentos (ou relações entre membros de uma classe)" (GRUBER, 2009).

5 "Visão simplificada ou resumida do mundo que se deseja representar para algum propósito" (GRUBER, 1993).
} 
Ontologias de aplicação descrevem conceitos dependendo do domínio e tarefa particular.

Algumas ontologias têm sido desenvolvidas especificamente para bioinformática. O projeto Gene Ontology ${ }^{6}$, por exemplo, tem como objetivo produzir um vocabulário controlado que pretende ser aplicado para a descrição de informações sobre genes de qualquer tipo de organismo. Para o desenvolvimento de ontologias, podem ser citados editores como o OntoEdit (SURE et al., 2002), o Inxight StarTree ${ }^{7}$ e o TreeBolic Generator ${ }^{8}$. Dentre esses editores, o Protégé-OWL ${ }^{9}$, consiste em um software livre, de código aberto, utilizado por diversos projetos de construção de ontologias para biomedicina.

De acordo com Maojo e Tsiknakis (2007), no contexto da medicina genômica, para prover sucesso à área são necessários novos métodos e ferramentas para integrar dados clínicos e genômicos, assim como para extrair conhecimentos a partir desses dados (MAOJO; TSIKNAKIS, 2007). Em seu artigo, os autores apresentam diversas tecnologias que podem auxiliar esse processo e, dentre essas tecnologias, afirmam que as ontologias são um método relevante, por exemplo, para integração de bancos de dados. Essa integração de bancos de dados pode ser feita, por exemplo, pelo uso de abordagens baseadas em ontologias que permitem mapear objetos de um banco de dados particular para conceitos de uma ontologia comum. Segundo Maojo e Tsiknakis, na biomedicina, quase não existem ainda ontologias que integrem dados clínicos e dados genômicos. Saias e Quaresma (2003) afirmam que ontologias permitem a definição de hierarquias de classe, propriedades de objetos e regras de relacionamentos. Os autores propuseram uma metodologia para a criação automática de ontologias OWL e instâncias de classes OWL. Essa metodologia se baseia em técnicas de processamento de linguagem natural para obter uma interpretação parcial de documentos. É importante ressaltar que a OWL (Ontology Web Language) consiste na linguagem recomendada pela $\mathrm{W} \mathrm{C}^{10}$ para a representação de ontologias (SAIAS; QUARESMA, 2003).

\subsubsection{Thesaurus}

Um thesaurus pode ser definido como um vocabulário controlado e estruturado que representa sinônimos, hierarquias e relacionamentos associativos entre termos para aju-

\footnotetext{
${ }^{6}$ http://www.geneontology.org/

${ }^{7}$ http://www.inxightfedsys.com/products/sdks/st/default.asp

${ }^{8}$ http://treebolic.sourceforge.net/en/index.html

${ }^{9} \mathrm{http}: / /$ protege.stanford.edu

${ }^{10}$ http://www.w3.org
} 
dar usuários a encontrar uma informação desejada (EBECKEN; LOPES; COSTA, 2003). O objetivo principal de um thesaurus é proporcionar ao usuário uma forma de encontrar algum termo que represente um determinado significado do que se procura, visto que usuários diferentes podem definir um mesmo conceito utilizando termos diferentes (EBECKEN; LOPES; COSTA, 2003). Um thesaurus resolve esse problema mapeando termos variantes como sinônimos, abreviações, acrônimos e ortografias alternativas para um termo preferido único para cada conceito. É interessante notar que thesauri são geralmente usados para domínios específicos como biologia, educação, saúde, arte, arquitetura, entre muitos outros.

No que se refere a vocabulários controlados médicos, é possível encontrar atualmente na literatura científica referências a diversos thesauri já construídos e que são comumente utilizados principalmente para indexação de documentos. Hersh (2003) faz referência a alguns dos mais utilizados dentre esses thesauri, como o MeSH (Medical Subject Headings), comumente utilizado para indexar literatura médica, o CID (Codificação Internacional de Doenças), usada para codificar diagnósticos, o SNOMED, que codifica informações clínicas e o CPT-4 que realiza codificação de procedimentos (HERSH, 2003).

\subsubsection{Unified Medical Language System (UMLS)}

O Sistema Unificado de Linguagem Médica (UMLS), mantido pela Biblioteca Nacional de Medicina dos EUA (NLM, do inglês National Library of Medicine), se constitui em uma fonte de informação para facilitar o processamento e gerenciamento de documentos biomédicos. Para atender esses anseios, o UMLS envolve um conjunto de fontes de conhecimento como, por exemplo, um Metathesaurus, uma rede semântica e o léxico SPECIALIST. Esse conjunto de tecnologias pode ser utilizado por uma variedade de aplicações para compensar as diferentes maneiras de expressar conceitos nas diferentes fontes de informações biomédicas.

Particularmente, o Metathesaurus é um vocabulário controlado no domínio de biomedicina, o qual inclui o MeSH (Medical Subject Headings), a SNOMED (Systematized Nomenclature of Medicine), e muitos outros artefatos linguísticos focados em subdomínios da área da saúde como Odontologia (Current Dental Terminology) e Enfermagem (Nursing Interventions Classifications). Termos pertencentes a vocabulários controlados do Metathesaurus são organizados em conceitos que refletem significados sinônimos. Por exemplo, o conceito "Chronic Childhood Arthritis" contém os sinônimos "Arthritis, Juvenile Rheumatoid" no MeSH e SNOMED e "Rheumatoid arthritis in children" na Library of 
Congress Subject Headings (CHEN; FULLER; FRIEDMAN, 2005). O Metathesaurus também mantém as informações organizadas hierarquicamente e a cada conceito é atribuído pelo menos um tipo semântico selecionado a partir de 135 categorias gerais do domínio da área de saúde como, por exemplo, "Amino Acid, Peptide, or Protein" e "Disease or Syndrome". O Metathesaurus é, portanto, uma grande base de dados multilíngue com vocabulário controlado para biomedicina e por isso permite que usuários mapeiem termos textuais biomédicos em conceitos (termos do vocabulário controlado), ou identifique um conjunto de termos distintos associados a um termo.

A rede semântica do UMLS (Semantic Network) é formada por uma ontologia de alto nível. Seus componentes são 135 tipos semânticos atribuídos aos conceitos do Metathesaurus e 54 relacionamentos. Os tipos semânticos são organizados em duas hierarquias com as raízes Entity e Event e são organizados em grupos de alto nível que refletem coerência semântica (CHEN; FULLER; FRIEDMAN, 2005). Por exemplo, "Procedure" inclui os seguintes tipos semânticos: "Diagnostic Procedure" e "Therapeutic or Preventive Procedure". Os 54 relacionamentos são organizados de acordo com nós que incluem physically_related_to, functionally_related_to e conceptually_related_to. A rede semântica categoriza conceitos no Metathesaurus e relacionamentos entre os conceitos.

O léxico SPECIALIST (SPECIALIST Lexicon), projetado para facilitar o processamento de linguagem natural para biomedicina, é um léxico que contém definições sintáticas para termos médicos. O SPECIALIST descreve as características sintáticas de termos gerais e de medicina em inglês, e assim provê a base para processamento de linguagem natural em informática biomédica. Flexões de substantivos, verbos e adjetivos e outras variações estão incluídas no SPECIALIST (CHEN; FULLER; FRIEDMAN, 2005).

A Tabela 1 sintetiza a organização do UMLS, de acordo com descrição apresentada por (CHEN; FULLER; FRIEDMAN, 2005) e resumida nesta seção.

Tabela 1: Síntese UMLS (elaborada de acordo com (CHEN; FULLER; FRIEDMAN, 2005))

\begin{tabular}{|c|c|c|c|c|}
\hline \multirow{11}{*}{$\begin{array}{c}\mathrm{U} \\
\mathrm{M} \\
\mathrm{l} \\
\mathrm{S}\end{array}$} & \multirow{3}{*}{ Metathesaurus } & \multicolumn{3}{|c|}{$\mathrm{MeSH}$} \\
\hline & & \multicolumn{3}{|c|}{ SNOMED } \\
\hline & & \multicolumn{3}{|c|}{$\ldots$} \\
\hline & \multirow{7}{*}{ Semantic Network } & \multirow{4}{*}{$\begin{array}{l}135 \text { Tipos Semânticos } \\
\text { organizados em: }\end{array}$} & \multirow[t]{2}{*}{ Entity } & Physical Object \\
\hline & & & & Conceptual Entity \\
\hline & & & \multirow[t]{2}{*}{ Event } & Activity \\
\hline & & & & Phenomenon \\
\hline & & \multirow{3}{*}{54 Tipos de Relacionamentos } & \multicolumn{2}{|c|}{ physically_related_to } \\
\hline & & & \multicolumn{2}{|c|}{ functionally_related_to } \\
\hline & & & & $\ldots$ \\
\hline & SPECIALIST Lexicon & \multicolumn{3}{|c|}{ Léxico com definições sintáticas para termos médicos } \\
\hline
\end{tabular}


O UMLS Terminology Services (UTS) consiste em uma aplicação que fornece acesso, via Internet, às fontes de conhecimento do UMLS (NLM, 2009). O objetivo do UTS é tornar os dados do UMLS mais acessíveis aos usuários e, em particular, aos desenvolvedores de sistemas. A arquitetura do UTS é baseada no modelo cliente-servidor, permitindo que usuários remotos (indivíduos, bem como programas de computador) enviem solicitações para um servidor central na NLM (NLM, 2009). O UTS, disponibilizado em dezembro de 2010, substituiu o UMLS Knowledge Source Server (UMLSKS) e fornece quatro vias de acesso à fontes de conhecimento do UMLS: (i) por meio de uma interface de linha de comando; (ii) por meio da World Wide Web; (iii) via interface de programação de socket com base em Extensible Markup Language (XML); e (iv) por meio de uma API ${ }^{11}$ de serviços Web. A API de serviços web do UTS, conhecida como UTS Web service $A P I^{12}$, consiste em um serviço designado a desenvolvedores que provê funções para recuperar dados do Metathesaurus, da Rede Semântica e do SPECIALIST Lexicon. O UTS permite ao usuário solicitar informações sobre um conceito particular do Metathesaurus, incluindo atributos como a definição do conceito, seu identificador único ( $\mathrm{CUI}^{13}$ ), seus tipos semânticos, assim como conceitos relacionados (NLM, 2009).

O MetaMap surgiu no contexto de um esforço para melhorar a recuperação de textos biomédicos, especificamente a recuperação de citações do MEDLINE/PubMed. Ele consiste em uma ferramenta amplamente disponível que fornece acesso aos conceitos do Metathesaurus do UMLS a partir de textos da área biomédica (ARONSON; LANG, 2010). Essa ferramenta utiliza uma abordagem de conhecimento intensivo, baseada em conhecimento simbólico, processamento de linguagem natural e técnicas de linguística computacional (ARONSON, 2001). De acordo com Aronson e Lang (2010), o MetaMap proporcionou uma ligação entre o texto da literatura biomédica e o conhecimento, incluindo relações de sinonímia, embutidas no Metathesaurus (ARONSON; LANG, 2010). Todavia, o fato de só poder ser aplicado a textos em inglês consiste em um dos pontos fracos do MetaMap (ARONSON; LANG, 2010). Outro ponto fraco da ferramenta é sua precisão reduzida na presença de ambiguidade (ARONSON; LANG, 2010). Usuários possuem quatro vias de acesso ao MetaMap: (i) acesso web por meio do Semantic Knowledge Representation (SKR), um serviço que permite que usuários enviem textos às máquinas servidoras do MetaMap e obtenham resultados de programas como o MetaMap, Medical Text Indexer (MTI) e SemRep; (ii) descarregamento ${ }^{14}$ do programa MetaMap original, desenvolvido

\footnotetext{
${ }^{11}$ Sigla para Interface de Programação de Aplicações, do inglês Application Programming Interface

${ }^{12} \mathrm{Ou}$ também UMLS Knowledge Source Server

${ }^{13}$ Do inglês Concept Unique Identifier

${ }^{14}$ Obtenção de arquivos por transferência de um computador distante para o seu próprio (download).
} 
em Prolog; (iii) acesso via API (java-based) de acesso ao SKR Scheduler, uma facilidade criada para prover aos usuários aptidão para submeter trabalhos ao Scheduler ao invés de utilizar as interfaces web; e (iv) descarregamento do MetaMap Transfer (MMTx) uma versão distribuível do MetaMap, desenvolvida em Java.

\subsubsection{Chronic Disease Ontology (CDO)}

Com o objetivo de armazenar e reusar conhecimento sobre três doenças crônicas de alta prevalência (principalmente informações genéticas) e adquirir novos conhecimentos a partir deles, Verma et al (VERMA et al., 2009) desenvolveram a Chronic Disease Ontology (CDO, que, em português, poderia ser chamada de Ontologia de Doenças Crônicas). A CDO inclui informações sobre doenças cardiovasculares, diabetes tipo II e obesidade, os genes e mutações relacionados a elas, assim como dados sobre saúde, nutrição e histórico de vida. A CDO contém cinco domínios essenciais: domínio do organismo (organism domain), domínio molecular (molecular domain), domínio médico (medical domain), domínio nutricional (nutritional domain) e mapa de informática biomédica (biomedical informatics map).

No início do desenvolvimento do presente trabalho, planejou-se o desenvolvimento de uma ontologia para o domínio de fatores de risco genéticos e epigenéticos para doenças crônicas. Até então não havia sido encontrada nenhuma ontologia já existente para o domínio, o que mudou com a publicação da CDO. O Open Biological and Biomedical Ontologies (OBO Foundry) recomenda que não se crie uma nova ontologia para um domínio para o qual já exista uma ontologia, mas sim que se procure juntar esforços e contribuir para a evolução e extensão da primeira. Por esse motivo, decidiu-se entrar em contato com os desenvolvedores da CDO, membros do grupo de pesquisa KEDRI, da Auckland University of Technology. Esse contato foi feito e uma parceria entre os grupos de pesquisa foi estabelecida.

Pretende-se, em um futuro próximo, estender a CDO com conhecimentos sobre mecanismos epigenéticos e fatores de risco epigenéticos para as referidas doenças crônicas obtidos dos artigos científicos recuperados pelo arcabouço de software proposto neste trabalho. 


\subsection{Terminologia Computacional}

O campo da terminologia se tornou um campo de grande interesse para muitos pesquisadores, com diferentes motivações e experiências de pesquisa. Especialistas em diversas áreas do conhecimento, como especialistas em ciência da informação, lexicógrafos, tradutores, entre outros experimentaram a necessidade de melhorar a comunicação e a maneira como informações específicas de um domínio são acessadas. Muitos tipos de recursos terminológicos, como dicionários especializados, bancos de termos, glossários e thesauri, foram construídos para satisfazer essas necessidades. Apesar de as motivações para a área não terem sido alteradas com o passar do tempo, os métodos de construção de recursos terminológicos evoluíram significativamente, pois, além de o volume de informação digital ter crescido muito nos últimos anos, diversas técnicas foram emprestadas de áreas como processamento de linguagem natural, recuperação de informação, linguística de corpus e inteligência artificial. Essas técnicas permitiram extração e representação de conhecimento especializado de maneiras eficientes e elegantes. Adicionalmente, especialistas em processamento de linguagem natural, que primariamente não estavam preocupados com aspectos da terminologia, começaram a perceber que a formalização de textos especializados é necessária para a construção de aplicações úteis, como tradução auxiliada por computador e sumarização automática (BOURIGAULT; JACQUEMIN; L, 2001).

Pesquisadores de terminologia computacional enfrentam diversos problemas que requerem percepções em pontos de vista teóricos e práticos. Por exemplo, a identificação automática de unidades terminológicas em textos corridos é uma tarefa que necessita de refinamento. Além disso, corpora utilizados para extração de unidades terminológicas podem ser explorados também para extração de informação semântica. Ferramentas de terminologia computacional têm sido desenvolvidas para uma ampla gama de domínios como recuperação de informação, construção de léxicos bilíngues e sumarização automática (BOURIGAULT; JACQUEMIN; L, 2001).

\subsection{Inteligência Artificial e Aprendizado de Máquina}

A Inteligência Artificial (IA) é uma área da Ciência da Computação que pode ser definida como a "[Automatização de] atividades que associamos ao pensamento humano, atividades como a tomada de decisões, a resolução de problemas, o aprendizado..." (BELLMAN, 1978). De acordo com Schalkoff (1990) a IA pode ser definida também como um "campo de estudo que procura explicar e emular o comportamento humano em termos de 
processos computacionais" (SCHALKOFF, ). A IA é composta por subáreas de pesquisa, como Robótica, Processamento de Linguagem Natural e Aprendizado de Máquina (RUSSELL; NORVIG, 2004).

O Aprendizado de Máquina é uma área da Inteligência Artificial que tem como objetivos o desenvolvimento de técnicas computacionais sobre o aprendizado e a construção de sistemas capazes de adquirir conhecimento de forma automática (MONARD; BARANAUSKAS, 2003). De acordo com Monard e Baranauskas (2003), é possível realizar um processo de classificação de um exemplo ao lembrar de outro similar cuja classe é conhecida e assumir que o novo exemplo terá a mesma classe" (MONARD; BARANAUSKAS, 2003). Essa característica é a base de um modelo de aprendizagem conhecido como aprendizagem baseada em instâncias, ou também aprendizagem baseada em memória. Esse modelo de aprendizagem é denominado lazy, ou preguiçoso e necessita manter os exemplos na memória para classificar novos padrões de entrada. Por esse motivo, segundo Haykin (2001), na aprendizagem baseada em instâncias praticamente todas as experiências passadas e classificadas corretamente são armazenadas em uma grande memória de exemplos (HAYKIN, 2001). O conceito de vizinhos mais próximos fundamenta-se nesse aprendizado por memorização de exemplos e, segundo Russel e Norvig (2004), sua idéia-chave consiste no fato de que as propriedades de qualquer ponto de entrada específico têm probabilidade de serem semelhantes às propriedades de outros pontos em sua vizinhança. Nesse sentido, o vizinho mais próximo de um padrão de entrada $x$ é definido como sendo o que apresenta a menor distância entre seu vetor de características e o vetor de características de $x$ (RUSSELL; NORVIG, 2004). Haykin afirma que o classificador que tem como suporte o conceito de $k$ vizinhos mais próximos é constituído de uma variante da regra do vizinho mais próximo. Ao invés de identificar apenas um vizinho mais próximo, esse classificador identifica $k$ vizinhos, sendo $k$ um número inteiro.

O conceito de redes neurais artificiais (RNAs) nasceu a partir da crença de que a capacidade de processamento de informações do cérebro emerge principalmente de redes de neurônios (RUSSELL; NORVIG, 2004). Por isso, RNAs são sistemas inspirados em propriedades simples do funcionamento de um sistema nervoso biológico. Conforme definida por Haykin (2001), "uma rede neural é um processador maciçamente paralelamente distribuído constituído de unidades de processamento simples, que têm a propensão natural para armazenar conhecimento experimental e torná-lo disponível para o uso". Segundo ele, numa rede neural o procedimento utilizado para realizar o processo de aprendizagem é conhecido como algoritmo de aprendizagem e sua função é modificar as forças de conexão entre neurônios, conhecidas como pesos sinápticos, de forma ordenada, a fim de 
alcançar um objetivo. A capacidade de generalização de uma rede neural, ou seja, sua capacidade de produzir saídas adequadas para entradas que não estavam presentes durante seu treinamento, demonstra o poder computacional de uma rede neural e caracteriza seu aprendizado. Haykin afirma que cada neurônio é uma unidade de processamento em uma rede neural e que possui três elementos básicos: um conjunto de sinapses ou elos de conexão entre o neurônio e seus sinais de entrada, um somador para somar os sinais de entrada ponderados pelos pesos das respectivas sinapses e uma função de ativação para restringir a amplitude da saída do neurônio.

Os algoritmos de vizinhos mais próximos e redes neurais artificias consistem apenas em dois exemplos dentre os inúmeros algoritmos de aprendizagem desenvolvidos por pesquisadores da área de Aprendizado de Máquina. Outros exemplos bastante conhecidos são redes bayesianas e árvores de decisão.

\subsection{Relacionamentos Textuais Semânticos em Bio- medicina}

De acordo com Hoffman e Valencia (2005), apesar de a World Wide Web ter modificado profundamente a maneira como as pessoas acessam informações, as ferramentas de recuperação de informação disponíveis para cientistas das áreas de biologia e medicina ainda estão muito aquém do esperado (HOFFMANN; VALENCIA, 2005). Essa dificuldade se deve ao fato de os sistemas de recuperação de informação para literatura científica terem suporte até o momento de buscas por palavras-chave, que, muitas vezes, retornam uma grande quantidade de informação nem sempre desejada. O sistema iHOP (Information Hyperlinked over Proteins) (HOFFMANN; VALENCIA, 2005) consiste em um serviço on-line que provê uma rede guiada por genes como uma maneira natural para acessar resumos do PubMed. Ele é composto por duas partes, a iHOP factory e a iHOP web application. O sistema, que foi desenvolvido utilizando-se de tecnologias Java, XML, XSL e PostgreSQL, identifica sinônimos de genes em textos biomédicos por meio de uma abordagem baseada em dicionários na tentativa de alcançar a máxima precisão e estabelecer relações cruzadas com bancos de dados externos. Segundo os autores, com o iHOP foi possível converter uma grande quantidade de informação proveniente do PubMed em um espaço de informação navegável. Assim como o presente trabalho, o sistema iHOP não foi projetado para substituir especialistas do domínio, mas para facilitar o acesso dos mesmos à informação.

Fizman et al. (2007) discutiram a extensão de um sistema de interpretação semântica 
para processar estruturas comparativas (FISZMAN et al., 2007). Essas estruturas provêem uma maneira de explicar características de uma entidade, em termos de uma segunda, fortalecendo a descrição da primeira (Ex: reportar resultados de ensaios clínicos). O trabalho explora o software SemRep que constrói predicações semânticas para, entre outras funções, processar expressões comparativas. No SemRep, predicações semânticas são construídas mapeando afirmações em textos biomédicos para UMLS (RINDFLESCH; FISZMAN, 2003). Os autores expandiram um interpretador semântico simbólico para identificar construções comparativas em textos biomédicos e, apesar de terem restrito o método para comparações entre terapias (com drogas), ele pode ser facilmente generalizado para outras entidades, como diagnósticos e procedimentos terapêuticos. Assim como pretendido pelo presente trabalho, o trabalho de Fizman et al. (2007) apoia a translação da pesquisa biomédica para a melhora da qualidade do atendimento de pacientes (o que também é conhecido como Bioinformática Translacional). Os trabalhos também estão relacionados pela identificação de diagnósticos e procedimentos terapêuticos (que podem ser fatores epigenéticos) com a utilização do UMLS.

Shah et al. (2009) desenvolveram uma ferramenta que extrai conceitos de uma ontologia a partir de textos (SHAH et al., 2009). Para atingir seus objetivos, os autores mapearam anotações textuais de bancos de dados de expressão gênica para conceitos do UMLS, permitindo buscas suportadas por ontologias e integração de dados de tecidos e de expressão gênica, assim como a identificação de conjuntos de dados sobre doenças específicas entre os dois repositórios. A ferramenta possui como funcionalidade principal permitir que usuários localizem dados biomédicos relacionados a algum conceito particular de uma ontologia. Mukherjea, Bamba e Kankar (2005) desenvolveram um sistema, denominado BioPatentMiner, que facilita descoberta e recuperação de informação a partir de patentes biomédicas (MUKHERJEA; BAMBA; KANKAR, 2005). Primeiramente, o sistema identifica termos biológicos e relacionamentos sobre as patentes e, em seguida, integra essas informações com conhecimentos armazenados em ontologias biomédicas para criar uma Web semântica. Esse trabalho se relaciona com o apresentado nesta dissertação pela identificação de termos biológicos e relacionamentos, assim como pela integração dessas informações com conhecimentos armazenados em ontologias biomédicas, uma vez que essas são tarefas fundamentais neste trabalho. Lee, Wu e Yang (2007) desenvolveram um protótipo para extrair automaticamente de registros clínicos relacionamentos entre câncer e fatores potenciais para o mesmo, o que consideram como uma contribuição valiosa para o domínio da saúde pública (LEE; WU; YANG, 2007). O protótipo integra uma ontologia para o domínio de câncer e técnicas de mineração de textos, envolvendo algoritmos de 
Self-Organizing Maps (SOM) e Support Vector Machines (SVM). Esse e o presente trabalho estão relacionados pela identificação automática de uma doença e fatores potenciais para a mesma a partir de registros clínicos.

Gudivada et al. (2008) afirmam que muitas doenças crônicas são causadas por interações entre múltiplos fatores e que essas entidades e relações podem ser representadas por grafos com nós e arestas definidos semanticamente (GUDIVADA et al., 2008). Por esse motivo, desenvolveram metodologias para identificar genes causadores de doenças usando representações de conhecimentos genotípicos e fenotípicos baseadas na Web Semântica. Segundo os autores, uma das tarefas consistiu em mapear características clínicas para conceitos do UMLS, o que foi feito com o auxílio da ferramenta MetaMap , que mapeia sintagmas nominais (frases substantivas) para conceitos do Metathesaurus da UMLS em textos livres do domínio biomédico. As características clínicas normalizadas para conceitos do UMLS foram utilizadas para construir um grafo de fenótipos. Para atingir os objetivos propostos, internamente foi desenvolvida uma ontologia (DCO - Disease Card Ontology) na linguagem OWL, com o auxílio da ferramenta Protégé (GUDIVADA et al., 2008). Esse trabalho se relaciona com o presente por mapear características clínicas para conceitos da UMLS.

Jang et al. (2006) desenvolveram um sistema que coleta resumos do PubMed e descobre relações entre diversas categorias de entidades biomédicas (JANG et al., 2006). Devido à grande quantidade de publicações científicas disponíveis na Internet, Armano, Manconi e Vargiu (2007) desenvolveram uma arquitetura multi-agente que, através de um processo de categorização de textos, recupera publicações científicas a partir da Web (ARMANO; MANCONI; VARGIU, 2007). Zhou et al. (2007) apresentaram uma abordagem para integrar literatura da medicina tradicional chinesa (TCM - do inglês Traditional Chinese Medicine) e dados biomédicos modernos para descobrir redes gênicas e conhecimentos funcionais sobre os genes, integrando assim dois repositórios complementares de dados biomédicos (ZHOU et al., 2007). Swanson e Smalheiser (1997) desenvolveram um sistema denominado Arrowsmith, com o objetivo de ajudar na descoberta de conhecimento a partir da literatura biomédica (SWANSON; SMALHEISER, 1997). O sistema compara dois conjuntos de literaturas para descobrir relacionamentos entre eles, uma vez que informações descobertas em uma área e valiosas para outras áreas podem nem sempre ser vistas pelos pesquisadores das diferentes áreas. Segundo Smith, Rindflesch e Wilbur (2004), taggers desenvolvidos para propósito geral não apresentam bom desempenho quando aplicados ao MEDLINE (SMITH; RINDFLESCH; WILBUR, 2004). Por esse motivo, os autores desenvolveram um tagger, denominado MedPost, especializado para corpus do MEDLINE. 
Assim como o trabalho apresentado nesta dissertação, esses trabalhos procuram descobrir conhecimentos a partir de publicações disponíveis na literatura, principalmente biomédica.

Eichmann, Ruiz e Srinivasan (1998) investigaram um método automático para recuperação de informação inter-lingual (CLIR, do inglês Cross Language Information Retrieval) que utiliza o Metathesaurus do UMLS para traduzir, para o inglês, consultas em linguagem natural originalmente em espanhol e francês. Os autores apresentam dois experimentos usando a coleção OHSUMED. No segundo experimento, o procedimento de tradução da consulta é aumentado com procedimentos de normalização de vocabulário com base em diagramas. Nesse estudo comparativo de eficácia, as medidas de recuperação utilizadas foram: precisão média de 11 pontos (11-AvgP); precisão média interpolada em recall de 0,1; e precisão não interpolada (i.e., exata) após 10 documentos recuperados. Esses resultados indicam que, para o espanhol, o método CLIR apoiado pelo Metathesaurus do UMLS parece ser equivalente a abordagens baseadas em dicionário multilingue (EICHMANN; RUIZ; SRINIVASAN, 1998).

Le, Chevalet e Lim (2008) descreveram um método de indexação conceitual usando o Metathesaurus do UMLS. Com o método, conceitos são automaticamente mapeados a partir de um texto em inglês usando a ferramenta MetaMap, enquanto para outras línguas uma ferramenta de mapeamento simplificado é utilizada. Os conceitos e suas ligações semânticas dadas pelo UMLS são usados para construir uma rede Bayesiana. O processo de recuperação consiste em um processo de inferência de probabilidades ou pesos. Diferentes tipos de relações são experimentados neste modelo para avaliar a sua eficiência na recuperação (LE; CHEVALLET; LIM, 2008).

Volk, Vintar e Buitelaar (2003) apresentaram uma abordagem para a utilização de ontologias como ferramenta interlinguística para CLIR no domínio médico. Essa abordagem tem como suporte o uso do UMLS como ontologia fundamental. Documentos e consultas são anotados com múltiplas camadas de informações linguísticas e, com base nessas informações, termos médicos e relações semânticas entre eles são identificados e mapeados para sua posição na ontologia. Os autores descrevem experimentos em recuperação de documentos monolíngues, assim como em recuperação de documentos entre línguas diferentes. Os experimentos são realizados em um corpus de resumos médicos e os resultados mostram que a informação semântica, especificamente o uso associado de conceitos e relações, aumenta a precisão na recuperação monolingual. Em recuperação multilingual, a anotação semântica supera a tradução automática das consultas, mas os melhores resultados são obtidos pela combinação dos códigos semânticos com um the- 
saurus de similaridade (VOLK; VINTAR; BUITELAAR, 2003).

De acordo com Hersh and Donohoe (1998), apesar de, no domínio médico, a maior parte da literatura mundial estar escrita em inglês, grande parte do mundo não utiliza essa língua como língua principal. Esse fato impulsionou um interesse crescente em pesquisas de CLIR, área na qual bases de dados textuais são consultadas em línguas diferentes daquela na qual os documentos estão escritos. Os autores descrevem melhorias para o sistema de recuperação de conceitos SAPHIRE, que mapeia documentos e consultas em texto livre para conceitos no Metathesaurus UMLS. Essas melhorias permitem ao sistema aceitar a entrada de texto em seis línguas diferentes e fornecer como saída conceitos do Metathesaurus. As seis línguas para as quais o sistema oferece suporte são: inglês, alemão, francês, russo, espanhol e português. A avaliação formativa de termos em alemão mostra que é necessário um trabalho adicional na manipulação de plurais e outras variantes de sufixo, bem como na expansão da busca por sinônimos no Metathesaurus (HERSH; DONOHOE, 1998).

O presente trabalho propõe relacionar documentos entre as línguas portuguesa e inglesa. Uma vez que o trabalho foi desenvolvido principalmente para o contexto do sistema de saúde brasileiro, os registros clínicos de pacientes encontram-se em português, enquanto os artigos científicos importantes para a área, por sua vez, encontram-se em sua maioria na língua inglesa. Por esses motivos, CLIR consiste em uma área de especial interesse para o presente trabalho.

\subsection{Considerações do Capítulo}

Com o objetivo de encontrar trabalhos relacionados ao apresentado na presente dissertação, foram buscados trabalhos em bases de publicações como ACM Digital Library, Portal CAPES, IEEE Digital Library, Journal of Universal Computer Science, Journal of Biomedical Informatics, entre outros.

Diversos trabalhos na literatura exploram extração de informações a partir de textos biomédicos e, dentre eles, um número notável aplica reconhecimento de conceitos, principalmente por meio do mapeamento de termos dos textos para conceitos do UMLS (por exemplo, (SHAH et al., 2009), (RINDFLESCH; FISZMAN, 2003), (FISZMAN et al., 2007), (ARONSON, 2001)). Diversos autores também experimentaram CLIR utilizando o Metathesaurus do UMLS, o qual é multilingue, para traduzir consultas a partir de uma língua para outra ((HERSH; DONOHOE, 1998), (VOLK; VINTAR; BUITELAAR, 2003), (LE; CHEVALLET; LIM, 
2008), (EICHMANN; RUIZ; SRINIVASAN, 1998)). No entanto, não foi encontrado ainda um trabalho que englobe todas as tecnologias cobertas por este trabalho, nem um trabalho com o mesmo objetivo de bioinformática translacional: prevenir doenças crônicas, alertando os profissionais de saúde sobre um fator de risco recuperando artigos científicos publicados com conhecimento sobre fatores de risco epigenéticos. 


\section{Sistema de Vigilância para Doenças Crônicas (Sis ViDas)}

Conforme mencionado no Capítulo 1, o presente trabalho tem como objetivo geral relacionar informações textuais biomédicas e de saúde, como artigos científicos e dados textuais de registros clínicos de pacientes, considerando suas estruturas conceituais e de linguagem para auxiliar na prevenção de doenças crônicas.

Este capítulo apresenta as etapas de trabalho realizadas para criar um sistema de vigilância para doenças crônicas apoiado por relacionamentos textuais semânticos para alertar os profissionais de saúde sobre os fatores de risco em três doenças crônicas: doenças cardiovasculares, diabetes mellitus e obesidade. Para atingir este objetivo, primeiramente foi necessário preparar uma coleção de artigos científicos no domínio dos fatores de risco genéticos e epigenéticos para doenças crônicas. Considerando esta coleção, o sistema desenvolvido é capaz de recuperar pesquisas científicas publicadas em artigos relacionados a um registro clínico.

O Sistema de Vigilância para Doenças Crônicas (SisViDas) tem sido desenvolvido em parceria com pesquisadores do Instituto da Criança da Faculdade de Medicina da USP (ICr), a qual foi consolidada principalmente por intermédio da Profa. Dra Sandra Grisi, professora titular do instituto, e das Dras. Maria Helena Valente e Filumena Maria da Silva Gomes.

\subsection{Projeto e Criação do SisViDas}

O SisViDas possui cinco principais casos de uso: (i) atualizar a coleção de artigos científicos; (ii) recuperar artigos científicos relevantes para um registro clínico; (iii) classificar pacientes em grupos de risco para doenças crônicas; (iv) expandir ontologia de doenças crônicas (CDO); e (v) validar ontologia. A Figura 4 apresenta um resumo sobre os casos de uso do sistema. No diagrama podem ser vistos os atores que farão uso de cada 
funcionalidade. O pediatra-pesquisador, uma especialização de médico pediatra, assim como o médico pediatra podem acessar o sistema por meio de uma interface gráfica de usuário.

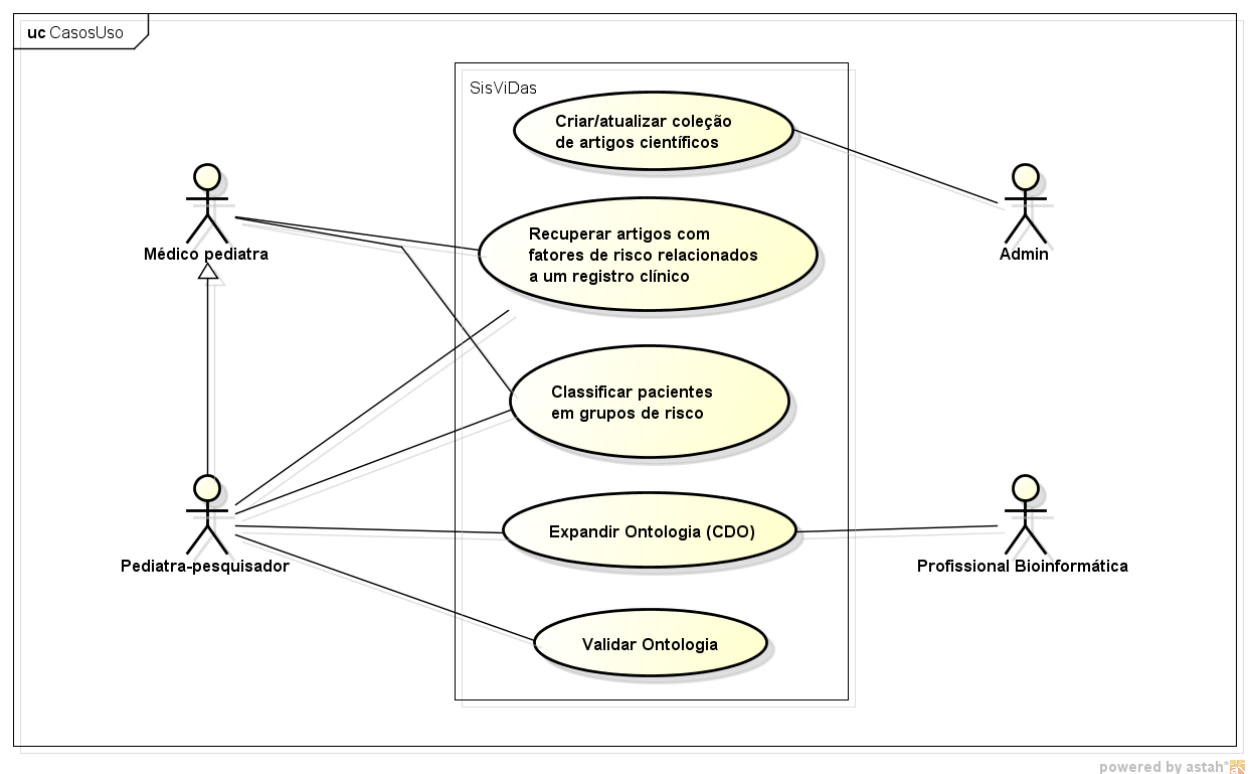

Figura 4: Diagrama de Casos de Uso

No contexto do presente trabalho, devido a limites de tempo, foram explorados principalmente os casos de uso "atualizar a coleção de artigos científicos" e "recuperar artigos científicos relevantes para um registro clínico". O projeto era ambicioso para ser desenvolvido por completo no tempo de um mestrado e, por esse motivo, tornou-se necessário concentrar esforços em apenas parte dele. Os requisitos para os dois casos do contexto do presente trabalho são apresentados, respectivamente, nas Figuras 5 e 6 e são listados em seguida. Essas figuras ilustram a interdependência entre os requisitos.

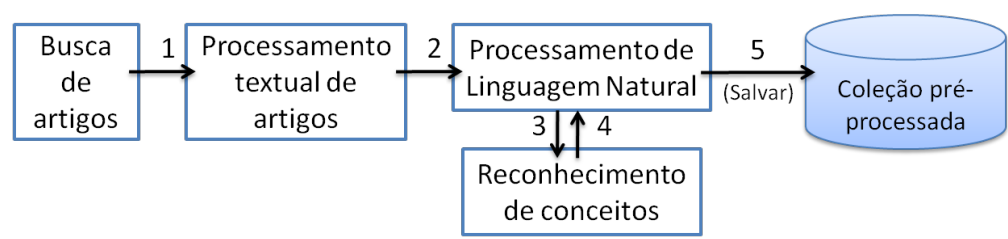

Figura 5: Requisitos para caso de uso de atualização da coleção de artigos científicos

Para a criação e atualização da coleção de artigos científicos são, portanto, necessários os seguintes requisitos funcionais:

R.1.1 Buscar e transferir artigos científicos digitais mais recentemente publicados para um computador local. 


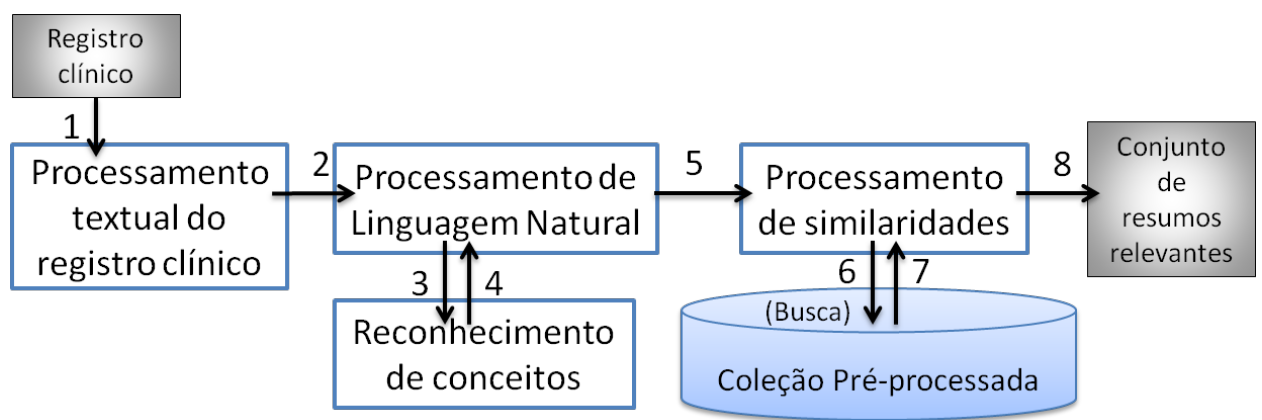

Figura 6: Requisitos para caso de uso de recuperação de artigos para um registro clínico

R.1.2 Processar textualmente os artigos científicos para identificar termos simples e compostos.

R.1.3 Identificar conceitos médicos e biomédicos definidos por thesauri e ontologias do domínio da saúde presentes nos artigos científicos da coleção.

R.1.4 Calcular frequências (term frequency), frequências inversas (inverse document frequency) e pesos dos conceitos nos documentos.

R.1.5 Armazenar resultados no banco de dados.

Para recuperação de artigos científicos a partir de um registro clínico são necessários os requisitos:

R.2.1 Processar textualmente o registro clínico para identificar termos simples e compostos presentes no mesmo.

R.2.2 Identificar conceitos médicos e biomédicos presentes no registro clínico e armazenar resultados no banco de dados.

R.2.3 Elaborar consulta composta por conceitos presentes no registro clínico.

R.2.4 Consultar informações armazenadas no banco de dados sobre a coleção de artigos científicos pré-processada.

R.2.5 Computar similaridade entre o registro clínico e artigos científicos da coleção.

R.2.6 Retornar artigos científicos mais relevantes.

Dentre os requisitos listados, a maioria consiste em requisitos funcionais ocultos ao usuário, sendo apenas o último requisito explícito, ou seja, visível ao usuário. Além 
desses requisitos funcionais, são necessários também usabilidade, confiabilidade, eficiência e manutenibilidade.

A Figura 7 apresenta a infraestrutura do sistema desenvolvido, seus módulos e interações entre os mesmos. Para concretizar o caso de uso de atualização da coleção de artigos científicos, o SisViDas possui um módulo responsável por interagir com repositórios públicos de artigos científicos e recuperar uma coleção de artigos de interesse, a partir de conceitos obtidos de ontologias do domínio. Após a recuperação da coleção, um módulo responsável pelo processamento de informações processa cada um dos novos artigos presentes na mesma, armazenando os dados resultantes do processamento textual realizado. Esse processamento textual inclui remoção de stop-words, processamento de n-gramas ${ }^{1}$, identificação de conceitos do domínio da saúde presentes nos artigos e cálculos de pesos dos conceitos nos documentos.

Para que o SisViDas possa recuperar os artigos mais relacionados a um registro clínico de paciente, ele primeiramente realiza o processamento textual do registro clínico de maneira similar ao processamento dos artigos científicos. Em seguida, realiza uma chamada ao módulo de processamento de similaridade entre documentos, o qual acessa as informações armazenadas sobre a coleção e identifica os artigos científicos mais similares ao registro clínico submetido. Esses artigos científicos identificados são apresentados ao profissional de saúde por meio de uma interface gráfica com o usuário.

Para classificar um paciente de acordo com grupos de risco para doenças crônicas, o SisViDas realiza o processamento textual do registro clínico, como no caso de uso de recuperação de artigos. Na sequência, carrega para a memória um classificador previamente treinado e armazenado de maneira persistente para classificar pacientes com o apoio de uma coleção de registros clínicos de referência. Com o auxílio do classificador previamente treinado, o novo registro clínico é classificado em um grupo de risco para uma das doenças crônicas consideradas pelo SisViDas: doenças cardiovasculares, diabetes mellitus ou obesidade.

O SisViDas foi instanciado inicialmente para interagir com os recursos Entrez Programming Utilities (E-utilities) e UMLS, para realizar, respectivamente, as atividades de busca de artigos no repositório PubMed e identificação de conceitos do domínio da saúde

\footnotetext{
${ }^{1}$ Decomposição de um documento em palavras, letras ou sequências de $n$ palavras ou letras. Por exemplo, no que se refere à decomposição relativa a letras, "the house" pode ser decomposta em bigramas $(n=2)$ como $\{$ th, he, ho, ou, us, se $\}$ (PARAPAR; FREIRE; BARREIRO, 2009). No presente trabalho, foi utilizada a decomposição relativa a palavras. Por exemplo, decompondo-se em trigramas $(n=3)$ a frase "Esse processamento textual inclui remoção de stop-words", obtém-se: \{esse processamento textual, processamento textual inclui, textual inclui remoção, inclui remoção de, remoção de stop-words\}.
} 


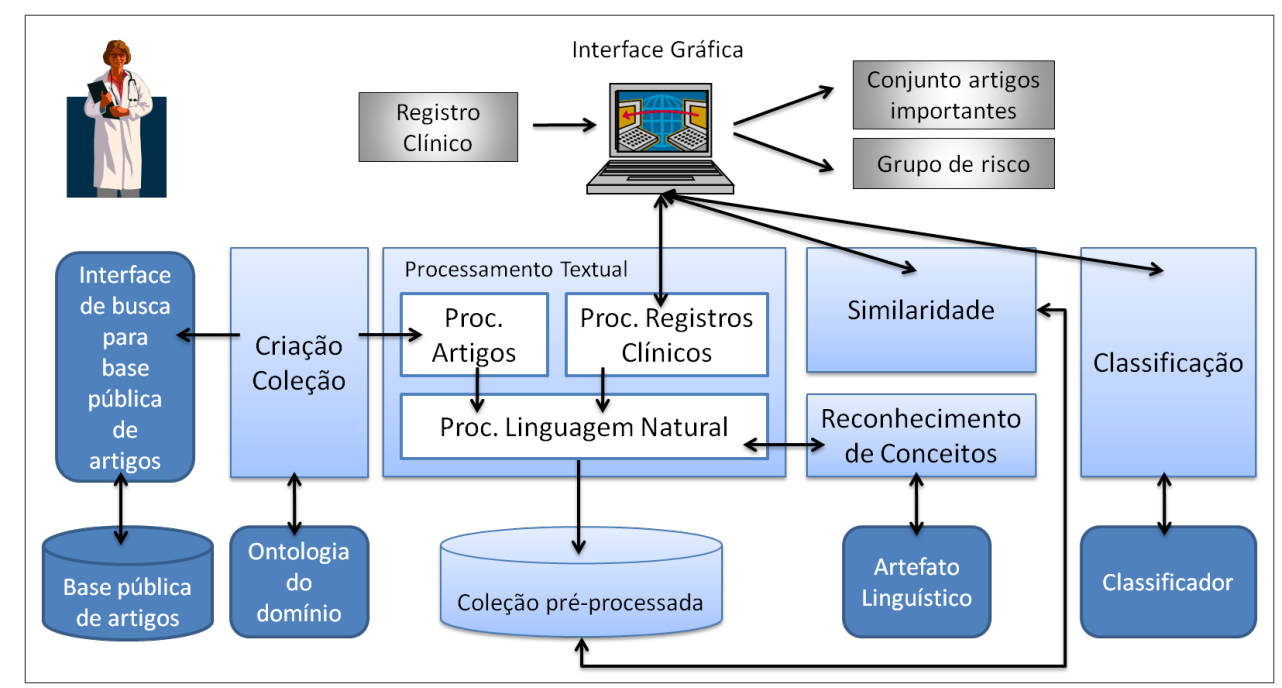

Figura 7: Infraestrutura do SisViDas com processos e repositório.

presentes nos artigos. Essa instanciação é detalhada nas subseções a seguir em função de suas responsabilidades e interações com sistemas externos, mas o sistema não se restringe ao manejo dessas fontes de informação, podendo ser expandido para interagir com outros recursos além do E-utilities e UMLS. As Subseções 4.1.1, 4.1.2, 4.1.3 e 4.1.4 detalham, respectivamente, os módulos de busca de artigos científicos, processamento textual de informações, identificação de conceitos e processamento de similaridade entre documentos.

\subsubsection{Criação e Atualização da Coleção de Artigos Científicos}

Por possibilitar o acesso a inúmeras revistas científicas das áreas médica e biomédica, o serviço PubMed é considerado uma boa fonte de informação para a vigilância da saúde populacional. O PubMed disponibiliza conhecimentos científicos sobre fatores de risco que podem ser controlados para prevenir doenças crônicas. Esse serviço, desenvolvido e mantido pelo U.S. National Center for Biotechnology Information (NCBI), acessa o banco de dados de citações, resumos e alguns artigos completos de periódicos das ciências da saúde e de livros on-line do repositório MEDLINE. Ele abrange, atualmente, mais de vinte milhões de citações e muitas delas contém hiperligações para os artigos referenciados. Dessa forma, o PubMed permite o acesso à grande maioria dos artigos científicos publicados para o domínio de interesse do presente trabalho, o que o torna uma excelente fonte de informação a ser manejada.

Ao realizar tarefas de mineração de textos em artigos científicos, é necessário considerar que: (i) o processamento textual de artigos completos gera um alto custo computacional e (ii) a indisponibilidade de alguns artigos completos na literatura pública. Para 
tratar a indisponibilidade de artigos completos, pode-se considerar os resumos dos artigos, pois abordam as informações essenciais dos mesmos e estão publicamente disponíveis para a grande maioria dos artigos (principalmente no domínio da saúde). Consequentemente, resumos reduzem o custo computacional de processamento consideravelmente. Além disso, revistas científicas no domínio da saúde frequentemente exigem que resumos dos artigos sejam organizados de acordo com uma estrutura pré-definida. Por esses motivos, decidiu-se trabalhar neste projeto com resumos de artigos científicos do domínio de doenças crônicas. Após analisar algumas fontes de informação médica e biomédica, decidiu-se que, em um primeiro momento, o SisViDas manejaria meta-dados como título, resumo em inglês e termos MeSH, extraídos do PubMed.

O SisViDas explora o E-utilities e Biopython para buscar automática e rotineiramente artigos relacionados ao domínio de fatores de risco genéticos e epigenéticos para doenças crônicas. Assim, uma consulta foi elaborada para filtrar o repositório do PubMed e definir uma coleção de artigos de interesse. A consulta, que pode ser vista no Apêndice B, é composta por subconsultas que abordam: (i) conceitos do domínio molecular da CDO, principalmente relacionados a genes (subconsulta 1) e mutações (subconsulta 2) ligados às doenças cardiovasculares, diabetes e obesidade; (ii) conceitos do UMLS relacionados a mecanismos epigenéticos (subconsulta 3); e (iii) conceitos referentes às doenças cardiovasculares, diabetes e obesidade (subconsulta 4).

A coleção de suporte gerada a partir da consulta elaborada é automática e semanalmente atualizada com os mais recentes artigos publicados no PubMed e, atualmente, possui 1153 resumos em inglês. Desse conjunto de documentos: 661 são artigos relacionados ao domínio de genes e mutações da CDO, 504 são artigos associados à epigenética e 12 se referem à intersecção entre os dois grupos anteriores.

\subsubsection{Processamento Textual e Armazenamento de Informações}

Quando a coleção é atualizada, é necessário que seus novos documentos sejam textualmente processados e que os resultados desse processamento sejam armazenados em um banco de dados. O processamento e subsequente armazenamento permitem buscas eficientes por relacionamentos entre documentos, uma vez que não é necessário reprocessar a coleção a cada consulta direta ou indireta executada por um profissional de saúde. O processamento textual inclui remoção de stop-words, processamento de n-gramas, identificação de conceitos e cálculos de pesos dos conceitos nos documentos.

A remoção de stop-words é suportada pela lista de stop-words em inglês extraída 
do projeto Snowball ${ }^{2}$; o processamento de n-gramas utiliza o pacote Python NLTK, que consiste em um pacote de módulos Python de código aberto, dados linguísticos e documentação para pesquisa e desenvolvimento nas áreas de processamento de linguagem natural e análise de textos (BIRD; KLEIN; LOPER, 2009). Para o cálculo de pesos dos conceitos nos documentos, o SisViDas utiliza a estratégia de ponderação para termos de índice tf-idf, apresentada na Seção 3.1, realizando, para isso, cálculos de frequências e frequências inversas dos conceitos contidos nos documentos.

O processamento de registros clínicos é similar ao processamento de documentos da coleção de artigos científicos, diferindo do anterior com relação ao idioma da lista de stopwords utilizada, a qual consiste, neste caso, na lista de stop-words em português extraída também do projeto Snowball ${ }^{3}$. A sequência de atividades do processo também difere, pois, no caso dos registros clínicos, após o processamento de n-gramas e identificação de conceitos de saúde relacionados aos n-gramas, um vetor contendo os conceitos encontrados é construído e submetido ao processamento de similaridade entre documentos para identificar relacionamentos entre o registro clínico e artigos científicos da coleção.

\subsubsection{Identificação de Conceitos Médicos: Interação com o UMLS}

Duas metodologias diferentes para busca de conceitos médicos no UMLS foram desenvolvidas para o sistema de vigilância SisViDas. A primeira utiliza os termos resultantes do processamento de n-gramas e interage com a API de serviços web do UMLS Terminology Services (UTS). A segunda abordagem é apoiada pela ferramenta MetaMap. Essas abordagens são detalhadas a seguir e ambas estão disponíveis no SisViDas para a tarefa de reconhecimento de conceitos do domínio da saúde. Seus resultados foram avaliados de acordo com a precisão e revocação de artigos para registros clínicos submetidos por profissionais da saúde especialistas no domínio (ver Seção 6.4.1).

\subsubsection{Abordagem 1: UTS Web Service API}

Nesta abordagem, o módulo de reconhecimento de conceitos do domínio da saúde presentes nos artigos científicos relaciona os termos resultantes do processamento de ngramas com conceitos do UMLS por meio de interação com a API de serviços web do UMLS Terminology Services (UTS). A interface entre o módulo desenvolvido e o UMLS é realizada por meio de SOAP (Simple Object Access Protocol) e utiliza softwares e tecnolo-

\footnotetext{
${ }^{2}$ http://snowball.tartarus.org/algorithms/english/stop.txt

${ }^{3}$ http://snowball.tartarus.org/algorithms/portuguese/stop.txt
} 
gias como Apache Tomcat, Apache Axis e WSDL (Web Services Description Language). O módulo, desenvolvido em Java, busca por conceitos relacionados a cada n-grama submetido a ele pelos demais módulos do SisViDas e recupera, além dos nomes dos conceitos, os identificadores únicos de conceito (CUIs), os tipos semânticos aos quais os conceitos estão associados, assim como os grupos semânticos associados. A conexão entre o módulo Java e os demais módulos do SisViDas, desenvolvidos em Python, é apoiada pelo pacote Python Py4J.

\subsubsection{Abordagem 2: MetaMap}

Em um trabalho de conclusão de curso desenvolvido com o apoio deste trabalho de mestrado, a aluna do curso de Informática Biomédica da USP-RP Flávia Pena Nicolas investigou ferramentas para o mapeamento de textos livres, escritos em língua inglesa, para conceitos ou termos-conceito de artefatos linguísticos como ontologias e dicionários. Essa investigação foi realizada em relação aos formatos de entrada, saída e entendimento do processamento dos textos (NICOLAS, 2010). Para que fosse alcançado o objetivo de mapeamento dos termos da CDO e do UMLS em artigos relacionados a doenças crônicas e seus fatores de risco, foram estudadas algumas ferramentas possíveis de serem utilizadas, a fim de escolher a mais adequada para o problema em questão. As ferramentas estudadas foram Mgrep, Torch e MetaMap, dentre as quais, o MetaMap foi escolhido para ser utilizado (NICOLAS, 2010).

Nesta abordagem para a reconhecimento de conceitos do domínio da saúde presentes nos artigos, o módulo de identificação de conceitos interage com a API de acesso ao SKR Scheduler ${ }^{4}$, submetendo os novos artigos científicos da coleção pelo modo Batch. A conexão entre o módulo Java e os demais módulos do SisViDas possui como suporte o pacote Python Py4J.

\subsubsection{Resultados Comparativos do Uso do UMLS}

O UMLS foi fundamental para o presente trabalho, uma vez que: (i) foi utilizado para a composição de parte da consulta executada pelo módulo de atualização da coleção por interface com o recurso E-utilities; (ii) diminuiu o número de termos considerados

\footnotetext{
${ }^{4}$ Em seu trabalho de conclusão de curso, a aluna Flávia Pena Nicolas utilizou o MetaMap Transfer (MMTx), disponível em http://mmtx.nlm.nih.gov/MMTx/, uma versão java distribuível do MetaMap. O MMTx, entretanto, não está mais recebendo suporte da equipe responsável pelo MetaMap, exceto para correções de erros graves, e seu uso tem sido desaconselhado. Por esse motivo esta mestranda optou por substituir o uso do MMTx em favor da SKR API como via de acesso ao MetaMap.
} 
pelo processamento de similaridade entre documentos; (iii) aumentou a especificidade dos termos considerados; e (iv) correlacionou termos entre as línguas portuguesa e inglesa.

Utilizando o UMLS, o número de termos considerados para a identificação de relacionamentos diminuiu de 150.664 n-gramas para 15.988 conceitos médicos e biomédicos com a abordagem via UTS Web Service API. Com a utilização do MetaMap, o número de conceitos identificados nos artigos foi de 9.589. Enquanto n-gramas consistem em termos genéricos, relacionados a todas as áreas do conhecimento, os conceitos do UMLS são termos específicos do domínio de saúde reunidos no Metathesaurus. Por esse motivo, os conceitos identificados são mais específicos e significativos para a identificação de relacionamentos entre registros clínicos e artigos científicos de saúde que simples n-gramas. Para efeitos de comparações entre as abordagens UTS e MetaMap e também com relação à não utilização do UMLS, a Tabela 2 apresenta exemplos de termos/n-gramas identificados, assim como conceitos do domínio de saúde reconhecidos pelo processamento dos documentos da coleção utilizando as abordagens UTS e MetaMap. Para cada abordagem, a tabela apresenta, o número de termos/conceitos armazenados no banco de dados, assim como os dez termos/conceitos mais frequentes e os dez termos/conceitos que aparecem no maior número de documentos.

Tabela 2: Termos e conceitos inseridos no banco de dados após processamento

\begin{tabular}{|c|c|c|c|}
\hline Abordagem & N-Gramas & Conceitos UTS & Conceitos MetaMap \\
\hline $\begin{array}{c}\text { Número de } \\
\text { Termos/Conceitos }\end{array}$ & 150.664 & 15.988 & 9.589 \\
\hline $\begin{array}{c}10 \\
\text { Termos/Conceitos } \\
\text { que aparecem } \\
\text { em maior } \\
\text { número de } \\
\text { documentos }\end{array}$ & $\begin{array}{l}\text { gene } \\
\text { associated } \\
\text { diabetes } \\
\text { study } \\
\text { patients } \\
\text { results } \\
\text { genetic } \\
\text { risk } \\
\text { association } \\
\text { polymorphism }\end{array}$ & $\begin{array}{l}\text { Genes, (C0017337) } \\
\text { Clinical Trials, (C0008976) } \\
\text { Clinical Research, (C0008972) } \\
\text { Study, (C2603343) } \\
\text { Scientific Study, (C0947630) } \\
\text { Study Object, (C1705923) } \\
\text { Room of building - Study, } \\
\text { (C0557651) } \\
\text { DICOM Study, (C1880229) } \\
\text { Result, (C1274040) } \\
\text { Associated with, (C0332281) }\end{array}$ & $\begin{array}{l}\text { Associated with, (C0332281) } \\
\text { Genes, (C0017337) } \\
\text { Result, (C1274040) } \\
\text { Negation, (C1518422) } \\
\text { Patients, (C0030705) } \\
\text { Clinical Trials, (C0008976) } \\
\text { Conclusion, (C1707478) } \\
\text { Genotype, (C0017431) } \\
\text { Genetic Polymorphism, (C0032529) } \\
\text { Alleles, (C0002085) }\end{array}$ \\
\hline $\begin{array}{c}10 \\
\text { Termos/Conceitos } \\
\text { com } \\
\text { maior } \\
\text { frequência }\end{array}$ & $\begin{array}{l}\text { gene } \\
\text { patients } \\
\text { diabetes } \\
\text { associated } \\
\text { risk } \\
\text { type } \\
\text { study } \\
\text { polymorphism } \\
\text { insulin } \\
\text { association }\end{array}$ & $\begin{array}{l}\text { Genes (C0017337) } \\
\text { Patients (C0030705) } \\
\text { Diabetes Mellitus (C0011849) } \\
\text { Diabetes Mellitus, Non-Insulin- } \\
\text { Dependent (C0011860) } \\
\text { Clinical Trials (C0008976) } \\
\text { Polymorphism (C1882417) } \\
\text { Clinical Research (C0008972) } \\
\text { Room of building - Study } \\
\text { (C0557651) } \\
\text { Scientific Study (C0947630) } \\
\text { Study Object (C1705923) }\end{array}$ & $\begin{array}{l}\text { Genetic Polymorphism, (C0032529) } \\
\text { Patients, (C0030705) } \\
\text { Genes, (C0017337) } \\
\text { Alleles, (C0002085) } \\
\text { Genotype, (C0017431) } \\
\text { Associated with, (C0332281) } \\
\text { Mutation, (C0026882) } \\
\text { Negation, (C1518422) } \\
\text { Deletion (action), (C1880274) } \\
\text { Chemical Association, (C0596306) }\end{array}$ \\
\hline
\end{tabular}


O uso do UMLS foi também importante para correlacionar termos escritos em línguas diferentes. Considerando que o Metathesaurus do UMLS inclui thesauri de diferentes línguas e classifica-os em uma lista de conceitos, a qual contém CUIs, termos em línguas diferentes podem ser conectados por meio de seus CUIs. Essa característica tornou-se de extrema importância, pois os resumos extraídos do PubMed encontram-se em inglês e os registros clínicos de pacientes em português, uma vez que o trabalho tem sido desenvolvido principalmente para o contexto do sistema de saúde brasileiro. Por utilizar o UMLS, o SisViDas não se limita ao relacionamento português/inglês apenas e poderia ser utilizado para recuperar artigos científicos em qualquer língua presente no Metathesaurus e a partir de registros clínicos também escritos em qualquer língua presente no Metathesaurus.

\subsubsection{Processamento de Similaridade entre Documentos}

Para o processamento de similaridade entre os documentos, o SisViDas utiliza o Modelo de Espaço Vetorial e compõe uma matriz de termos (conceitos) por documento a partir dos pesos calculados durante o processamento textual da coleção. Na matriz de pesos, cada documento é representado por um vetor e cada dimensão do espaço é formada por um conceito do conjunto de termos classificadores. A distância entre os documentos se constitui na distância entre os vetores dispersos pelo espaço vetorial. Portanto, a partir da matriz de pesos, pode ser calculado o cosseno do ângulo entre os vetores de termos representativos dos documentos para se definir a distância entre os mesmos. Quanto maior o cosseno entre dois vetores, maior a similaridade entre eles e, dessa forma, calculase a similaridade entre cada documento (artigo científico) presente na matriz de pesos e o registro clínico. Os resultados são retornados em ordem decrescente de similaridade, ou seja, do mais similar para o menos similar, até um limiar (threshold) de similaridade desejado, sendo $0 \leqslant$ limiar $\leqslant 1$, por exemplo, limiar $=0,67$.

\subsubsection{Expansão de Consultas}

Conforme mencionado no Capítulo 3, na tentativa de recuperar os documentos mais relevantes de uma coleção, consultas de usuário em sistemas de recuperação de informação podem ser seletivamente modificadas com o auxílio de metodologias de expansão de consultas (ROCCHIO, 1971) (BAEZA-YATES; RIBEIRO-NETO, 1999). Para aplicar expansão de consultas ao presente trabalho, foi utilizada a abordagem de análise automática global, ou seja, apoiada por informações globais procedentes da coleção de artigos científicos. Foram implementadas três abordagens para a expansão de consultas, todas utilizando a Equação 
de Rocchio (ROCCHIO, 1971) para reformulação de pesos da consulta.

Na primeira abordagem, a expansão de consultas foi aplicada com o auxílio da metainformação "MeSH Terms" dos artigos do PubMed. Assim, foram considerados como documentos relevantes para a Equação de Rocchio todos os artigos contendo termos MeSH cadastrados e relacionados à consulta. Essa decisão foi tomada, pois os termos MeSH são informações atribuídas por analistas da NLM qualificados no assunto, os quais examinam os artigos do PubMed e atribuem a eles os termos MeSH aplicáveis e mais específicos de acordo com o conteúdo central do documento (tipicamente são atribuídos dez a doze termos MeSH para cada artigo).

Na segunda abordagem, foram considerados como documentos relevantes documentos com conceitos identificados a partir de n-gramas (4-gramas, trigramas e bigramas) presentes no registro clínico. Caso o registro clínico apresentasse ao menos um conceito reconhecido para termos com granularidade maior que 1 (4-gramas, trigramas e bigramas), foram considerados como documentos irrelevantes documentos contendo apenas conceitos reconhecidos para unigramas do registro clínico.

Na terceira abordagem, a expansão de consultas foi aplicada com o auxílio da metainformação "Publication Type" dos artigos do PubMed. Assim, foram considerados como documentos relevantes artigos com os valores "review", "editorial" e "comment" para a atributo "Publication Type". Essa decisão foi tomada pois, segundo a equipe de especialistas do ICr em colaboração com o presente trabalho, artigos de revisões e de estudos clínicos ou epidemiológicos devem ter um peso maior que outros tipos de artigos. De acordo com a equipe, artigos descrevendo trabalhos experimentais de alterações genéticas raras acabam tendo pouca utilidade na prática clínica. Segundo Gomes, F. M. S. do ICr, a Síndrome de Prader-Willi, por exemplo, além de ser raríssima, está relacionada a alterações epigenéticas mas apresenta um tipo de comprometimento diferente, por exemplo, das origens fetais da síndrome metabólica.

\subsubsection{Interface com o Usuário}

O SisViDas pode ser explorado para a criação de diferentes interfaces gráficas que estabeleçam uma interface com o usuário final, ou seja, o profissional de saúde. Essas interfaces gráficas de usuário podem ser, por exemplo, uma interface que auxilie pesquisadores em pediatria a descobrir e comprovar relacionamentos entre potenciais fatores risco e as doenças crônicas, por meio de consulta por esses fatores potenciais. 
Outro exemplo é uma interface a ser executada em paralelo com um sistema de informação em saúde (SIS) ou prontuário eletrônico de pacientes (PEP) para análise de registros clínicos de uma maneira transparente ao profissional de saúde em atendimento. Com uma interface gráfica nesse segundo formato, o SisViDas pode, por exemplo, analisar um registro clínico armazenado no banco de dados e enviar um alerta (com um artigo científico que o comprove) caso alguma associação com fatores de risco para doenças crônicas seja encontrada. É interessante notar que, neste segundo caso, os artigos retornados devem estar em menor número e devem ser mais específicos. No primeiro caso, esses artigos apoiam pesquisas científicas e uma maior revocação pode ser interessante para ampliar o campo de pesquisa.

Para realizar testes de uma interface gráfica no segundo formato seria necessário um sistema de informação em saúde no domínio e, uma vez que a equipe do ICr em colaboração com o presente trabalho não possui ainda um SIS, testes para essa abordagem de interface gráfica seriam inviáveis. Por esse motivo, foi desenvolvida uma interface gráfica para o primeiro contexto mencionado. É interessante notar, entretanto, que, apesar de a interface ter sido desenvolvida para consultas por fatores potenciais, ela aceita consultas longas, para abranger registros clínicos completos, transformados em formato texto quando possuírem formato estruturado. Dessa forma, a interface desenvolvida atende aos requisitos da interface para auxílio a pesquisadores e atende também, parcialmente, os requisitos para o segundo tipo de interface, com a excessão de que ela não é executada de maneira transparente ao profissional de saúde por não estar associada a um SIS ou PEP e a seu respectivo banco de dados. Duas interfaces gráficas desenvolvidas para o SisViDas são apresentadas nas Figuras 8 e 9. A Figura 8 apresenta a interface gráfica a ser utilizada pelos profissionais de saúde para submissão de consultas por fatores potenciais ou registros clínicos em formato texto. A Figura 9 apresenta a interface gráfica de retorno após a submissão de uma consulta. Nessa interface, são exibidos os resultados para a consulta submetida (i.e. os artigos científicos relevantes para a consulta), com informações como título do artigo, autores, resumo e hiperligação para a página do artigo no PubMed.

\subsubsection{Classificação de Pacientes em Grupos de Risco}

Essa funcionalidade, que não foi selecionada como foco para concentração de esforços no período do presente mestrado, está ainda em fase de desenvolvimento, porém já em fase bastante adiantada devido à reutilização de componentes dos projetos de trabalho de conclusão de curso (POLlETTINI, 2008)(POLLETTINI et al., 2009) e iniciação científica 


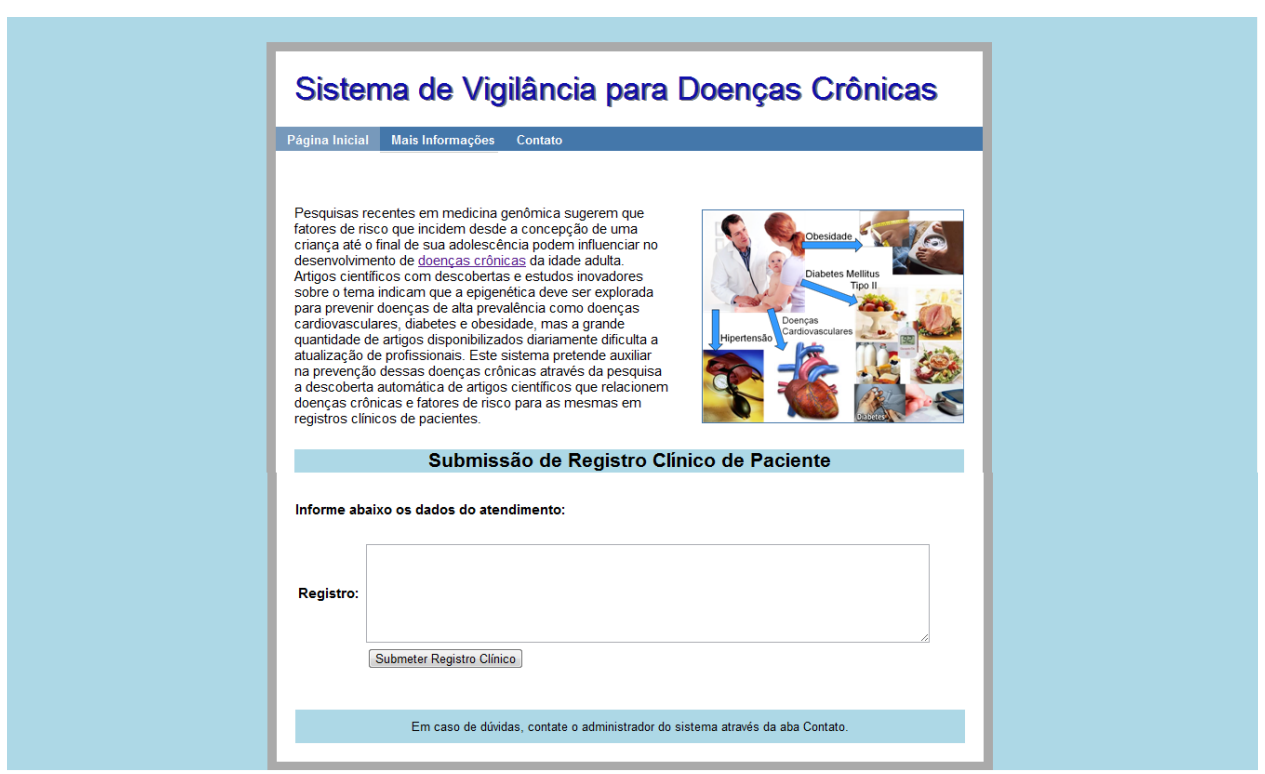

Figura 8: Interface Gráfica de Usuário para submissão de consultas por fatores potenciais ou registros clínicos em formato texto

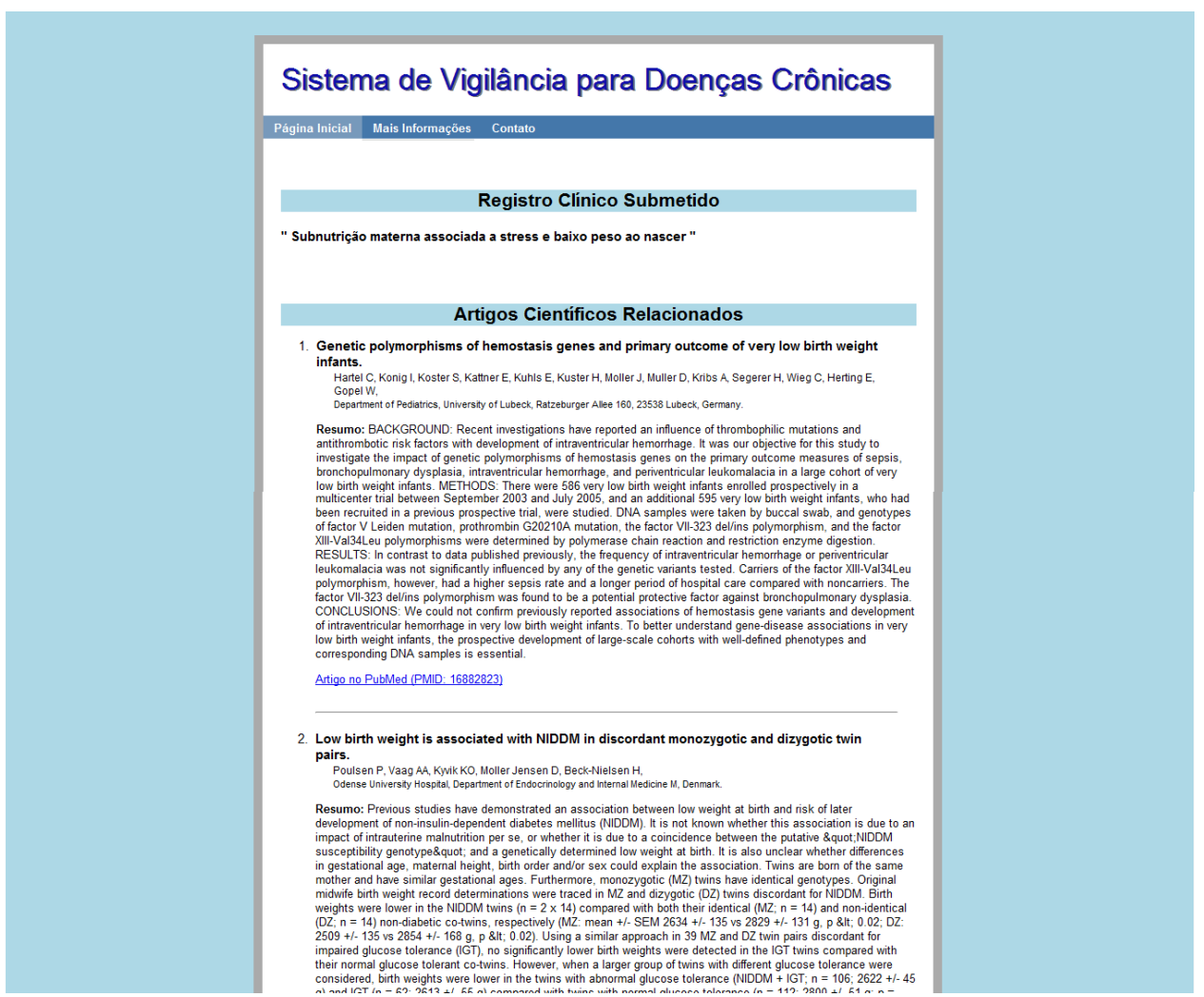

Figura 9: Interface Gráfica de Usuário para exibição de resultados para uma consulta submetida

(POLLETTINI et al., 2008)(POLLETTINI et al., 2009) da mestranda e de algoritmos de aprendizado de máquina presentes no pacote Weka (WITTEN; FRANK, 2005).

Para o desenvolvimento da funcionalidade de classificação de pacientes em grupos de 
risco para doenças crônicas, tornaram-se necessários: (i) um conjunto de classificadores e (ii) um método para organização dos dados em arquivos de formato ARFF (AttributeRelation File Format) ${ }^{5}$. Para satisfazer esses requisitos, primeiramente, foram incorporados ao SisViDas três algoritmos de classificação que estendem a classe weka.classifiers. Classifier, do pacote Weka. Os classificadores weka.classifiers.IBK e weka.classifiers.MultilayerPerceptron têm como suporte, respectivamente, os conceitos de vizinhos mais próximos e redes neurais artificiais apresentados no Capítulo 3. O terceiro classificador (RFCat) tem como suporte conceitos de categorização e Relevance Feedback e foi desenvolvido no contexto do trabalho anterior da mestranda (POLLETTINI, 2008)(POLLETTINI et al., 2009). Outros classificadores poderão ser incorporados ao SisViDas, após avaliação de viabilidade e adequação.

No que se refere à organização dos dados, um método para geração arquivos em formato ARFF está sendo desenvolvido para a classe representativa de registros clínicos de pacientes. Esse método deverá ser estendido por cada classe que estenda a classe representativa desses documentos. Para o classificador de Relevance Feedback RFCat, os atributos do arquivo ARFF (no contexto deste trabalho de mestrado) são organizados em função dos conceitos presentes nos registros clínicos. Para os demais classificadores, weka.classifiers.IBK e weka.classifiers.MultilayerPerceptron, os atributos do arquivo ARFF são organizados em função dos tipos semânticos do UMLS.

\subsection{Exemplo de Uso e Resultados}

Considerando-se uma consulta por fatores potenciais que inclua termos em português como "subnutrição materna ou stress" e "baixo peso ao nascer", com limiar=0,001 para a similaridade mínima aceitável entre os documentos, utilizando a abordagem UTS para reconhecimento de conceitos, o SisViDas pode recuperar 143 citações do PubMed com conteúdo relacionado ao domínio de interesse (fatores de risco para doenças crônicas) ${ }^{6}$. Utilizando a abordagem MetaMap para reconhecimento de conceitos, o SisViDas pode recuperar 63 citações. Um resumo sobre os 5 primeiros documentos recuperados para a referida consulta, utilizando a abordagem UTS para reconhecimento de conceitos, pode ser visto na Tabela 3. A Tabela 4 apresenta um resumo sobre os 5 primeiros documentos recuperados, utilizando a abordagem MetaMap. Ao submeter ao PubMed essa mesma

\footnotetext{
${ }^{5}$ Um arquivo ARFF é um arquivo de texto com codificação ASCII contendo uma lista de instâncias partilhando um conjunto de atributos (ARFF, ). Arquivos ARFF são utilizados por softwares de aprendizado de máquina como o Weka.

${ }^{6}$ Consulta feita em $15 / 11 / 2011$ às $23 h 50$
} 
consulta, sem o uso do SisViDas, nenhum documento é recuperado. Ao considerar uma consulta composta pelos mesmos termos em inglês ("maternal undernutrition or stress" e "low birth weight"), o PubMed retorna 6215 citações. Porém, a maioria dos documentos retornados possui conteúdo distante do domínio específico de interesse, por mencionarem esses termos em contextos que diferem de fatores de risco para doenças crônicas.

\subsection{Considerações do Capítulo}

Pelos motivos apresentados, o SisViDas foi inicialmente instanciado para manejar apenas títulos, resumos e termos MeSH dos artigos científicos, mas não é restrito a esses atributos, podendo ser estendido para manejar outros meta-dados dos artigos e até mesmo artigos completos.

Conforme mencionado, o sistema SisViDas não se limita ao relacionamento de registros clínicos e artigos entre as línguas portuguesa e inglesa, poderia ser utilizado para recuperar artigos científicos em qualquer língua presente no Metathesaurus do UMLS e a partir de registros clínicos também escritos em qualquer língua presente no mesmo artefato linguístico. O SisViDas pode ainda ser explorado para a criação de diferentes interfaces gráficas que estabeleçam uma interface com o usuário final, ou seja, o profissional de saúde. Essas características demonstram a extensibilidade do sistema para trabalhos futuros e sua ampla aplicabilidade em diferentes contextos de vida profissional de diferentes profissionais de saúde. Esses requisitos não funcionais do trabalho levaram à definição de um arcabouço de software a ser apresentado no próximo capítulo. 
Tabela 3: Resumo sobre os 5 primeiros documentos recuperados para um registro clínico fictício contendo os termos "subnutrição materna ou stress" e "baixo peso ao nascer", utilizando a abordagem UTS para reconhecimento de conceitos

\begin{tabular}{|c|c|c|}
\hline PMID & Título & Parte do Resumo \\
\hline 16824679 & $\begin{array}{l}\text { Early and late weight gain and } \\
\text { the timing of puberty. }\end{array}$ & $\begin{array}{l}\text { Nutrition is an important regulator of the } \\
\text { tempo of growth and obesity is usually as- } \\
\text { sociated with tall childhood stature and } \\
\text { earlier pubertal development. Several lon- } \\
\text { gitudinal studies have demonstrated that } \\
\text { timing of puberty is most closely linked to } \\
\text { infancy weight gain: suggesting an early } \\
\text { window for programming of growth and } \\
\text { development... }\end{array}$ \\
\hline 10990085 & $\begin{array}{l}\text { Maternal diabetes alters birth } \\
\text { weight in glucokinase-deficient } \\
\text { (MODY2) kindred but has no in- } \\
\text { fluence on adult weight, height, } \\
\text { insulin secretion or insulin sensi- } \\
\text { tivity. }\end{array}$ & $\begin{array}{l}\text { AIMS/HYPOTHESIS: Altered fetal in- } \\
\text { sulin secretion caused by fetal or mater- } \\
\text { nal glucokinase mutations influence birth } \\
\text { weight. Here, we attempt to answer two } \\
\text { additional questions: firstly, whether this } \\
\text { variation in birth weight (from low birth } \\
\text { weight to macrosomia) has an effect on } \\
\text { adult height or weight. Secondly, whether } \\
\text { maternal hyperglycaemia during fetal life } \\
\text { has an effect on metabolic phenotypes of } \\
\text { the adult offspring... }\end{array}$ \\
\hline 21125351 & Epigenetics and hypertension. & $\begin{array}{l}\text { Epigenetics refers to mechanisms for } \\
\text { environment-gene interactions (mainly by } \\
\text { methylation of DNA and modification of } \\
\text { histones) that do not alter the underly- } \\
\text { ing base sequence of the gene. This ar- } \\
\text { ticle reviews evidence for epigenetic con- } \\
\text { tributions to hypertension. For example, } \\
\text { DNA methylation at CpG islands and hi- } \\
\text { stone acetylation pathways are known to } \\
\text { limit nephron development, thereby un- } \\
\text { masking hypertension associated with ex- } \\
\text { posure to a high-salt diet. Maternal wa- } \\
\text { ter deprivation and protein deficiency are } \\
\text { shown to increase expression of renin- } \\
\text { angiotensin system genes in the offspring. } \\
\text { The methylation pattern of a serine pro- } \\
\text { tease inhibitor gene in human placentas is } \\
\text { shown... }\end{array}$ \\
\hline 9421468 & $\begin{array}{l}\text { Imprinting of female offspring } \\
\text { with testosterone results in in- } \\
\text { sulin resistance and changes in } \\
\text { body fat distribution at adult age } \\
\text { in rats. }\end{array}$ & $\begin{array}{l}\text { In women, a relative hyperandrogenicity } \\
\text { is statistically associated with insulin re- } \\
\text { sistance and centralization of body fat, } \\
\text { which are predictors for the development } \\
\text { of non-insulin-dependent diabetes melli- } \\
\text { tus.... }\end{array}$ \\
\hline 20443665 & $\begin{array}{l}\text { Epigenetic malprogramming of } \\
\text { the insulin receptor promoter due } \\
\text { to developmental overfeeding. }\end{array}$ & $\begin{array}{l}\text { AIM: Prenatal and neonatal overfeeding } \\
\text { programs a permanent obesity and dia- } \\
\text { betes disposition, e.g., due to induction } \\
\text { of hypothalamic insulin resistance. We } \\
\text { investigated acquired alterations of the } \\
\text { DNA methylation pattern of the hypotha- } \\
\text { lamic insulin receptor promoter (IRP) } \\
\text { which might be an underlying molecular } \\
\text { mechanism... }\end{array}$ \\
\hline
\end{tabular}


Tabela 4: Resumo sobre os 5 primeiros documentos recuperados para um registro clínico fictício contendo os termos "subnutrição materna ou stress" e "baixo peso ao nascer", utilizando a abordagem MetaMap para reconhecimento de conceitos

\begin{tabular}{|c|c|c|}
\hline PMID & Título & Parte do Resumo \\
\hline 10990085 & $\begin{array}{l}\text { Maternal diabetes alters birth } \\
\text { weight in glucokinase-deficient } \\
\text { (MODY2) kindred but has no in- } \\
\text { fluence on adult weight, height, } \\
\text { insulin secretion or insulin sensi- } \\
\text { tivity. }\end{array}$ & $\begin{array}{l}\text { AIMS/HYPOTHESIS: Altered fetal in- } \\
\text { sulin secretion caused by fetal or mater- } \\
\text { nal glucokinase mutations influence birth } \\
\text { weight. Here, we attempt to answer two } \\
\text { additional questions: firstly, whether this } \\
\text { variation in birth weight (from low birth } \\
\text { weight to macrosomia) has an effect on } \\
\text { adult height or weight. Secondly, whether } \\
\text { maternal hyperglycaemia during fetal life } \\
\text { has an effect on metabolic phenotypes of } \\
\text { the adult offspring... }\end{array}$ \\
\hline 17143606 & $\begin{array}{l}\text { Relationships of maternal and pa- } \\
\text { ternal birthweights to features of } \\
\text { the metabolic syndrome in adult } \\
\text { offspring: an inter-generational } \\
\text { study in South India. }\end{array}$ & $\begin{array}{l}\text { AIMS/HYPOTHESIS: The association } \\
\text { between lower birthweight and metabolic } \\
\text { syndrome may result from fetal under- } \\
\text { nutrition (fetal programming hypothesis) } \\
\text { and/or genes causing both low birth- } \\
\text { weight and insulin resistance (fetal in- } \\
\text { sulin hypothesis). We studied associa- } \\
\text { tions between the birthweight of parents } \\
\text { and metabolic syndrome in the offspring... }\end{array}$ \\
\hline 9112021 & $\begin{array}{l}\text { Low birth weight is associ- } \\
\text { ated with NIDDM in discordant } \\
\text { monozygotic and dizygotic twin } \\
\text { pairs. }\end{array}$ & $\begin{array}{l}\text { Previous studies have demonstrated } \\
\text { an association between low weight at } \\
\text { birth and risk of later development of } \\
\text { non-insulin-dependent diabetes mellitus } \\
(\text { NIDDM)... }\end{array}$ \\
\hline 18626486 & $\begin{array}{l}\text { Methyl donor supplementation } \\
\text { prevents transgenerational ampli- } \\
\text { fication of obesity. }\end{array}$ & $\begin{array}{l}\text { BACKGROUND: The obesity epidemic, } \\
\text { recognized in developed nations for } \\
\text { decades, is now a worldwide phenomenon. } \\
\text { All age groups are affected, includ- } \\
\text { ing women of childbearing age, fuel- } \\
\text { ing concern that maternal obesity be- } \\
\text { fore and during pregnancy and lactation } \\
\text { impairs developmental establishment of } \\
\text { body weight regulatory mechanisms in the } \\
\text { fetus or infant, causing transgenerational } \\
\text { amplification of obesity prevalence and } \\
\text { severity... }\end{array}$ \\
\hline 11914751 & $\begin{array}{l}\text { A retroviral long terminal repeat } \\
\text { adjacent to the HLA DQB1 gene } \\
\text { (DQ-LTR13) modifies Type I di- } \\
\text { abetes susceptibility on high risk } \\
\text { DQ haplotypes. }\end{array}$ & $\begin{array}{l}\text { AIMS/HYPOTHESIS: HLA-DQ genes, } \\
\text { located in the human leukocyte antigen } \\
\text { region on chromosome } 6 \mathrm{p} \text {, are the main } \\
\text { inherited factors predisposing to Type } \\
\text { I (insulin-dependent) diabetes mellitus. } \\
\text { Endogenous retroviral long-terminal re- } \\
\text { peats are integrated at several sites within } \\
\text { this region, one of which is known to en- } \\
\text { hance susceptibility for Type I diabetes. } \\
\text { We examined another LTR within the } \\
\text { HLA-region as an additional genetic risk } \\
\text { marker... }\end{array}$ \\
\hline
\end{tabular}




\section{Arcabouço de Software para Sistemas de Vigilância Epidemiológica apoiados por Relacionamentos Textuais Semânticos}

"Arcabouços de software (do inglês, framework) são projetos reusáveis de todo ou parte de um sistema descrito por um conjunto de classes abstratas e a forma como as instâncias dessas classes colaboram" ${ }^{1}$ (ROBERTS; JOHNSON, 1996). O conceito de arcabouço, em Engenharia de Software, é utilizado para designar a tecnologia que oferece recursos a desenvolvedores para aumentar a reutilização de componentes de software e permitir que aplicações distintas sejam criadas por meio de sua instanciação. Segundo Roberts e Johnson (1996), um bom arcabouço de software, que pode ser implementado com linguagens existentes programação orientada a objetos, pode reduzir o custo de desenvolvimento de um aplicativo por permitir a reutilização de projeto e código, entretanto o custo de se desenvolver um bom arcabouço é alto (ROBERTS; JOHNSON, 1996).

Roberts e Johnson (1996) afirmam que as pessoas desenvolvem abstrações a partir da generalização de exemplos concretos, pois toda tentativa de determinar abstrações corretas sem realmente ter desenvolvido um sistema está fadada ao fracasso. Um arcabouço é um projeto reutilizável e, portanto deve ser desenvolvido olhando-se para os exemplos concretos que presumidamente o arcabouço representa. Assim, quanto maior o número de exemplos que forem utilizados, mais geral será o arcabouço, entretanto esse número não deve ser muito grande devido aos custos de produção desses exemplos. Os autores recomendam o desenvolvimento de três exemplos, pois, se o número de exemplos for grande, corre-se o risco de o arcabouço nunca ficar pronto (ROBERTS; JOHNSON, 1996).

\footnotetext{
${ }^{1}$ Frameworks are reusable designs of all or part of a software system described by a set of abstract classes and the way instances of those classes collaborate.
} 
O presente capítulo apresenta o arcabouço de software ASSim-VigiE (Arcabouço de Software para Sistemas de Vigilância Epidemiológica) criado a partir de dois exemplos concretos e das abstrações que seriam necessárias para o desenvolvimento de um terceiro exemplo. Os dois exemplos concretos utilizados foram: SisViDas, apresentado no Capítulo 4 e GV-Automático, desenvolvido como Iniciação Científica e Trabalho de Conclusão de Curso de graduação da presente mestranda. Em seguida, foram analisadas as abstrações necessárias para o desenvolvimento de um exemplo similar ao SisViDas com o objetivo de prevenção de outras doenças de interesse.

\subsection{Exemplos Utilizados para Abstração do Arcabouço}

O arcabouço de software ASSim-VigiE foi abstraído partindo-se, inicialmente, do sistema de vigilância SisViDas, com o auxílio dos exemplos apresentados nas Subseções 5.1.1 e 5.1.2.

\subsubsection{GV-Automático}

O conhecimento sobre o processo de desenvolvimento humano é importante para os profissionais que trabalham na área de saúde, uma vez que as informações coletadas nesse processo podem auxiliar em trabalhos preventivos, aprimorando a qualidade de vida dos pacientes. O papel da equipe de saúde das unidades básicas de saúde (UBSs), principalmente no âmbito da pediatria, é significativo e, portanto, os profissionais que atuam em atenção básica a saúde devem ser capazes de detectar, o mais cedo possível, crianças em situação de risco visando promover encaminhamentos ou intervenções que busquem minimizar ou corrigir os problemas detectados para cada uma delas, assim como identificar crianças que contam com fatores protetores para a promoção da saúde e do desenvolvimento (Salles, 2001).

Com o objetivo de realizar estudos que visam a sistematização de procedimentos para o acompanhamento do processo de desenvolvimento humano e a promoção da saúde de pacientes atendidos em UBSs, pesquisadores de diferentes universidades brasileiras, integrantes de um núcleo de pesquisa (Diretório Lattes CNPq) denominado "Núcleo Interdisciplinar de Pesquisa e Ensino (NIPE)" realizaram, durante as últimas décadas, diversas pesquisas, propondo a utilização de um índice denominado Grau de Vigilância (GV) (PANICO; CANZIANI; GUERCHON, 1997). O GV consiste em um índice cuja utilização permite a definição de procedimentos pediátricos a serem adotados no atendimento básico a 
saúde, por meio da associação de fatores de risco e de proteção à saúde e ao processo de desenvolvimento, aos quais estão expostos os pacientes (crianças e adolescentes) e suas famílias. O GV varia em valores gradativos possibilitando a definição de ações educativas, terapêuticas ou terapêuticas especializadas requeridas pelos pacientes e respectivas famílias e pode ser estabelecido de acordo com os graus cumulativos GV Rotina, GV1, GV2, GV3 e GV Urgência (PANICO; CANZIANI; GUERCHON, 1997)(SALLES, 2001).

Buscando melhorias no atendimento a seus pacientes e no fluxo de informação gerada por esses atendimentos, o Centro Médico Social e Comunitário de Vila Lobato (CMSC Vila Lobato), uma unidade de atendimento primário à saúde, localizada na periferia da cidade de Ribeirão Preto, estabeleceu uma parceria com alunos e pesquisadores do curso de Informática Biomédica. Dessa parceria, nasceu o SI-VilaLobato (Sistema de Informação Vila Lobato), um sistema de informação que visa a informatização dos procedimentos de atendimento e acompanhamento de saúde das crianças e adolescentes atendidos pelo CMSC Vila Lobato, assim como suas respectivas famílias.

O trabalho de Iniciação Científica da presente mestranda, apoiado pela FAPESP², teve como objetivo desenvolver módulos de classificação automática do GV apoiados por conceitos de k-Vizinhos Mais Próximos e Redes Neurais Artificiais. O resultado dessas pesquisas gerou um sistema denominado GV-Automático, que foi citado para ser utilizado em uma unidade de atendimento primário à saúde da cidade de Ribeirão Preto (o Centro Médico Social e Comunitário de Vila Lobato - CMSC Vila Lobato) e foi incorporado como subsistema do SI-VilaLobato (POLLETTINI et al., 2008)(POLLETTINI et al., 2009). O trabalho de conclusão de curso da aluna, para graduação em Informática Biomédica, propôs a definição automática, ou semi-automática em alguns casos especiais, do GV do paciente a partir do manejo e análise de informações provenientes de prontuários de atendimento utilizando Relevance Feedback (POLLETTINI, 2008)(POLLETTINI et al., 2009).

O classificador apoiado por Relevance Feedback e categorização desenvolvido naquele momento utilizava transformação dos dados estruturados dos atendimentos para o formato bag of words e realizava os processos de retirada de stop-words e stemming ${ }^{3}$ para, em seguida, gerar uma matriz de pesos de cada termo para cada documento, similar à matriz descrita na Seção 4.1.4. Todavia a aplicação de reconhecimento de conceitos e construção

\footnotetext{
${ }^{2}$ Processo FAPESP n ${ }^{\circ}$ 2006/06715-8

${ }^{3}$ Técnica caracterizada pela tentativa de reduzir cada palavra à sua provável raiz através da extração de sufixos (EBECKEN; LOPES; COSTA, 2003). De acordo com Matsubara, Martins e Monard (2003), algoritmos de stemming consistem em uma normalização linguística em que formas variantes de um mesmo termo são reduzidas a uma forma comum denominada stem ou radical. Para isso, são removidos prefixos e/ou sufixos de um termo, ou, caso se trate de uma variação de conjugação verbal, é realizada a transformação do verbo para sua forma no infinitivo (MATSUBARA; MARTINS; MONARD, 2003).
} 
da matriz de pesos em função desses conceitos reconhecidos é perfeitamente aplicável ao contexto do GV-Automático.

\subsubsection{Sistema de Vigilância para Outras Enfermidades}

O SisViDas, apresentado no Capítulo 4, foi desenvolvido para o contexto de fatores de risco genéticos e epigenéticos para doenças crônicas, todavia, a estrutura criada para o mesmo permite o desenvolvimento de sistemas de vigilância para outras doenças sem grandes esforços. Para tanto, é necessário aplicar modificações apenas à funcionalidade de criação da coleção de artigos científicos, para manejar outras ontologias de domínio diferentes da ontologia de doenças crônicas (CDO) e outros conceitos do UMLS para a criação da consulta a ser submetida ao PubMed. Assim será possível filtrar o repositório do PubMed e definir uma coleção de artigos de interesse para o domínio da doença e fatores de risco desejados.

\subsection{Identificação de Pontos Fixos e de Flexibilização}

Segundo Roberts e Johnson (1996), um arcabouço de software normalmente possui partes flexíveis, que podem mudar de aplicação para aplicação. Esses pontos de flexibilização são chamados também de hot spots (ROBERTS; JOHNSON, 1996). Partes fixas de um arcabouço, ou seja, aquelas que não mudam entre as diferentes aplicações são chamadas também de frozen spots.

O arcabouço ASSim-VigiE deve permitir adaptações para manejar: (i) outras fontes de artigos científicos diferentes do PubMed; (ii) outras ontologias de domínio para a criação da consulta a ser utilizada para filtragem dos artigos na fonte de informação desejada (ex. PubMed) (iii) outras ontologias e/ou thesauri para reconhecimento de conceitos médicos e biomédicos além do UMLS; (iv) diferentes tipos de registros clínicos ou ainda outros tipos de documentos do domínio da saúde; (v) outros classificadores e estratégias de classificação. Esses, juntamente com templates e visões para interface com o usuário, constituem-se como pontos de flexibilização do ASSim-VigiE. Dentre os pontos de flexibilização mencionados, é provável que o menos flexível seja o manejo de outros artefatos linguísticos além do UMLS. Como o arcabouço deve realizar processamento interlingual (principalmente entre português e inglês), é necessário que o artefato linguístico a ser utilizado estabeleça o relacionamento de conceitos entre as duas línguas, além dos relacionamentos semânticos naturalmente presentes nos artefatos. No domínio de saúde, 
o UMLS representa a melhor opção a ser utilizada para o reconhecimento de conceitos e, por esse motivo, a princípio será utilizada por todas as aplicações. Todavia, a extensão do arcabouço para manejar outros artefatos linguísticos já foi preparada para o caso de se tornar necessária (ou interessante).

Como pontos fixos do arcabouço é possível mencionar as classes abstratas para permitir cada ponto de flexibilização citado, por exemplo, uma classe abstrata para representar características comuns de diferentes coleções de documentos e outra para as características comuns dos diferentes tipos de documentos. Outros pontos fixos do arcabouço devem consistir nas classes responsáveis pela identificação de relacionamentos entre documentos e pelo processamento textual dos documentos (remoção de stop-words, processamento de n-gramas), além de classes conectoras entre as camadas de apresentação e lógica, apresentadas na Seção 5.3.

\subsection{Projeto do Arcabouço}

O arcabouço ASSim-VigiE possui atualmente dois casos de uso concretos, o GVAutomático e SisViDas. No que se refere aos requisitos do SisViDas apresentados no Capítulo 4, o ASSim-VigiE implementa os três primeiros casos de uso do sistema de vigilância: (i) atualizar a coleção de artigos científicos; (ii) recuperar artigos científicos relevantes para um registro clínico; e (iii) classificar pacientes em grupos de risco. A funcionalidade de classificação, apesar de não ter sido um dos focos do presente trabalho para o período do mestrado, foi bastante beneficiada por reutilização de componentes do GVAutomático. Por esse motivo, apesar de não estar ainda finalizada, são necessárias apenas mais algumas poucas adaptações para a finalização da mesma. Porém, essa funcionalidade pode ser vislumbrada no ASSim-VigiE.

A Figura 10 apresenta a infraestrutura do ASSim-VigiE, organizada em três camadas: apresentação, lógica e armazenamento, sendo a camada lógica subdividida entre a camada de negócio e camadas de conectores para as camadas de apresentação e de armazenamento. Na camada lógica, o módulo Busca Por Artigos é responsável por interagir com repositórios públicos de artigos científicos e recuperar uma coleção de artigos de interesse, a partir de conceitos presentes em ontologias do domínio. O módulo Processamento Textual é responsável pelo processamento de informações textuais de registros clínicos e artigos científicos. O módulo Processamento Linguagem Natural é responsável pela aplicação de técnicas de processamento de linguagem natural, como processamento de 
n-gramas. O módulo Reconhecimento de Conceitos utiliza métodos e classes de APIs de acesso ao UMLS para identificar conceitos do domínio da saúde. Finalmente, os módulos Similaridade e Classificação são responsáveis, respectivamente, pelo processamento de similaridade entre documentos e classificação de pacientes em grupos de risco para doenças ou de acordo com Graus de Vigilância.

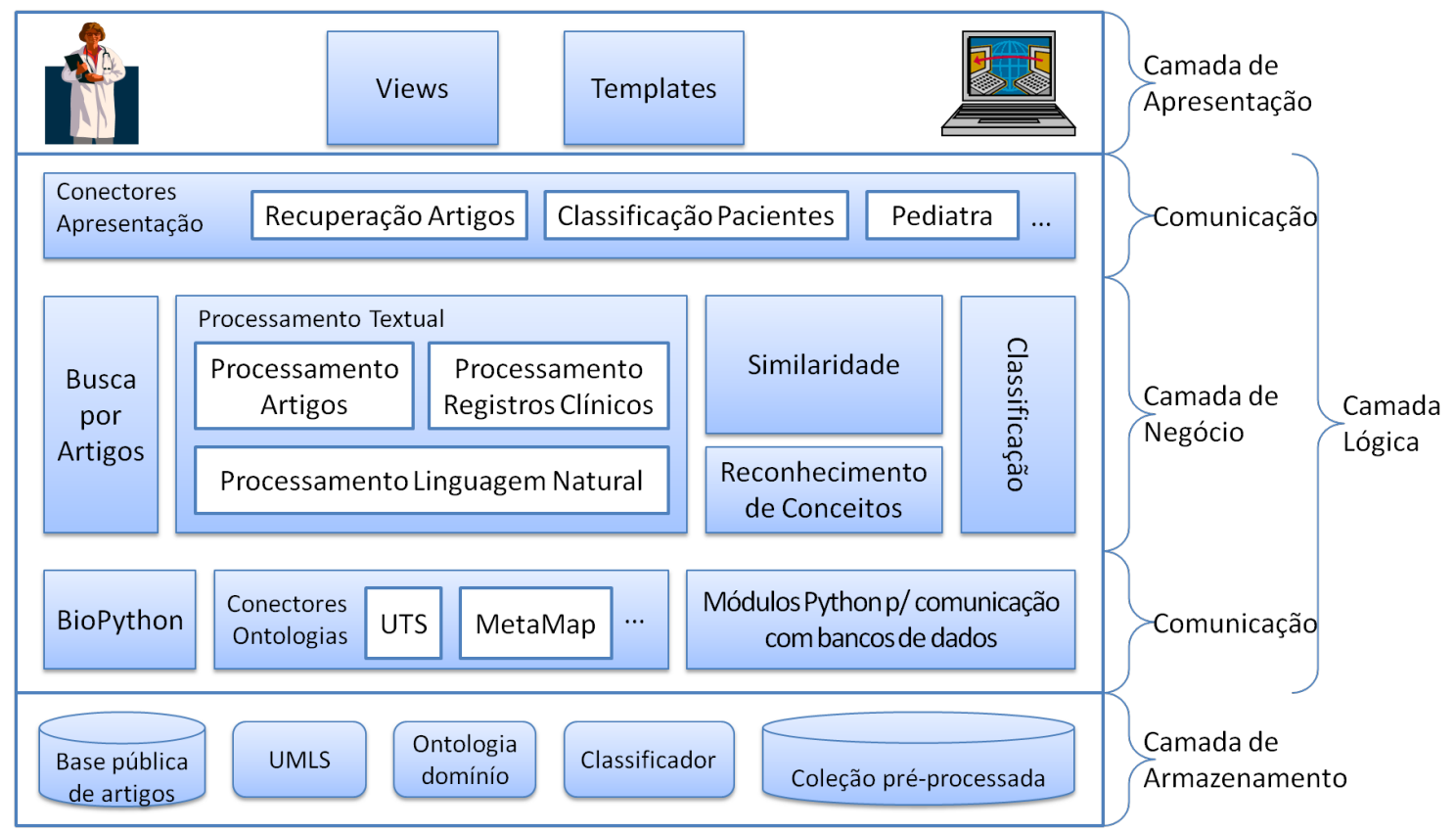

Figura 10: Infraestrutura, com processos e repositório, do arcabouço.

\subsection{Diagrama de Classes}

A Figura 11 apresenta o Diagrama de Classes da camada lógica para o arcabouço desenvolvido. Nela, podem ser vistas classes responsáveis por: (i) manejar a coleção de artigos científicos, como CreateUpdateCollection e Collection, que buscam e salvam artigos científicos para a coleção; (ii) realizar o processamento textual dos documentos, como Document e Term; (iii) identificar conceitos do domínio da saúde, como Concept, NGramsProcessing e MeshTerm; (iv) calcular a similaridade entre registros clínicos e artigos da coleção, como RelationshipIdentification; (v) classificar pacientes em grupos de risco para doenças crônicas ou de acordo com um Grau de Vigilância, como PatientsClassifier; e (vi) estabelecer a comunicação entre as camadas lógica e de apresentação, como PatientsClassification, PaperRetrieval e Pediatrician.

Na Figura 11, conforme código de cores apresentado na legenda da mesma, as classes pertencentes ao módulo Busca por Artigos estão apresentadas na cor azul. As classes pertencentes ao módulo Processamento Textual estão apresentadas em tons de verde, com 
diferença de tons relacionada ao tipo de informação textual manejada pela classe (artigo científico, registro clínico ou ambos). As classes representadas na cor amarela pertencem ao módulo Processamento Linguagem Natural, enquanto os módulos de Reconhecimento de Conceitos, desenvolvidos em linguagem Java e diretamente responsáveis pela identificação de conceitos do domínio da saúde presentes no UMLS, estão representados na cor marrom. Nas cores vermelha e roxa estão representados, respectivamente os módulos Similaridade e Classificação, enquanto as classes representadas na cor branca pertencem ao módulo de comunicação com a camada de apresentação.

\subsection{Considerações do Capítulo}

Para tratar a indisponibilidade de artigos completos, assim como para reduzir o custo computacional do processamento textual de artigos completos, o arcabouço foi inicialmente instanciado para manejar apenas títulos, resumos e termos $\mathrm{MeSH}$ dos artigos científicos, mas não é restrito a esses atributos, podendo ser estendido para manejar outros meta-dados dos artigos e até mesmo artigos completos. Como os resumos dos artigos abordam as informações essenciais dos mesmos e revistas científicas no domínio da saúde frequentemente exigem que resumos dos artigos sejam organizados de acordo com uma estrutura pré-definida, considerou-se que, nesta fase do trabalho, os benefícios providos pelo processamento apenas dos meta-dados escolhidos compensariam os prejuízos causados pela perda de informações presentes em outras partes dos artigos completos.

Conforme mencionado anteriormente, o arcabouço apresentado não se limita ao relacionamento de registros clínicos e artigos entre as línguas portuguesa e inglesa e poderia ser utilizado para recuperar artigos científicos em qualquer língua presente na ontologia e/ou thesaurus utilizado para reconhecimento de conceitos do domínio da saúde (por exemplo, o metathesaurus do UMLS) e a partir de registros clínicos também escritos em qualquer língua presente no mesmo artefato linguístico. O arcabouço pode ainda ser explorado para a criação de diferentes interfaces gráficas que estabeleçam uma interface com o usuário final, ou seja, o profissional de saúde. 


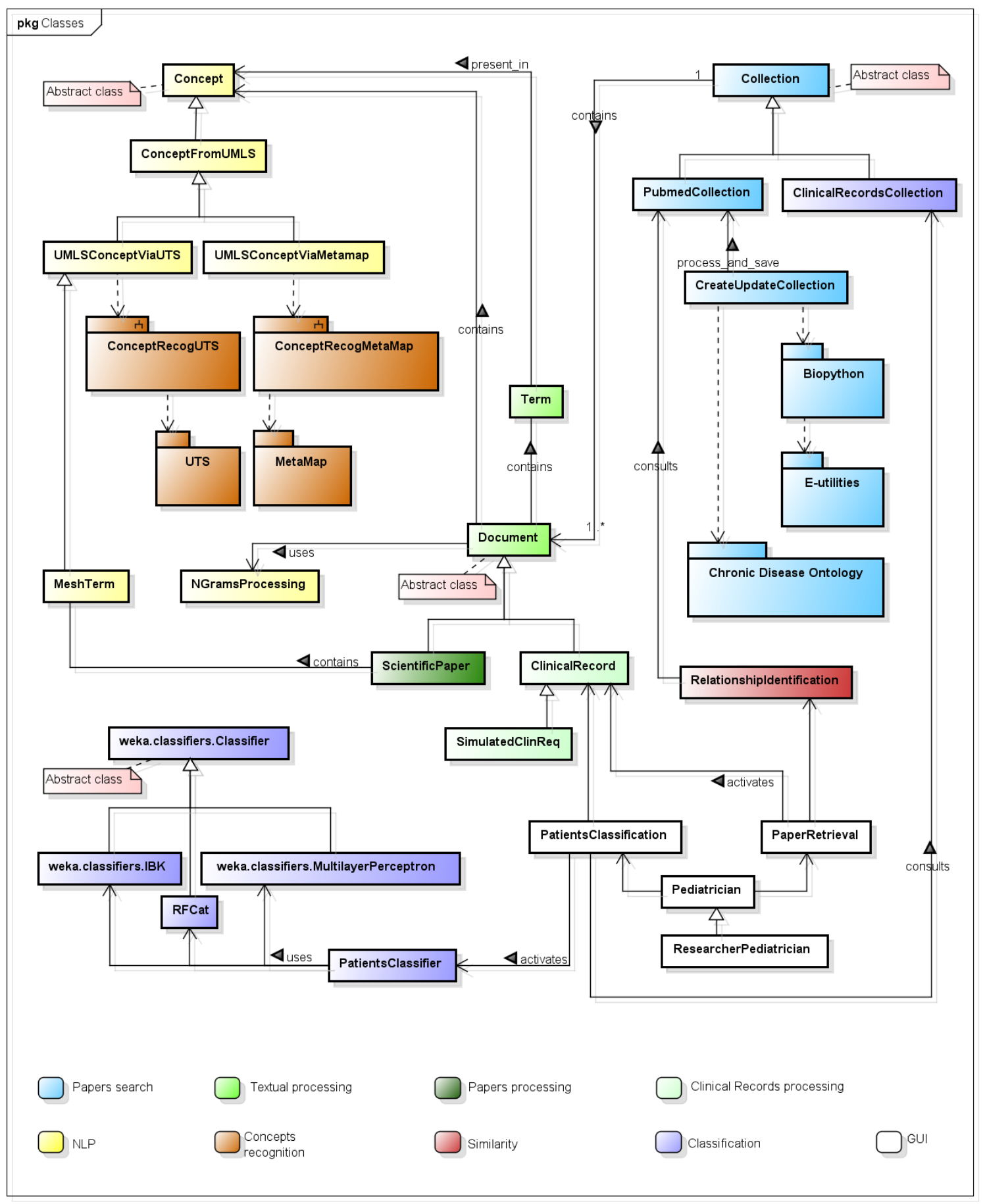

powered by astah

Figura 11: Diagrama de classes 


\section{Avaliação e Resultados para o Caso de Uso Sis ViDas}

Conforme mencionado no Capítulo 4, este trabalho tem sido desenvolvido em parceria com pesquisadores do Instituto da Criança da Faculdade de Medicina da USP (ICr). A equipe do ICr, especialista no domínio de origens fetais para a saúde e doença (domínio DOHaD), acompanha, com o trabalho de uma equipe multiprofissional, um estudo de coorte $^{1}$ no Centro de Saúde-Escola Samuel B. Pessoa - FMUSP (também conhecido como "centro de saúde-escola Butantã") com aproximadamente duas mil crianças. Essas crianças, das quais os pesquisadores conhecem as condições de nascimento, são acompanhadas sob a perspectiva de "puericultura sob medida". O estudo, que começou por volta de setembro de 2007, tem como objetivo identificar perfis de risco e prevenir de doenças do adulto com início em estágios precoces da vida. O estudo também permite aos pesquisadores conhecer detalhadamente o histórico de três gerações antecedentes de cada uma das crianças.

Para colaborar com o presente trabalho, alguns pesquisadores do ICr prepararam uma lista de termos e expressões mais frequentes nos registros clínicos dos pacientes do Centro de Saúde Escola "Samuel B. Pessoa". A equipe de pesquisadores do ICr, forneceu também à mestranda e orientadora um prontuário de atendimento (não preenchido) do centro de saúde-escola utilizado para acompanhamento de saúde da criança. O prontuário e a lista de termos e expressões foram utilizados para avaliação de precisão e revocação do sistema SisViDas. A avaliação contou com a ajuda desses profissionais principalmente para a criação de uma coleção de referência contendo relacionamentos entre artigos científicos e casos clínicos. Optou-se por realizar uma simulação de prontuários de pacientes para a execução dos testes, uma vez que o acesso a prontuários reais de pacientes envolve questões éticas. A simulação, a criação da coleção de referência, os resultados obtidos e alguns resultados para ferramentas de busca conhecidas são apresentados neste capítulo.

\footnotetext{
${ }^{1}$ Estudo observacional em que pacientes são selecionados de acordo com exposição a determinado fator e são seguidos para avaliar a incidência de doenças
} 


\subsection{Simulação de Prontuários}

Com o objetivo de simular prontuários de pacientes com dados de possíveis atendimentos, foram selecionados alguns campos da estrutura do prontuário e seus valores possíveis. Os campos selecionados foram: idade do paciente, sexo, diagnóstico nutricional, crescimento, desenvolvimento (DNPM), vacinação, alimentação, cotidiano infantil, familiograma, ambiente emocional, condições ambientais, condições sócio-econômico-culturais, fatores de risco (Riscos e proteção familiares relacionados à saúde), fatores de proteção (riscos e proteção familiares relacionados à saúde), doenças atuais, doenças anteriores ou crônicas e antecedentes familiares. Os campos do prontuário e seus respectivos valores possíveis serão referidos no restante da dissertação, respectivamente, como atributos e valores.

Para escolher os atributos que fariam parte do prontuário simulado, a mestranda utilizou como suporte informações obtidas em reunião presencial com a Dra. Filumena Maria da Silva Gomes e o documento que continha a lista de termos e expressões. Durante a reunião, Dra. Filumena mencionou que os campos do final do prontuário utilizado para acompanhamento de crianças no Centro de Saúde-Escola, de certa forma, resumiam as informações mais "alarmantes" encontradas no restante do prontuário. Por meio da lista de termos e expressões, a mestranda notou que muitas das informações do restante do prontuário realmente estavam presentes nos valores que aqueles campos finais podiam receber. Por esses motivos, esses foram os campos do prontuário selecionados como atributos para a simulação.

Com o auxílio do software "Mathematica", versão 8.0.0, foram geradas matrizes contendo números aleatórios correspondentes aos valores sorteados para cada um dos atributos do prontuário. Assim, foram geradas matrizes contendo números correspondentes às opções de cada um dos campos selecionados do prontuário original e a criação dessas matrizes foi apoiada por sorteios de números aleatórios.

Os atributos "fatores de risco (riscos e proteção familiares relacionados à saúde)", "doenças atuais", "doenças anteriores ou crônicas" e "antecedentes familiares" permitem de um a seis valores simultâneos. Uma vez que a mestranda e orientadora desejavam ter na coleção de referência casos com as seis diferentes quantidades de valores para esses atributos, sessenta prontuários foram simulados e categorizados da seguinte maneira: (i) 10 prontuários com apenas um valor sorteado para cada um dos atributos "fatores de risco (riscos e proteção familiares relacionados à saúde)", "doenças atuais", "doenças 
anteriores ou crônicas" e "antecedentes familiares"; (ii) 10 prontuários com dois valores para os referidos atributos; (iii) 10 prontuários com três valores para os referidos atributos; (iv) 10 prontuários com quatro valores para os referidos atributos; (v) 10 prontuários com cinco valores para os referidos atributos; e (vi) 10 prontuários com seis valores para os referidos atributos.

Ao final do processo de simulação, foram selecionados 30 casos dentre os 60 criados. Essa seleção se deu pela exclusão de casos incoerentes, que continham, por exemplo, o valor "família continente" para o atributo "fatores de proteção (riscos e proteção familiares relacionados à saúde)" e os valores "depressão materna", "Mãe ou familiares com problemas psiquiátricos ou com necessidades especiais" e "Estresse psicossocial por drogadição na família" para os atributos "ambiente emocional", "fatores de Risco (Riscos e proteção familiares relacionados à saúde)" e "antecedentes familiares", respectivamente.

\subsection{Criação de Coleção de Referência}

Após o processo de simulação de casos de pacientes, um módulo do SisViDas (ver Figura 12) foi criado para que os profissionais da equipe de especialistas do ICr elaborassem a distância uma coleção de referência que estabelecesse os relacionamentos entre artigos científicos e os casos simulados. O sistema apresenta uma lista dos casos e, para cada caso da lista, é apresentada uma ligação para outra página. Essa outra página contém detalhes sobre o caso e os artigos científicos cujos relacionamentos para com o caso devem ser preenchidos. Para cada artigo, foram disponibilizados título, resumo, autores, instituição e hiperligação para página do artigo no PubMed. Cada relacionamento pode ser classificado em: "Fortemente relevante", "Relevante", "Baixa relevância" ou "Totalmente Irrelevante". Foram criados 5 usuários para o sistema e a ordem dos "pacientes" na lista de casos difere para cada usuário. Como usuários normalmente começam a preencher os casos na ordem em que aparecem (começando pelo primeiro), essa decisão de apresentar os casos ordenados de forma diferente para os diferentes usuários foi tomada para que, caso cada usuário preenchesse apenas os primeiros casos da coleção, o número de casos fosse o maior possível.

Para compor a coleção de referência, foram selecionados 216 artigos relacionados ao domínio de fatores de risco epigenéticos para doenças crônicas. Conforme apresentado no Capítulo 4, a subcoleção mais relacionada a fatores epigenéticos é composta por 445 documentos, contudo seria inviável pedir aos colaboradores que avaliassem todos os rela- 


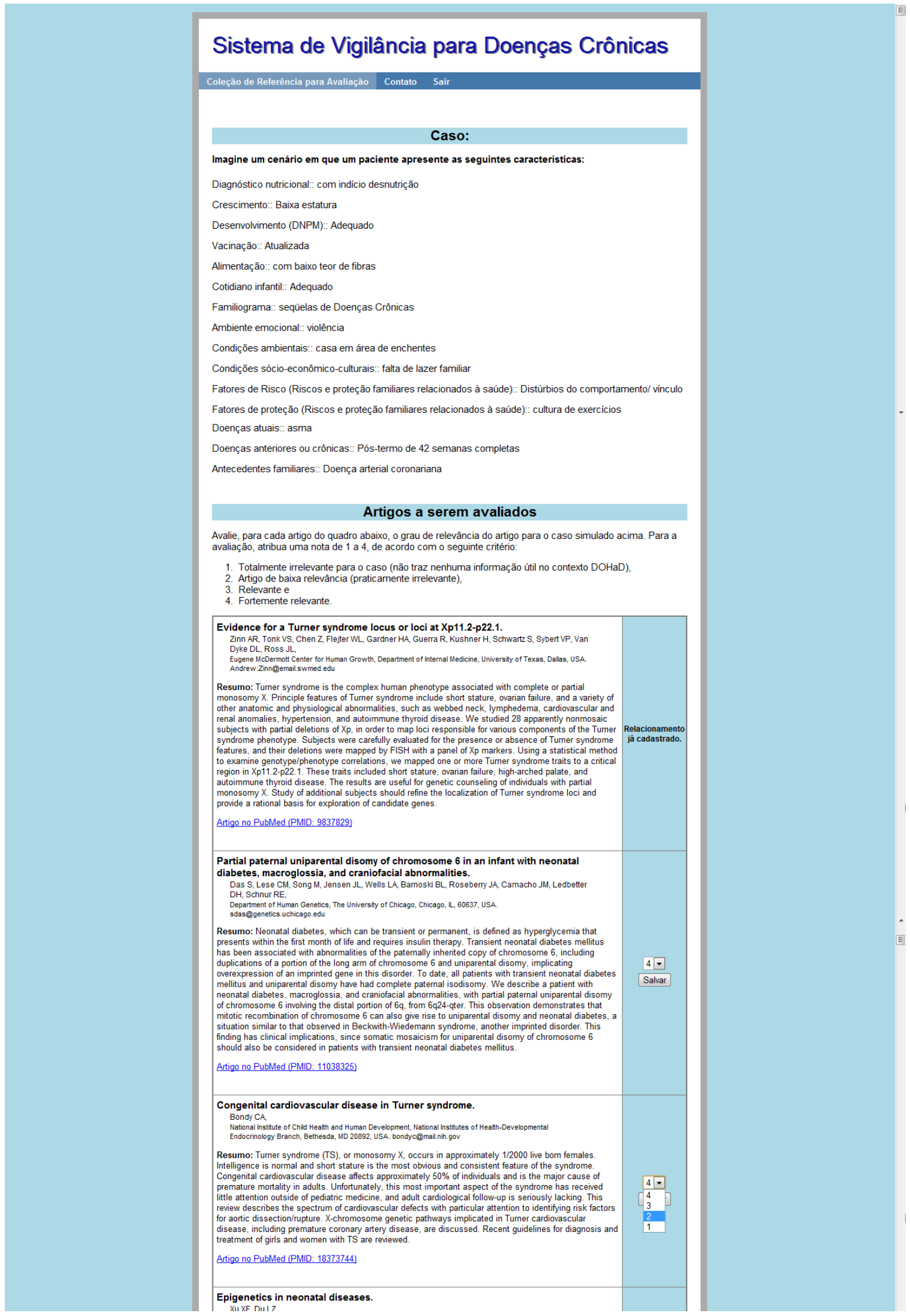

Figura 12: Página para preenchimento de relacionamentos entre caso simulado e artigos científicos para criação de coleção de referência 
cionamentos entre os 30 casos e os 445 documentos (o que totalizaria 13.350 relacionamentos). Para que a coleção abrangesse o máximo de dados possível para avaliação de precisão, o critério utilizado para essa seleção foi apoiado pelo limiar de similaridade entre os documentos e os casos simulados. Assim, foram selecionados todos os artigos que apresentaram similaridade maior que um limiar para pelo menos um dos casos simulados em pelo menos uma das abordagens consideradas pelo SisViDas para identificação de conceitos do domínio da saúde. Os limiares considerados para a abordagem que utilizou o UTS para identificação de conceitos e para a abordagem que utilizou o MetaMap foram, respectivamente, de 0,67 e de 0,27. Esses valores foram escolhidos de maneira empírica com o apoio dos valores médios de similaridade apresentados por cada abordagem.

Dentre os artigos da coleção de referência, para cada caso simulado foram classificados, pelos profissionais do ICr, em média: 53 artigos como "Fortemente relevantes"; 19 como "Relevantes", 25 como de "Baixa relevância" e 129 como "Totalmente Irrelevantes".

\subsection{Avaliação de Precisão e Revocação}

A avaliação de Precisão x Revocação dos resultados de um sistema consiste em um tipo de avaliação bastante comum na área de recuperação de informação. Os índices de precisão e de revocação medem, respectivamente: (i) o número de documentos relevantes dentre os que foram recuperados pelo sistema, i.e., a fração de documentos recuperados que são relevantes e (ii) o número de documentos relevantes recuperados pelo sistema dentre o total de documentos relevantes da coleção.

Dentre os trinta casos simulados e disponibilizados aos especialistas no domínio para avaliação de relacionamentos com artigos, apenas seis casos foram avaliados pelos mesmos, em tempo hábil para apresentação nesta dissertação. Esses casos foram avaliados quanto a resultados de precisão e revocação para as duas abordagens de reconhecimento de conceitos do sistema SisViDas: abordagem UTS e abordagem MetaMap. Os resultados foram avaliados também considerando como documentos relevantes para cada caso simulado: (i) apenas os documentos considerados como "Fortemente relevantes" pelos especialistas; (ii) os documentos considerados pelos especialistas como "Fortemente relevantes" ou "Relevantes"; (iii) os documentos considerados pelos especialistas como de alguma relevância (i.e.: "Fortemente relevantes", "Relevantes" ou "Baixa relevância"). Os Resultados de precisão e revocação para os seis casos, cujos relacionamentos com artigos foram avaliados por especialistas, são apresentados na Seção 6.3.1. 
Como a coleção de referência possui atualmente apenas seis casos avaliados, a mestranda e a orientadora decidiram realizar uma segunda avaliação apoiada pelos Termos MeSH dos artigos no PubMed. Como mencionado anteriormente, termos MeSH são informações atribuídas por analistas da NLM qualificados no assunto, os quais examinam os artigos do PubMed e atribuem a eles os termos MeSH aplicáveis e mais específicos de acordo com o conteúdo central do documento. Assim, esses termos fornecem informações que podem ser utilizadas para avaliação de precisão e revocação. Os resultados dessa avaliação são apresentados na Seção 6.3.2.

Devido à necessidade de se avaliar os casos em termos de precisão e revocação apoiada por Termos MeSH, as avaliações apresentadas neste capítulo foram realizadas sem considerar expansão de consulta apoiada por Termos MeSH.

\subsubsection{Precisão e Revocação com Coleção de Referência}

A Figura 13 apresenta os resultados de precisão e revocação para ilustrar um dos casos cujos relacionamentos com artigos foram avaliados pelos especialistas do ICr. O caso apresenta os seguintes valores para os atributos:

- Idade (Faixa etária): Adolescente;

- Sexo: Masculino;

- Diagnóstico nutricional: com indício desnutrição;

- Crescimento: Baixa estatura;

- Desenvolvimento (DNPM): Atraso do desenvolvimento;

- Vacinação: efeitos colaterais diversos, como BCG ite, edema de glote, síndrome convulsiva;

- Alimentação: obesogênica;

- Cotidiano infantil: Falta de atividade física;

- Familiograma: ambiente de risco para Doenças Crônicas;

- Ambiente emocional: drogadição dos pais;

- Condições ambientais: ambiente úmido; 
- Condições sócio-econômico-culturais: família contribui com $20 \%$ da renda familiar para dízimo da igreja;

- Fatores de Risco (Riscos e proteção familiares relacionados à saúde): Mortes de crianças na família;

- Fatores de proteção (Riscos e proteção familiares relacionados à saúde): cultura de exercícios;

- Doenças atuais: displasia broncopulmonar;

- Doenças anteriores ou crônicas: sífilis congênita tratada;

- Antecedentes familiares: Diabetes.

Para este caso, são apresentadas as curvas relativas às duas abordagens de reconhecimento de conceitos e também relativas ao nível de relevância dos artigos considerados (apenas "Fortemente relevantes"; "Fortemente relevantes" ou "Relevantes"; ou de alguma relevância). As curvas consideram como limiar de similaridade entre documentos os valores de 67\% para as abordagens UTS e 27\% para as abordagens MetaMap. Para valores baixos de revocação, as três abordagens apoiadas pelo UTS (considerando os diferentes níveis de relevância dos artigos que compõe o conjunto de documentos relevantes) apresentam valores altos de precisão, todavia apresentam valor máximo de revocação menor que 10\%. Já as abordagens apoiadas pelo MetaMap, apresentam precisão mais baixa que as abordagens UTS para valores baixos de revocação, todavia essa precisão aumenta para valores mais altos de revocação até aproximadamente $20 \%$ a 40\%, dependendo do nível de relevância considerado para a composição do conjunto de documentos relevantes. A precisão para níveis de revocação maiores que aproximadamente 7\% para abordagens UTS e maiores que $20 \%$ a $40 \%$ para abordagens MetamMap caem para 0, pois nem todos os documentos relevantes foram recuperados. Os valores de revocação podem ser aumentados se valores mais baixos forem considerados para o limiar de similaridade entre documentos, todavia, o limiar de similaridade não pode ser muito baixo pois, neste contexto, é preferível ter baixa revocação e alta precisão (i.e. poucos documentos recuperados, mas documentos com alta precisão) a ter alta revocação, mas baixa precisão.

A Figura 14 apresenta as curvas relativas à precisão média para cada nível de revocação $(10 \%, 20 \%, 30 \%, \ldots, 100 \%)$, considerando os seis casos preenchidos pelos especialistas. Cada curva no gráfico representa uma abordagem para reconhecimento de conceitos (UTS ou MetaMap) e um nível de relevância dos artigos considerados como relevantes. No 


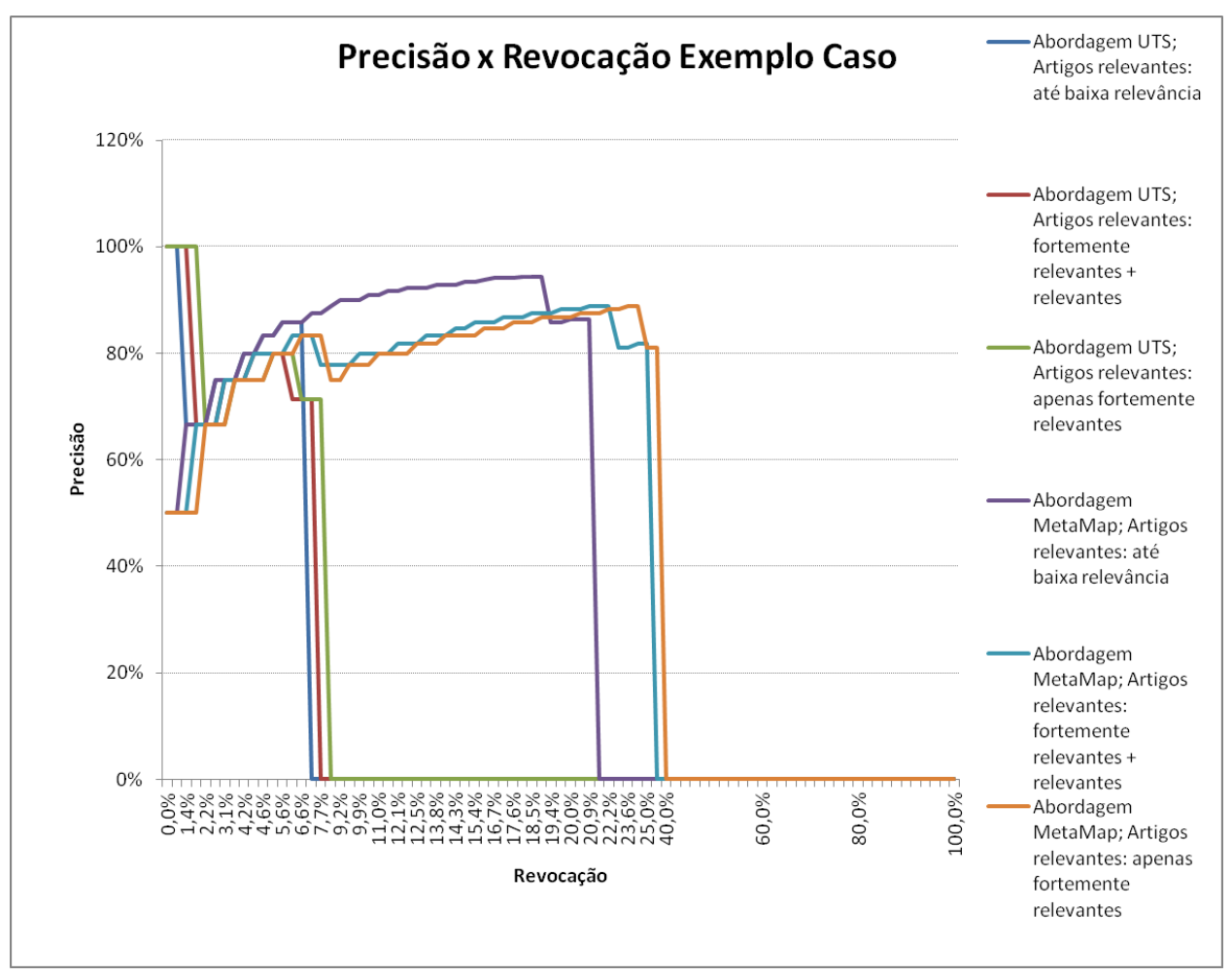

Figura 13: Exemplo de Precisão x Revocação para um caso da coleção de referência

geral, como pode ser visto pela Figura 14, as abordagens MetaMap para reconhecimento de conceitos nos artigos científicos apresentam melhores resultados de precisão para os diferentes níveis de revocação, mas as abordagens UTS apresentam um comportamento mais estável. Assim como na Figura 13, a precisão para níveis de revocação maiores que aproximadamente $40 \%$ caem para 0 , pois nem todos os documentos relevantes foram recuperados.

\subsubsection{Precisão e Revocação com Termos MeSH}

Para a avaliação de precisão e revocação, apoiada por Termos MeSH, foram considerados os todos os trinta casos simulados para a coleção de referência. A Figura 15 apresenta as curvas relativas à precisão média para cada nível de revocação $(10 \%, 20 \%$, $30 \%, \ldots, 100 \%$ ), considerando as diferentes abordagens para reconhecimento de conceitos (UTS ou MetaMap). A abordagen MetaMap para reconhecimento de conceitos nos artigos científicos apresenta resultados de precisão ligeiramente mais altos que os do UTS para níveis de revocação até 7\%. A partir desse valor de revocação a abordagem UTS apresenta melhores resultados, até a revocação de 40\%. Para níveis de revocação maiores que $40 \%$ para a abordagem UTS e $15 \%$ para a abordagem MetaMap caem para 0, pois nem todos os documentos relevantes foram recuperados. 


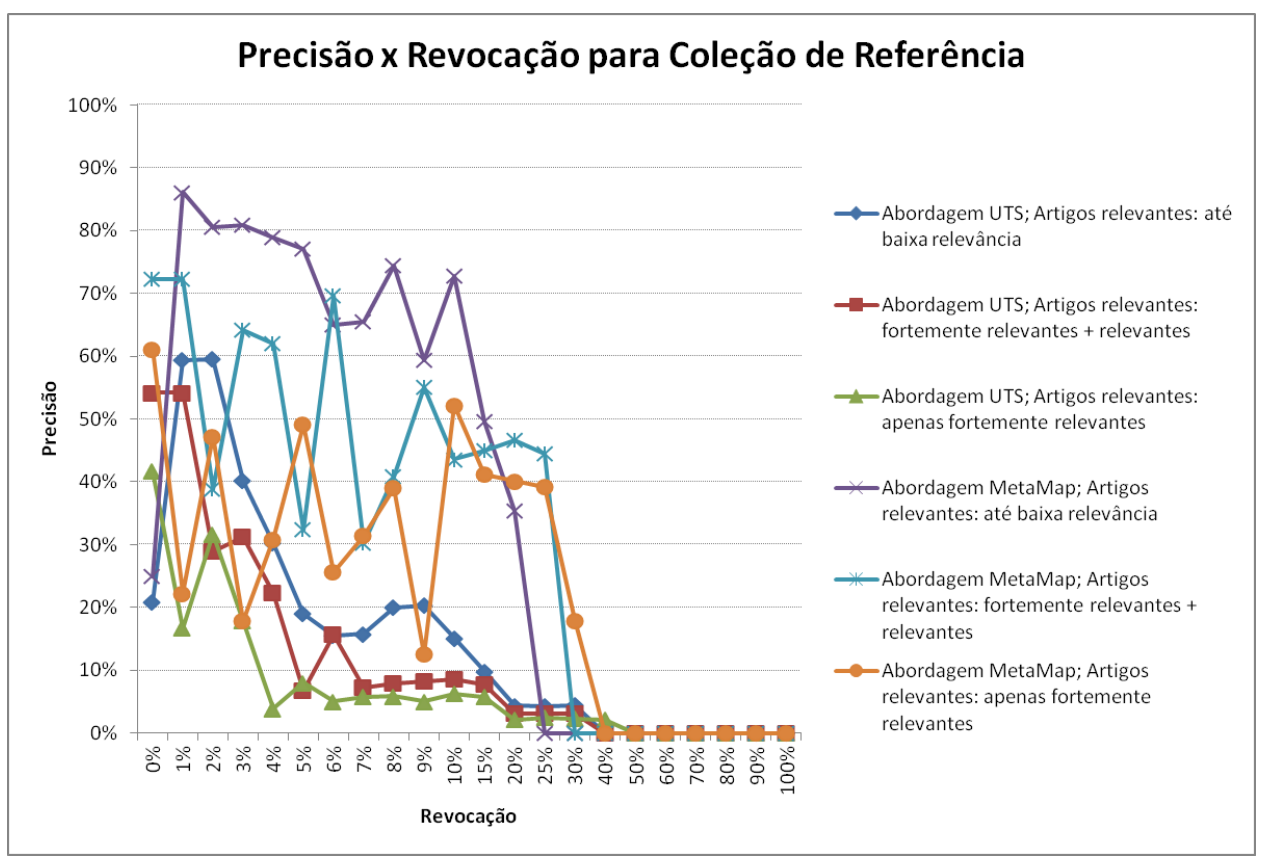

Figura 14: Precisão x Revocação médias para coleção de referência

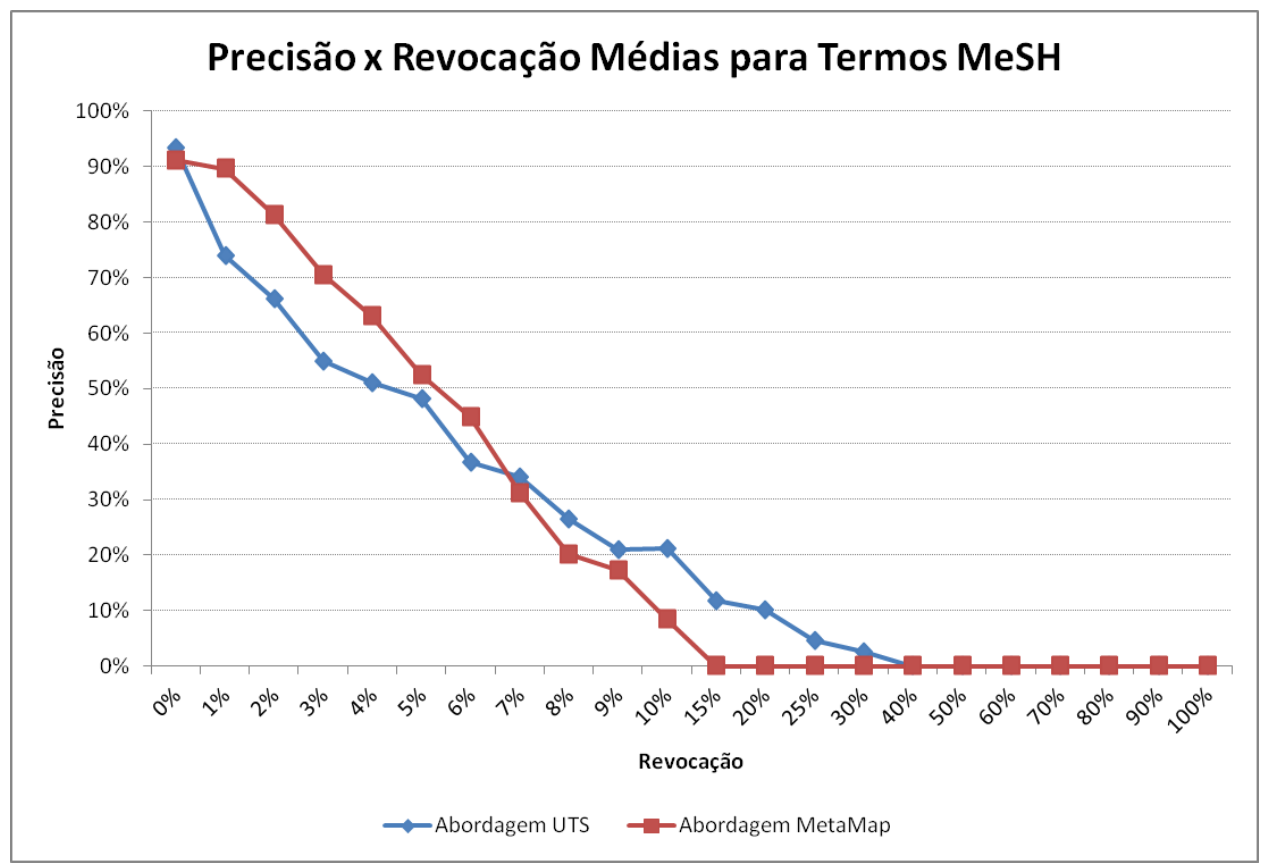

Figura 15: Precisão x Revocação médias para coleção de referência

\subsection{Resultados para Ferramentas de Busca}

Para avaliação dos resultados foram também realizadas consultas em algumas ferramentas de busca disponíveis atualmente, cujos resultados foram comparados com os resultados do SisViDas. As ferramentas consideradas foram: Google ${ }^{2}$, Google Acadêmico

\footnotetext{
${ }^{2}$ Uma marca registrada da Google Inc
} 
e PubMed. Dos resultados retornados pelas ferramentas, os dez primeiros foram avaliados em termos de precisão por esta mestranda, entretanto, por questões de espaço, as Tabelas 5, 6 e 7 apresentam apenas os cinco primeiros resultados.

\subsubsection{Busca por Prontuário}

Considerando como expressão de consulta todos os valores dos campos de cada prontuário simulado, as buscas por documentos nas ferramentas Google, Google Acadêmico e PubMed não retornaram resultado. Como exemplo, para um dos casos simulados foram submetidas às ferramentas as seguintes expressões de consulta (diferindo apenas com relação à presença de pontuação entre os atributos e valores do prontuário):

- Diagnóstico nutricional: excesso de massa corporal; Crescimento: Adequado; Desenvolvimento (DNPM): Adequado; Vacinação: Atualizada; Alimentação: densamente calórica; Cotidiano infantil: Sedentarismo; Familiograma: pais adolescentes; Ambiente emocional: doença psiquiátrica nos pais; Condições ambientais: sem esgoto público; Condições sócio-econômico-culturais: baixa escolaridade da mãe; Fatores de Risco (Riscos e proteção familiares relacionados à saúde): Peso de nascimento < 2.500 grs; Fatores de proteção (Riscos e proteção familiares relacionados à saúde): e vida saudável; Doenças atuais: Pré-natal com intercorrências como Hipertensão arterial; Doenças anteriores ou crônicas: sífilis congênita tratada; Antecedentes familiares: Doença hereditária;

- Diagnóstico nutricional excesso de massa corporal Crescimento Adequado Desenvolvimento (DNPM) Adequado Vacinação Atualizada Alimentação densamente calórica Cotidiano infantil Sedentarismo Familiograma pais adolescentes Ambiente emocional doença psiquiátrica nos pais Condições ambientais sem esgoto público Condições sócio-econômico-culturais baixa escolaridade da mãe Fatores de Risco (Riscos e proteção familiares relacionados à saúde) Peso de nascimento $<2.500$ grs Fatores de proteção (Riscos e proteção familiares relacionados à saúde) e vida saudável Doenças atuais Pré-natal com intercorrências como Hipertensão arterial Doenças anteriores ou crônicas sífilis congênita tratada Antecedentes familiares Doença hereditária

- Diagnóstico nutricional excesso de massa corporal Crescimento Adequado Desenvolvimento DNPM Adequado Vacinação Atualizada Alimentação densamente calórica Cotidiano infantil Sedentarismo Familiograma pais adolescentes Ambiente emocional doença psiquiátrica nos pais Condições ambientais sem esgoto público Condi- 
ções sócio-econômico-culturais baixa escolaridade da mãe Fatores de Risco Riscos e proteção familiares relacionados à saúde Peso de nascimento 2.500 grs Fatores de proteção Riscos e proteção familiares relacionados à saúde e vida saudável Doenças atuais Pré-natal com intercorrências como Hipertensão arterial Doenças anteriores ou crônicas sífilis congênita tratada Antecedentes familiares Doença hereditária

No caso do Google e Google Acadêmico, acredita-se que a ausência de resultados deve-se ao fato de essas ferramentas limitarem suas expressões de consulta, respectivamente, a 32 palavras e 250 caracteres. O Google apresenta como resultado uma página de erro quando consultas com mais de 32 palavras são submetidas. Enquanto isso, o Google Acadêmico limita automaticamente o número de caracteres da expressão de consulta antes de sua submissão, eliminando automaticamente da expressão todos os caracteres subsequentes ao $250^{\circ}$. O Google Acadêmico permite também pesquisa avançada. Para as opções "Encontrar artigos com todas as palavras" e "Encontrar artigos com a frase exata", da mesma forma que para a consulta submetida na página inicial da ferramenta, não foi obtido nenhum resultado. Ao considerar a opção "Encontrar artigos com no mínimo uma das palavras", que considera o conector "OR" entre os termos da consulta, conforme pode ser visto pela Figura 16, foram obtidos 11.200 .000 resultados. Esses resultados, contudo, foram obtidos para uma consulta limitada aos 250 primeiros caracteres da consulta original.

No caso do PubMed, acredita-se que a ausência de resultados deve-se ao fato de a consulta submetida, por ser derivada do prontuário, estar em português, enquanto o PubMed trabalha apenas com buscas na língua inglesa. Para consultas com poucas palavras (por exemplo, três palavras), em alguns casos, o PubMed realiza automaticamente uma tradução de termos, mas isso não acontece para consultas maiores como as consultas compostas pelas palavras de um registro clínico de paciente. Submetendo-se a consulta previamente ao tradutor do Google e em seguida ao PubMed, obteve-se um erro causado pelo termo "Familiograma"3, não traduzido do português para o inglês pelo tradutor e não encontrado na base de dados do PubMed.

\subsubsection{Busca por Expressão}

Como expressões de consulta para busca por expressões nas ferramentas Google, Google Acadêmico e PubMed foram consideradas duas expressões constantes na lista

\footnotetext{
${ }^{3}$ Presente em todos os prontuários por ser o título de um atributo bastante importante para o contexto DOHaD.
} 


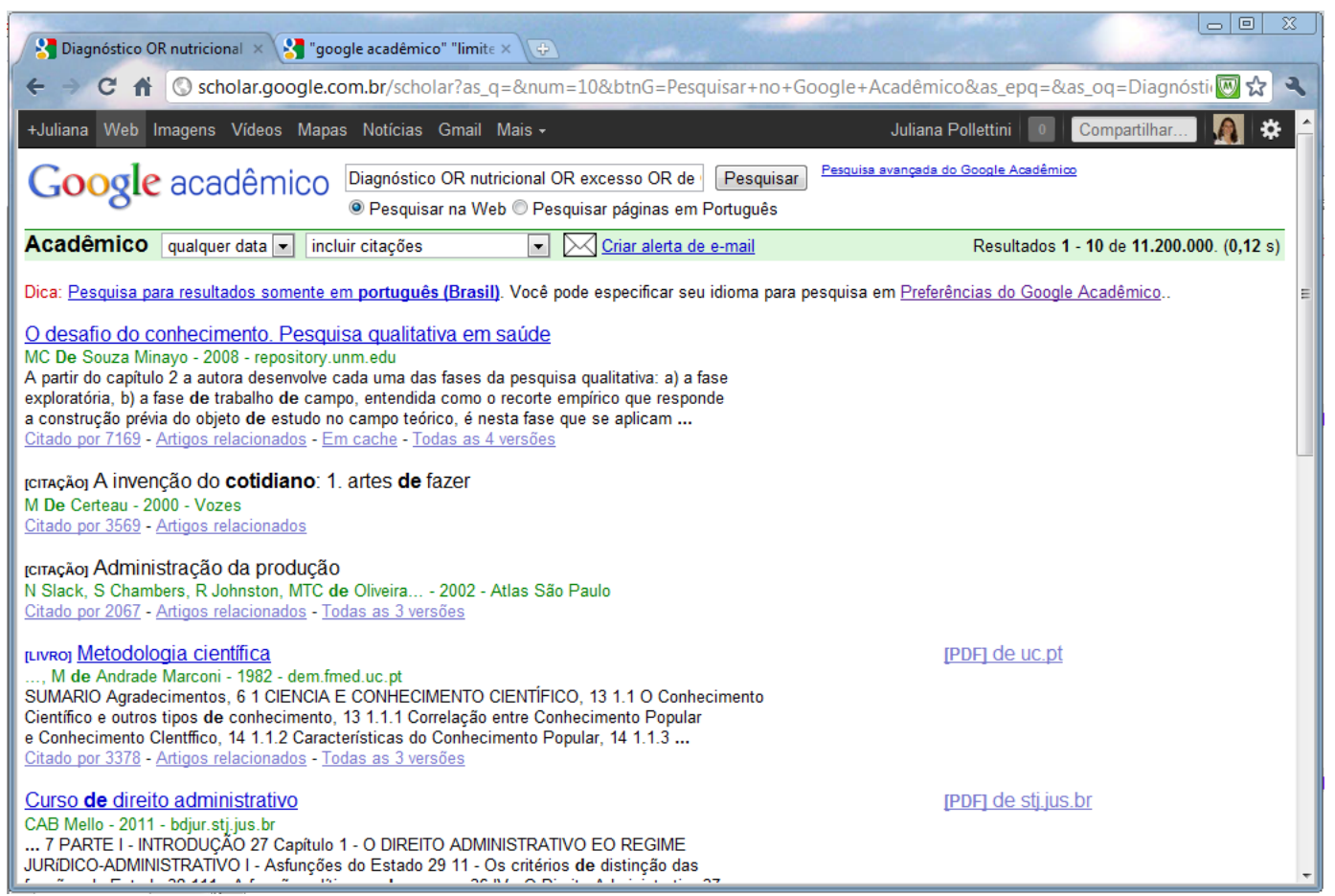

Figura 16: Página de retorno do Google Acadêmico para consulta submetida no campo para expressão na própria página do Google Acadêmico

de termos e expressões fornecida pela equipe parceira. Expressões de consulta submetidas em português ao PubMed não retornaram nenhum resultado para as buscas realizadas. Para a expressão de consulta "Doenças atuais: Pré-natal com intercorrências como Hipertensão arterial", as buscas por expressões nas ferramentas Google e Google Acadêmico retornaram os resultados apresentados, respectivamente, na segunda e na terceira colunas da Tabela 5. Os resultados obtidos para a mesma consulta em inglês "Current diseases, prenatal complications such as hypertension", traduzida previamente do português para o inglês por intermédio da ferramenta Google Tradutor, podem ser observados na quarta coluna da Tabela 5. Os resultados obtidos pelo SisViDas estão apresentados na última coluna da tabela.

Tabela 5: Resumo sobre os 5 primeiros documentos recuperados para a expressão "Doenças atuais: Pré-natal com intercorrências como Hipertensão arterial"

\begin{tabular}{|c|c|c|c|c|}
\hline $\mathrm{N}^{\mathbf{O}}$ & Google & Google Acadêmico & PubMed & SisViDas \\
\hline & $\begin{array}{l}\text { Título: }[\mathrm{PDF}] \text { Hipertensão e } \\
\text { gravidez }\end{array}$ & $\begin{array}{l}\text { Título: [HTML] Rastrea- } \\
\text { mento populacional de anor- } \\
\text { malidades cardíacas fetais por } \\
\text { ecocardiografia pré-natal em } \\
\text { gestações de baixo risco no } \\
\text { município de Porto Alegre }\end{array}$ & $\begin{array}{l}\text { Título: The metabolic syn- } \\
\text { drome: common origins of a } \\
\text { multifactorial disorder }\end{array}$ & $\begin{array}{l}\text { Título: The developmental } \\
\text { origins of health and disease } \\
\text { hypothesis }\end{array}$ \\
\hline
\end{tabular}




\begin{tabular}{|c|c|c|c|c|}
\hline $\mathrm{N}^{\circ}$ & Google & Google Acadêmico & ubMed & SisViDas \\
\hline 1 & 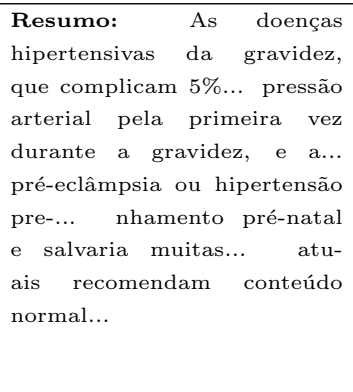 & $\begin{array}{l}\text { Resumo: } \ldots \text { Dos falso- } \\
\text { negativos, o primeiro cor- } \\
\text { responde a uma doença } \\
\text { com reconhecida dificuldade } \\
\text { de... ouro para o controle } \\
\text { pós-natal, absolutamente } \\
\text { inexeqüível no estágio at- } \\
\text { ual de organização... que a } \\
\text { prevalência de malformações } \\
\text { cardiovasculares deva ser } \\
\text { maior no período pré-natal... }\end{array}$ & 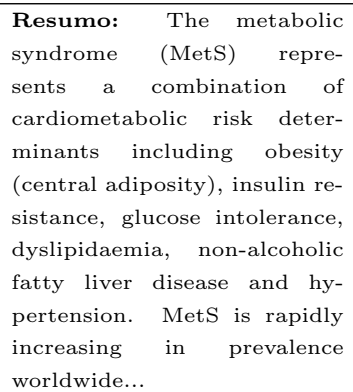 & $\begin{array}{l}\text { Resumo: Artigo sem } \\
\text { resumo no PubMed } \\
\text { (http://www.ncbi.nlm.nih.gov/ } \\
\text { pubmed/20687308). }\end{array}$ \\
\hline 2 & $\begin{array}{l}\text { Título: [PDF] } \\
\text { E PUERÉ-NATAL } \\
\begin{array}{l}\text { Resumo: } \text { Em } \\
\text { hol: prenatal y }\end{array} \text { puerpe- } \\
\text { rio. atención calificada } \\
\text { y humanizada... } \\
\text { CORRÊNCIAS INTER- } \\
\text { MAIS CLÍNICAS } \\
\text { 13.5 Hipertensão arterial } \\
\text { na gestação e eclâmpsia... } \\
\text { adequado dos problemas } \\
\text { que ocorrem neste período... } \\
\text { obstétrica e neonatal, con- } \\
\text { siderando as evidências } \\
\text { científicas atuais e as... }\end{array}$ & $\begin{array}{l}\text { Título: }[\mathrm{PDF}] \text { Determinantes } \\
\text { diretos do parto prematuro } \\
\text { eletivo e os resultados } \\
\text { neonatais } \\
\text { Resumo: ... outros serviços } \\
\text { em } 29(29,3 \%) \text { e apenas uma } \\
(1 \%) \text { não freqüentou pré- na- } \\
\text { tal... canal arterial Ente- } \\
\text { rocolite necrozante Retinopa- } \\
\text { tia Hérnia inguinal Displa- } \\
\text { sia broncopulmonar Doença } \\
\text { metabólica óssea... neonatal, } \\
\text { representando um dos maiores } \\
\text { desa- fios para a Obstetrícia } \\
\text { atual... }\end{array}$ & $\begin{array}{l}\text { Título: Pheochromocytoma } \\
\text { and Von Hippel-Lindau in } \\
\text { pregnancy } \\
\text { Resumo: Pheochromocy- } \\
\text { toma is an infrequent but } \\
\text { well-acknowledged primary } \\
\text { cause of malignant hyperten- } \\
\text { sion in pregnancy. Although } \\
\text { the majority of pheochromo- } \\
\text { cytomas are sporadic, those } \\
\text { that present as bilateral or } \\
\text { multifocal tumors may be a } \\
\text { manifestation of a rare can- } \\
\text { cer susceptibility syndrome, } \\
\text { such as Von Hippel-Lindau } \\
\text { (VHL)... }\end{array}$ & $\begin{array}{l}\text { Título: Epigenetics in neona- } \\
\text { tal diseases } \\
\text { Resumo: OBJECTIVE: To } \\
\text { review the role of epigenetic } \\
\text { regulation in neonatal dis- } \\
\text { eases and better understand } \\
\text { Barker's "fetal origins of adult } \\
\text { disease hypothesis"... RE- } \\
\text { SULTS: There is a wealth of } \\
\text { epidemiological evidence that } \\
\text { lower birth weight is strongly } \\
\text { correlated with an increased } \\
\text { risk of adult diseases, such as } \\
\text { type } 2 \text { diabetes mellitus, hy- } \\
\text { pertension, and cardiovascu- } \\
\text { lar disease... }\end{array}$ \\
\hline & $\begin{array}{lcr}\text { Título: } & {[\mathrm{PDF}]} & \text { AS- } \\
\text { SISTÊNCIA AO } & \text { PRÉ-NATAL }\end{array}$ & $\begin{array}{l}\text { Título: [HTML] Óbito fe- } \\
\text { tal em microrregião de Minas } \\
\text { Gerais: causas e fatores asso- } \\
\text { ciados }\end{array}$ & \begin{tabular}{lcc} 
Título: & \multicolumn{2}{c}{ Homocysteine } \\
metabolism & disorders & as \\
a potential & predictor & of \\
preeclamsia & & \\
& &
\end{tabular} & 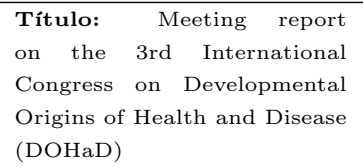 \\
\hline 3 & 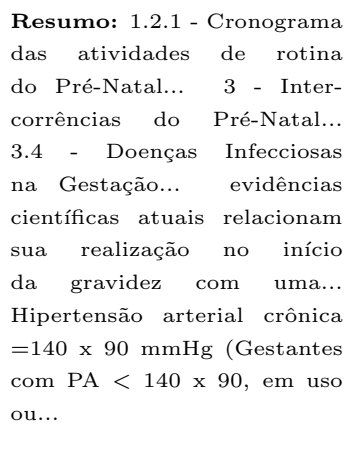 & $\begin{array}{l}\text { Resumo: ... Em referência } \\
\text { à síndrome hipertensiva da } \\
\text { gravidez (representada pela } \\
\text { doença hipertensiva específica } \\
\text { da... profiláticas para a } \\
\text { prevenção primária da pré- } \\
\text { eclâmpsia, o pré-natal bem } \\
\text { conduzido... com vasculopa- } \\
\text { tias, gravidez múltipla e novo } \\
\text { parceiro na gestação atual, } \\
\text { esses casos... }\end{array}$ & $\begin{array}{l}\text { Resumo: Preeclampsia is one } \\
\text { of the main causes of mater- } \\
\text { nal and fetal mortality. We } \\
\text { lack a reliable test that would } \\
\text { identify the "at risk" group } \\
\text { of pregnant women, thus al- } \\
\text { lowing us to implement a spe- } \\
\text { cific prevention... The aim } \\
\text { of this paper is to review the } \\
\text { current literature related to } \\
\text { the pathology of preeclampsia } \\
\text { and to evaluate the usefulness } \\
\text { of assessment of homocysteine } \\
\text { level... }\end{array}$ & $\begin{array}{l}\text { Resumo: Developmental } \\
\text { origins of health and disease } \\
\text { (DOHaD) focuses on the } \\
\text { earliest stages of human } \\
\text { development, and provides } \\
\text { a novel paradigm to com- } \\
\text { plement other strategies for } \\
\text { lifelong prevention of common } \\
\text { chronic health conditions. } \\
\text { The } 3 \text { International Congress } \\
\text { on DOHaD, held in 2005, } \\
\text { retained the most popular } \\
\text { features from the first two } \\
\text { biannual Congresses... }\end{array}$ \\
\hline
\end{tabular}




\begin{tabular}{|c|c|c|c|c|}
\hline $\mathrm{N}^{\mathbf{O}}$ & oogle & oogle Acadêmico & PubMed & isViDas \\
\hline 4 & $\begin{array}{l}\text { Resumo: Pós-Doutorado } \\
\text { em Hipertensão Arterial pela } \\
\text { Universidade de Chicago, } \\
\text { USA... As intercorrências } \\
\text { clínicas da gravidez não } \\
\text { se expressam apenas nos } \\
\text { índices de... Pré-eclâmpsia } \\
\text { é uma doença hipertensiva } \\
\text { peculiar à gravidez humana, } \\
\text { que... da prevenção da pré- } \\
\text { eclâmpsia revolucionaria o } \\
\text { acompanhamento pré-natal } \\
\text { e... }\end{array}$ & $\begin{array}{l}\text { Título: }[\mathrm{PDF}] \text { Diagnósticos } \\
\text { de enfermagem identificados } \\
\text { em gestantes durante o pré- } \\
\text { natal } \\
\text { Resumo: ... Pode ser indício } \\
\text { de diferentes transtornos: } \\
\text { edema, gestação múltipla, } \\
\text { doença hipertensiva específica } \\
\text { da... sobre os padrões } \\
\text { mínimos preconizados nas } \\
\text { políticas de atendimento à } \\
\text { mulher no pré-natal... No } \\
\text { atual modelo de saúde, as } \\
\text { consultas de enfermeiros } \\
\text { (assim como de... }\end{array}$ & $\begin{array}{l}\text { Título: Ian: a } 7 \text {-year old } \\
\text { with prenatal drug exposure } \\
\text { and early exposure to family } \\
\text { violence } \\
\text { Resumo: CASE: A } 7(1 / 2) \text { - } \\
\text { year-old boy is brought to } \\
\text { a new primary care pediatri- } \\
\text { cian because his grandparents, } \\
\text { who have legal custody, want } \\
\text { a "fresh look" at his behav- } \\
\text { ior. Ian's grandmother be- } \\
\text { gins the history with the com- } \\
\text { ment, "He started out kind of } \\
\text { rough." He was exposed to } \\
\text { methamphetamine and mari- } \\
\text { juana throughout gestation... }\end{array}$ & $\begin{array}{l}\text { Título: Developmental ori- } \\
\text { gins of health and disease: } \\
\text { brief history of the approach } \\
\text { and current focus on epige- } \\
\text { netic mechanisms } \\
\text { Resumo: "Barker's hy- } \\
\text { pothesis" emerged almost } \\
25 \text { years ago from epidemio- } \\
\text { logical studies of birth and } \\
\text { death records that revealed } \\
\text { a high geographic correla- } \\
\text { tion between rates of infant } \\
\text { mortality and certain classes } \\
\text { of later adult deaths as well } \\
\text { as an association between } \\
\text { birthweight and rates of adult } \\
\text { death from ischemic heart } \\
\text { disease. These observations } \\
\text { led to a theory that... }\end{array}$ \\
\hline 5 & $\begin{array}{l}\text { Título: DoençA Hipertensiva } \\
\text { EspecíFica Da Gravidez } \\
\text { Resumo: A pré-eclâmpsia } \\
\text { é a doença mais comum da } \\
\text { gestação na segunda metade... } \\
10 \% \text { das gestações apresen- } \\
\text { tarão hipertensão arterial;... } \\
\text { Pequena parcela realiza os ex- } \\
\text { ames mínimos de pré-natal; } \\
\text { Hipertensão é principal causa } \\
\text { de morte perinatal (20\% de... } \\
\text { EVIDÊNCIAS ATUAIS SO- } \\
\text { BRE A TERAPIA ANTI- } \\
\text { HIPERTENSIVA... }\end{array}$ & $\begin{array}{l}\text { Título: }[\text { HTML }] \text { Modelo } \\
\text { preditivo para cesariana com } \\
\text { uso de fatores de risco } \\
\text { Resumo: } \ldots \text { teórico de } \\
\text { agravamento do risco acom- } \\
\text { panhando a história natural } \\
\text { da doença, vista como... base } \\
\text { um modelo biológico (plau- } \\
\text { sibilidade) em que se ad- } \\
\text { mite, no estado atual do con- } \\
\text { hecimento... A assistência } \\
\text { pré-natal, de efeito variável } \\
\text { pela literatura, foi pelo estudo } \\
\text { identificada como... }\end{array}$ & $\begin{array}{l}\text { Título: Antepartum testing } \\
\text { in patients with hypertensive } \\
\text { disorders in pregnancy } \\
\text { Resumo: Antepartum fetal } \\
\text { testing in pregnant patients } \\
\text { with hypertensive disorders } \\
\text { may be beneficial in prevent- } \\
\text { ing stillbirth and hypoxic se- } \\
\text { quelae in the fetus. The high- } \\
\text { est risk patients in this cate- } \\
\text { gory are those with intrauter- } \\
\text { ine growth restriction, super- } \\
\text { imposed preeclampsia, asso- } \\
\text { ciated medical complications } \\
\text { such as diabetes, systemic lu- } \\
\text { pus... }\end{array}$ & $\begin{array}{l}\text { Título: Epigenetic priming of } \\
\text { the metabolic syndrome } \\
\text { Resumo: The metabolic } \\
\text { syndrome (MetS) represents } \\
\text { a cluster of cardiometabolic } \\
\text { risk factors, including central } \\
\text { obesity, insulin resistance, } \\
\text { glucose intolerance, dyslipi- } \\
\text { demia, hypertension... A } \\
\text { continued and greater under- } \\
\text { standing of these mechanisms } \\
\text { will eventually aid in the } \\
\text { identification of individuals } \\
\text { at high risk of cardiovascular } \\
\text { disease (CVD) and type } 2 \\
\text { diabetes, and help develop } \\
\text { therapeutic interventions... }\end{array}$ \\
\hline
\end{tabular}

Para a expressão de consulta "Fatores de Risco (Riscos e proteção familiares relacionados à saúde): Peso de nascimento < 2.500 grs", as buscas por expressões nas ferramentas Google e Google Acadêmico retornaram os resultados apresentados, respectivamente, na segunda e na terceira colunas da Tabela 6. Os resultados obtidos para a mesma consulta em inglês "Risk Factors (Risk and protective family health-related): Birth weight $<2.500$ grams", traduzida previamente do português para o inglês por intermédio da ferramenta Google Tradutor, podem ser observados na quarta coluna da Tabela 6. Os resultados obtidos pelo SisViDas estão apresentados na última coluna da tabela.

Tabela 6: Resumo sobre os 5 primeiros documentos recuperados para a expressão "Fatores de Risco (Riscos e proteção familiares relacionados à saúde): Peso de nascimento < 2.500 grs"

\begin{tabular}{|c|c|c|c|c|}
\hline $\mathrm{N}^{\mathbf{O}}$ & Google & Google Acadêmico & PubMed & SisViDas \\
\hline & $\begin{array}{l}\text { Título: Revista Brasileira de } \\
\text { Saúde Materno Infantil - Ob- } \\
\text { stetric, social... }\end{array}$ & $\begin{array}{l}\text { Título: Modelo hierar- } \\
\text { quizado: uma proposta de } \\
\text { modelagem aplicada à inves- } \\
\text { tigação de fatores de risco } \\
\text { para diarréia grave }\end{array}$ & $\begin{array}{l}\text { Título: Nenhum artigo retor- } \\
\text { nado. }\end{array}$ & $\begin{array}{l}\text { Título: Pathways linking the } \\
\text { early environment to long- } \\
\text { term health and lifespan. }\end{array}$ \\
\hline
\end{tabular}




\begin{tabular}{|c|c|c|c|c|}
\hline $\mathbf{N}^{\circ}$ & Google & Google Acadêmico & PubMed & SisViDas \\
\hline 1 & $\begin{array}{l}\text { Resumo: Entre os numerosos } \\
\text { fatores condicionantes do } \\
\text { risco neonatal que ainda... } \\
\text { o baixo peso de nascimento } \\
(¡ 2500 \mathrm{~g}) \text { e o peso insufi- } \\
\text { ciente ao nascer ( } 2500 \text { a } 3000 \\
\text { g)... são determinadas por } \\
\text { diversos fatores complexos e } \\
\text { inter-relacionados que se ... } \\
\text { escolaridade, ocupação, renda } \\
\text { familiar, número de partos, } \\
\text { data nascimento ... }\end{array}$ & $\begin{array}{l}\text { Resumo: } \ldots \text { Mãe ado- } \\
\text { lescente e gemelaridade car- } \\
\text { acterizaram riscos indepen- } \\
\text { dentes, respectivamente, } 3,8 \text { e } \\
11,6 \ldots \text { para a idade materna } \\
\text { (primeira coluna) e para os } \\
\text { demais fatores de confusão ... } \\
\text { O controle para variáveis de } \\
\text { confusão não modificou sub- } \\
\text { stancialmente o risco repre- } \\
\text { sentado pelo ... }\end{array}$ & \begin{tabular}{llrr} 
Resumo: & \multicolumn{2}{c}{ Apenas } & a \\
hiperligação & "See & Bw18 \\
(WEIGHT 2) & Body & weight \\
QTL 18 in the & Gene \\
database" para a página \\
http://www.ncbi.nlm.nih.gov/- \\
gene/326486 do gene Bw18 \\
no banco de genes do NCBI.
\end{tabular} & $\begin{array}{l}\text { Resumo: The intrauterine } \\
\text { environment is a major con- } \\
\text { tributor to normal physiolog- } \\
\text { ical growth and development } \\
\text { of an individual. Disturbances } \\
\text { at this critical time can affect } \\
\text { the long-term health of the } \\
\text { offspring. Low birth weight } \\
\text { individuals have strong cor- } \\
\text { relations with increased sus- } \\
\text { ceptibility to type } 2 \text { diabetes } \\
\text { and cardiovascular disease in } \\
\text { later-life. }\end{array}$ \\
\hline 2 & $\begin{array}{l}\text { Resumo: OBJETIVO: Anal- } \\
\text { isar os fatores de risco associ- } \\
\text { ados aos óbitos neonatais em } \\
\ldots \text { saúde) e proximal (fatores } \\
\text { biológicos) foram submetidas } \\
\text { à análise ... nascidos vivos } \\
\text { com baixo peso estão rela- } \\
\text { cionados com a atenção à ges- } \\
\text { tante e ... O peso ao nascer } \\
\text { inferior a } 2.500 \text { g é apontado } \\
\text { como .... do nível socioe- } \\
\text { conômico da família. ... }\end{array}$ & $\begin{array}{l}\text { Título: Fatores de risco para } \\
\text { mortalidade neonatal e pós- } \\
\text { neonatal na Região Centro- } \\
\text { Oeste do Brasil: linkage entre } \\
\text { bancos de dados de nascidos } \\
\text { vivos e óbitos infantis } \\
\text { Resumo: ... Estas, em } \\
\text { virtude da grande magnitude } \\
\text { dos seus riscos, esvaziam a } \\
\text { associação do tipo de gravidez } \\
\text { com a mortalidade infantil } \\
\text { nos perío- dos neonatal e } \\
\text { pós-neonatal. ... Page } 7 . \\
\text { FATORES DE RISCO PARA } \\
\text { MORTALIDADE NEONA- } \\
\text { TAL E PÓS-NEONATAL } 483 \\
\text { Cad. ... }\end{array}$ & Título: - & $\begin{array}{l}\text { Resumo: } \\
\text { GROUND/AIMS: (1) To } \\
\text { outline the findings that al- } \\
\text { terations in nutrition in utero } \\
\text { and in early postnatal life } \\
\text { influence health in later life. } \\
\text { (2) To review the evidence } \\
\text { that alterations in epigenetic } \\
\text { markings may be a means } \\
\text { by which the genome records } \\
\text { environmental (including } \\
\text { nutritional) exposure... }\end{array}$ \\
\hline 3 & $\begin{array}{l}\text { Título: A gravidez na ado- } \\
\text { lescência é fator de risco para } \\
\text { o baixo peso ao ... } \\
\text { Resumo: O baixo peso ao } \\
\text { nascer (BP), definido pela Or- } \\
\text { ganização Mundial de Saúde } \\
\text { (OMS) ... A gestação na ado- } \\
\text { lescência tem sido citada en- } \\
\text { tre os fatores de risco para } \\
\text { o ... mas estaria relacionada } \\
\text { com a potencialização de out- } \\
\text { ros fatores de risco3 e ... de } \\
\text { partos únicos, com peso de } \\
\text { nascimento menor que } 2.500 \\
\text { g, definido pela ... }\end{array}$ & $\begin{array}{l}\text { Título: }[\mathrm{PDF}] \text { Efeito moder- } \\
\text { ador do risco social na relação } \\
\text { entre risco biológico e desem- } \\
\text { penho funcional infantil } \\
\text { Resumo: ... transações dos } \\
\text { diversos fatores em diferentes } \\
\text { aspectos do desenvolvimento } \\
\text { infantil. A literatura in- } \\
\text { dica que, na relação entre a } \\
\text { criança em risco para atraso } \\
\text { ou distúrbio do ... crianças } \\
\text { que não são expostas a tais } \\
\text { riscos. } 27 \text { A ajuda excessiva, } \\
\text { fornecida pelos cuidadores ... }\end{array}$ & Resumo: - & $\begin{array}{l}\text { Título: Fetal origins of adult } \\
\text { disease. } \\
\text { Resumo: Dr. David Barker } \\
\text { first popularized the concept } \\
\text { of fetal origins of adult dis- } \\
\text { ease (FOAD). Since its in- } \\
\text { ception, FOAD has received } \\
\text { considerable attention. The } \\
\text { FOAD hypothesis holds that } \\
\text { events during early develop- } \\
\text { ment have a profound im- } \\
\text { pact on one's risk for develop- } \\
\text { ment of future adult disease. } \\
\text { Low birth weight, a surrogate } \\
\text { marker of poor fetal growth } \\
\text { and nutrition... }\end{array}$ \\
\hline
\end{tabular}




\begin{tabular}{|c|c|c|c|c|}
\hline$N^{\circ}$ & Google & Google Acadêmico & PubMed & SisViDas \\
\hline 4 & $\begin{array}{l}\text { Título: }[\mathrm{PDF}] \text { Atenção hu- } \\
\text { manizada ao recém-nascido de } \\
\text { baixo peso } \\
\text { Resumo: nascimento (peso } \\
\text { inferior a } 2.500 \mathrm{~g} \text {, sem con- } \\
\text { siderar a idade gestacional)... } \\
\text { risco, bebê em situação difícil, } \\
\text { dentre outras). - o psiquismo } \\
\ldots \text { fatores e os sinais de } \\
\text { risco comportamentais para a } \\
\text { mãe no pós-parto,... } 1.1 \text { Ori- } \\
\text { entar a mãe e a família so- } \\
\text { bre as condições de saúde da } \\
\text { criança,... relacionados a este } \\
\text { processo:... }\end{array}$ & $\begin{array}{l}\text { Título: }[\mathrm{PDF}] \\
\text { risco patores de } \\
\text { de crianças e } \text { hospitalização } \\
\text { asmáticos } \\
\text { Resumo: ... } \\
\text { uso de cromoglicato dissódico, } \\
\text { corti-costeróides inalados ou } \\
\text { prednisona oral; conhecimen- } \\
\text { tos sobre a doença - indis- } \\
\text { pensáveis a seu manejo - por } \\
\text { parte de pacientes e/ou famil- } \\
\text { iares e considerados ... Em } \\
\text { uma segunda etapa, os fatores } \\
\text { de risco associados à... }\end{array}$ & Resumo: - & $\begin{array}{l}\text { Título: Environmental and } \\
\text { genetic risk factors in obesity. } \\
\text { Resumo: Because of its high } \\
\text { prevalence and the associ- } \\
\text { ated medical and psychosocial } \\
\text { risks, research into the causes } \\
\text { of childhood obesity has ex- } \\
\text { perienced a tremendous up- } \\
\text { swing. Formal genetic data } \\
\text { based on twin, adoption, and } \\
\text { family studies lead to the con- } \\
\text { clusion that at least } 50 \% \text { of } \\
\text { the interindividual variance of } \\
\text { the body mass index... }\end{array}$ \\
\hline 5 & $\begin{array}{l}\text { Título: [PDF] CAPÍTULO 1: } \\
\text { COMPREENDENDO OS DE- } \\
\text { TERMINANTES DA SA... } \\
\text { Resumo: que } 2500 \text { g. ... peso } \\
\text { do nascimento e à idade gesta- } \\
\text { cional (se RN pré- termo). } \\
\ldots . \text { de Doenças e Problemas } \\
\text { Relacionados à Saúde CID-10 } \\
\text { considera-se natimorto o ... } \\
\text { comprimento de corpo, ou } 500 \\
\text { gramas de peso ao nascer .... } \\
\text { mais informações sobre a in- } \\
\text { cidência dos fatores de risco } \\
\text { para asfixia. .... sobre a saúde } \\
\text { familiar. ... }\end{array}$ & $\begin{array}{l}\text { Título: }[\mathrm{PDF}] \text { Ainfluência } \\
\text { das variáveis ambientais } \\
\text { no desenvolvimento da lin- } \\
\text { guagem em uma amostra de } \\
\text { crianças } \\
\text { Resumo: ... A detecção pre- } \\
\text { coce de atrasos de linguagem } \\
\text { eo conhecimento dos seus fa- } \\
\text { tores de risco e proteção são } \\
\text { de fun- damental importância } \\
\text { para a organi- zação de pro- } \\
\text { gramas de intervenção na ... } \\
\text { Esse quadro é freqüentemente } \\
\text { observado, uma vez que os fa- } \\
\text { tores de risco para o ... }\end{array}$ & Resumo: - & $\begin{array}{l}\text { Título: Meeting report } \\
\text { on the 3rd International } \\
\text { Congress on Developmental } \\
\text { Origins of Health and Disease } \\
\text { (DOHaD). } \\
\text { Resumo: Developmental } \\
\text { origins of health and disease } \\
\text { (DOHaD) focuses on the } \\
\text { earliest stages of human } \\
\text { development, and provides } \\
\text { a novel paradigm to com- } \\
\text { plement other strategies for } \\
\text { lifelong prevention of common } \\
\text { chronic health conditions. } \\
\text { The } 3 \text { International Congress }\end{array}$ \\
\hline
\end{tabular}

Para a expressão de consulta "Diagnóstico nutricional: excesso de massa corporal", as buscas por expressões nas ferramentas Google e Google Acadêmico retornaram os resultados apresentados, respectivamente, na segunda e na terceira colunas da Tabela 7. Os resultados obtidos para a mesma consulta em inglês "Nutritional diagnosis: excess body mass", traduzida previamente do português para o inglês por intermédio da ferramenta Google Tradutor, podem ser observados na quarta coluna da Tabela 7. Os resultados obtidos pelo SisViDas estão apresentados na última coluna da tabela.

Tabela 7: Resumo sobre os 5 primeiros documentos recuperados para a expressão "Diagnóstico nutricional: excesso de massa corporal"

\begin{tabular}{|c|c|c|c|c|}
\hline $\mathrm{N}^{\mathbf{O}}$ & Google & Google Acadêmico & PubMed & SisViDas \\
\hline & $\begin{array}{l}\text { Título: [PDF] Cadernos de } \\
\text { Atenção Básica - Obesidade }\end{array}$ & $\begin{array}{l}\text { Título: }[\mathrm{PDF}] \text { Valores } \\
\text { críticos do índice de massa } \\
\text { corporal para classificação do } \\
\text { estado nutricional de crianças } \\
\text { e adolescentes brasileiros }\end{array}$ & $\begin{array}{l}\text { Título: E-KINDEX: a di- } \\
\text { etary screening tool to assess } \\
\text { children's obesogenic dietary } \\
\text { habits }\end{array}$ & $\begin{array}{l}\text { Título: The Barker hypothe- } \\
\text { sis: how pediatricans will di- } \\
\text { agnose and prevent common } \\
\text { adult-onset diseases }\end{array}$ \\
\hline
\end{tabular}




\begin{tabular}{|c|c|c|c|c|}
\hline $\mathrm{N}^{\mathbf{O}}$ & Google & Google Acadêmico & PubMed & SisViDas \\
\hline 1 & $\begin{array}{l}\text { Resumo: } 5 \text { Diagnóstico nu- } \\
\text { tricional - Avaliação do es- } \\
\text { tado nutricional... Da mesma } \\
\text { forma que o excesso de massa } \\
\text { corporal traz risco, o padrão } \\
\text { de distribuição... }\end{array}$ & $\begin{array}{l}\text { Resumo: ... } \\
\text { International 1997, a } \\
\text { Fobesity Task } \\
\text { Force (IOTF) propôs definir } \\
\text { o estado nutricional dos } \\
\text { menores de } 20 \text { anos com } \\
\text { base em desfechos que, na } \\
\text { idade adulta, definiam os } \\
\text { diagnósticos de desnutrição, } \\
\text { excesso de peso e obesidade } \\
\text { e/ou na alteração de diversos } \\
\ldots\end{array}$ & $\begin{array}{l}\text { Resumo: BACKGROUND: } \\
\text { To date, no published di- } \\
\text { etary indices have evaluated } \\
\text { the overall effects of various } \\
\text { dietary components... OB- } \\
\text { JECTIVE: To develop a di- } \\
\text { etary index that contains di- } \\
\text { etary characteristics and prac- } \\
\text { tices implicated in the devel- } \\
\text { opment of obesity... }\end{array}$ & $\begin{array}{l}\text { Resumo: } \text { Artigo sem } \\
\text { resumo no PubMed } \\
\text { (http://www.ncbi.nlm.nih.gov/ } \\
\text { pubmed/19768178). }\end{array}$ \\
\hline 2 & $\begin{array}{l}\text { Título: INDICADORES DE } \\
\text { SAÚDE - SISVAN } \\
\text { Resumo: SISVAN munici- } \\
\text { pal - Estado Nutricional dos } \\
\text { Usuários da Atenção Básica... } \\
\text { O peso por idade expressa a } \\
\text { relação entre a massa corporal } \\
\text { e a idade... diagnóstico pre- } \\
\text { ciso de sobrepeso e obesidade, } \\
\text { apenas de excesso de peso de } \\
\text { uma forma... }\end{array}$ & $\begin{array}{l}\text { Título: Índice de massa } \\
\text { corporal (massa corporal. } \\
\text { estatura-2) como indicador do } \\
\text { estado nutricional de adultos: } \\
\text { revisão da literatura } \\
\text { Resumo: ... Em países em } \\
\text { desenvolvimento, além do } \\
\text { diagnóstico de excesso de } \\
\text { reserva energética (obesi- } \\
\text { dade), permanece o desafio do } \\
\text { diagnóstico da deficiência... } \\
\text { Dados recentes da Pesquisa } \\
\text { Nacional de Saúde e Nutrição } \\
\text { (PNSN) de adultos brasileiros } \\
18 \text { corroboram esta... }\end{array}$ & $\begin{array}{l}\text { Título: Association between } \\
\text { dyslipidemia and anthropo- } \\
\text { metric indicators in adoles- } \\
\text { cents } \\
\text { Resumo: The dyslipidemia } \\
\text { associated with excess weight } \\
\text { is a risk profile global call for } \\
\text { cardiovascular disease (CVD). } \\
\text { The aim of this study was to } \\
\text { investigate the association be- } \\
\text { tween dyslipidemias and other } \\
\text { risk factors for cardiovascu- } \\
\text { lar diseases (CVD) in adoles- } \\
\text { cents, considering sexual mat- } \\
\text { uration... }\end{array}$ & $\begin{array}{l}\text { Título: Congenital cardio- } \\
\text { vascular disease in Turner } \\
\text { syndrome } \\
\text { Resumo: Turner syndrome } \\
\text { (TS), or monosomy X, occurs } \\
\text { in approximately } 1 / 2000 \text { live } \\
\text { born females. Intelligence is } \\
\text { normal and short stature is } \\
\text { the most obvious and con- } \\
\text { sistent feature of the syn- } \\
\text { drome. Congenital cardiovas- } \\
\text { cular disease affects approxi- } \\
\text { mately } 50 \% \text { of individuals and } \\
\text { is the major cause of prema- } \\
\text { ture mortality in adults... }\end{array}$ \\
\hline & $\begin{array}{l}\text { Título: Jornal de Pediatria } \\
\text { - Diagnosing the nutritional } \\
\text { status of ... }\end{array}$ & $\begin{array}{l}\text { Título: [PDF] Diagnóstico de } \\
\text { sobrepeso e obesidade em es- } \\
\text { colares: utilização do índice } \\
\text { de massa corporal segundo } \\
\text { padrão internacional }\end{array}$ & $\begin{array}{l}\text { Título: An evolutionary } \\
\text { perspective on the trans- } \\
\text { generational basis of obesity }\end{array}$ & $\begin{array}{l}\text { Título: Bisulphite sequenc- } \\
\text { ing of the transient neonatal } \\
\text { diabetes mellitus DMR facil- } \\
\text { itates a novel diagnostic test } \\
\text { but reveals no methylation } \\
\text { anomalies in patients of un- } \\
\text { known aetiology }\end{array}$ \\
\hline 3 & $\begin{array}{l}\text { Resumo: Diagnóstico do es- } \\
\text { tado nutricional de escolares: } \\
\text { comparação entre critério na- } \\
\text { cional e... Utilizou-se o índice } \\
\text { de massa corporal (IMC) por } \\
\text { gênero e idade para... peso } \\
\text { adequado e excesso de peso, } \\
\text { empregando-se critérios pro- } \\
\text { postos por Cole... }\end{array}$ & $\begin{array}{l}\text { Resumo: ... Ele apresen- } \\
\text { tou concordância com o ex- } \\
\text { cesso de adiposidade corpórea, } \\
\text { calculada a partir da medida } \\
\text { de dobras cutâneas, e com as } \\
\text { gorduras visceral e central, es- } \\
\text { timadas indiretamente a par- } \\
\text { tir das circunferências de cin- } \\
\text { tura... Diagnóstico do estado } \\
\text { nutricional da criança ... }\end{array}$ & $\begin{array}{l}\text { Resumo: Until recently, obe- } \\
\text { sity was considered the prod- } \\
\text { uct of interactions between } \\
\text { genotype and lifestyle. How- } \\
\text { ever, recent work suggests } \\
\text { that the genetic heritability } \\
\text { of adiposity has been over- } \\
\text { estimated, whilst epidemio- } \\
\text { logical studies show that al- } \\
\text { though many genes are associ- } \\
\text { ated with nutritional status... }\end{array}$ & $\begin{array}{l}\text { Resumo: Transient neona- } \\
\text { tal diabetes mellitus (TNDM) } \\
\text { is associated with overexpres- } \\
\text { sion of an imprinted locus } \\
\text { on chromosome } 6 \mathrm{q} 24 \text {; this lo- } \\
\text { cus contains a differentially } \\
\text { methylated region (DMR)... } \\
\text { patients showed a near-total } \\
\text { absence of DNA methylation } \\
\text { at the TNDM locus, the } \\
\text { patients with no identified } \\
\text { molecular anomaly showed no } \\
\text { marked methylation variation } \\
\text { from controls. }\end{array}$ \\
\hline
\end{tabular}




\begin{tabular}{|c|c|c|c|c|}
\hline $\mathrm{N}^{\mathbf{O}}$ & Google & Google Acadêmico & PubMed & SisViDas \\
\hline 4 & $\begin{array}{l}\text { Resumo: Nutrição e ex- } \\
\text { cesso de massa corporal: fa- } \\
\text { tores de risco cardiovascular } \\
\text { em... índice de massa corporal } \\
\text { (IMC=kg/m2), classificação } \\
\text { nutricional, diagnóstico... }\end{array}$ & $\begin{array}{l}\text { Título: [HTML] Diagnóstico } \\
\text { do estado nutricional da } \\
\text { criança e do adolescente } \\
\text { Resumo: ... em percentis } \\
\text { seja mais aceita e recomen- } \\
\text { dada nos estudos de avaliação } \\
\text { nutricional sob o ponto de } \\
\text { vista populacional, a porcent- } \\
\text { agem de adequação é um } \\
\text { instrumento diagnóstico com } \\
\text { o... da massa magra, dificul- } \\
\text { tando a diferenciação entre o } \\
\text { sobrepeso com excesso de gor- } \\
\text { dura... }\end{array}$ & $\begin{array}{l}\text { Título: Hypocaloric consid- } \\
\text { erations in patients with po- } \\
\text { tentially hypometabolic dis- } \\
\text { ease States } \\
\text { Resumo: The provision of } \\
\text { nutrition has traditionally } \\
\text { been driven by the desire } \\
\text { to provide adequate calories. } \\
\text { However, over the past decade } \\
\text { it has become evident that } \\
\text { provision of excess calories } \\
\text { can be detrimental... This } \\
\text { review examines patient pop- } \\
\text { ulations for whom hypocaloric } \\
\text { nutrition... }\end{array}$ & $\begin{array}{l}\text { Título: Molecular diagnosis } \\
\text { of Prader-Willi and Angelman } \\
\text { syndromes: methylation, cy- } \\
\text { togenetics and FISH analysis } \\
\text { Resumo: BACKGROUND: } \\
\text { The diagnosis of Prader-Willi } \\
\text { and Angelman syndromes is } \\
\text { difficult, since their pheno- } \\
\text { typic manifestations are vari- } \\
\text { able and unspecific. The } \\
\text { study of the methylation state } \\
\text { of DNA in 15(q11-q13) us- } \\
\text { ing polymerase chain reac- } \\
\text { tion, called methylation test... } \\
\text { AIM: To assess the effective- } \\
\text { ness of methylation test in the } \\
\text { diagnosis of Prader-Willi and } \\
\text { Angelman syndromes... }\end{array}$ \\
\hline 5 & $\begin{array}{l}\text { Título: [PDF] Vigilância ali- } \\
\text { mentar e nutricional - SISVAN } \\
\text { - BVS Ministério da Saú... } \\
\text { Resumo: como fazer o di- } \\
\text { agnóstico nutricional individ- } \\
\text { ual e o coletivo e sobre os } \\
\text { parâmetros utilizados pelo... } \\
\text { Distúrbio Nutricional: mani- } \\
\text { festações produzidas pelo ex- } \\
\text { cesso e/... expressa a har- } \\
\text { monia entre as dimensões de } \\
\text { massa corporal e altura... }\end{array}$ & $\begin{array}{l}\text { Título: [HTML] Body mass } \\
\text { index cutoff points for evalu- } \\
\text { ation of nutritional status in } \\
\text { Brazilian children and adoles- } \\
\text { cents } \\
\text { Resumo: ... Em 1997, a } \\
\text { International Obesity Task } \\
\text { Force (IOTF) propôs definir } \\
\text { o estado nutricional dos } \\
\text { menores de } 20 \text { anos com } \\
\text { base em desfechos que, na } \\
\text { idade adulta, definiam os } \\
\text { diagnósticos de desnutrição, } \\
\text { excesso de peso e obesi- } \\
\text { dade e/ou na alteração de } \\
\text { diversos... }\end{array}$ & $\begin{array}{l}\text { Resumo: Weight loss is com- } \\
\text { mon in older people. It is as- } \\
\text { sociated with increased mor- } \\
\text { bidity and mortality, particu- } \\
\text { larly when unintentional, ex- } \\
\text { cessive ( } i 5 \% \text { body weight), } \\
\text { or associated with low body } \\
\text { weight (body mass index } i 22 \\
\mathrm{~kg} / \mathrm{m}(2)) \ldots\end{array}$ & $\begin{array}{l}\text { Título: Molecular charac- } \\
\text { terization of co-occurring } \\
\text { Duchenne muscular dystro- } \\
\text { phy and X-linked oculo-facio- } \\
\text { cardio-dental syndrome in a } \\
\text { girl } \\
\text { Resumo: Duchenne mus- } \\
\text { cular dystrophy is an X- } \\
\text { linked condition at the se- } \\
\text { vere end of the spectrum of } \\
\text { dystrophinopathies. Females } \\
\text { with dystrophin mutations are } \\
\text { at risk for cardiomyopathy, } \\
\text { but are usually asymptomatic } \\
\text { during childhood. However, } \\
\text { some girls can exhibit features } \\
\text { of Duchenne muscular dystro- } \\
\text { phy... }\end{array}$ \\
\hline
\end{tabular}

\subsection{Considerações do Capítulo}

Os resultados de avaliações para o SisViDas em termos de precisão x revocação demonstraram que a abordagem apoiada pelo software MetaMap para reconhecimento de conceitos do domínio da saúde em artigos científicos escritos em inglês apresentou melhores resultados quando comparada à abordagem apoiada pelo UTS. Por esse motivo, o SisViDas será configurado para utilizar por padrão a abordagem MetaMap para reconhecimento de conceitos nos artigos científicos. Esse resultado era esperado, uma vez que a ferramenta MetaMap está em desenvolvimento há mais de dez anos. Todavia, a exclusividade de uso do MetaMap para textos em inglês consiste em uma limitação crítica do mesmo para o contexto do presente trabalho, que tem como um de seus objetivos realizar recuperação de informação inter-lingual (CLIR).

Ao comparar o sistema SisViDas e as ferramentas de busca Google, Google Acadêmico e PubMed com buscas por expressão, verificou-se que o SisVidas consegue recuperar um maior numero de artigos relacionados a fatores de riscos e a epigenética em relação às outras ferramentas. Nas três buscas demonstradas nas Tabelas 5, 6 e 7, o SisViDas obteve um total de nove artigos relevantes dentre os quinze apresentados. Mais especificamente, o 
SisViDas obteve quatro artigos relevantes para a busca apresentada na Tabela 5 (números 1, 2, 4 e 5), quatro para a consulta apresentada na Tabela 6 (números 1, 2, 3 e 4) e um artigo para a consulta apresentada na Tabela 7 (número 1). As demais ferramentas retornaram bem poucos resultados relevantes, nenhum deles relacionados a epigenética e, no caso do PubMed, houve buscas que não retornaram nenhum artigo. Apesar de ser uma avaliação qualitativa, é possível perceber uma melhor precisão do SisViDas em relação às ferramentas de busca. Para buscas por prontuário, mais importantes para o contexto do presente trabalho, as ferramentas de busca não conseguiram recuperar satisfatoriamente nenhum documento (a única ferramenta que forneceu retorno, o Google Acadêmico para busca avançada, considerou apenas os primeiros caracteres da expressão de consulta e apresentou resultados pouco relevantes para o contexto deste trabalho). 


\section{Conclusão}

A medicina genômica tem sugerido que a exposição a fatores de risco que incidem desde a concepção de uma criança até o final de sua adolescência influencia na expressão gênica e, consequentemente, induz o desenvolvimento de doenças crônicas na idade adulta. Artigos científicos com essas descobertas indicam que a epigenética deve ser explorada para prevenir doenças de alta prevalência (como doenças cardiovasculares, diabetes e obesidade). Contudo, a grande quantidade de informação científica existente impede que profissionais se mantenham constantemente atualizados. O sistema e o arcabouço de software desenvolvidos pretendem apoiar a criação de sistemas de vigilância que alertem profissionais de saúde a cerca de problemas no desenvolvimento humano, como o desenvolvimento de doenças crônicas. Esse objetivo pode ser atingido pela identificação automática de artigos científicos que relacionem fatores de risco presentes em registros clínicos de pacientes a doenças crônicas. Como resultado, espera-se que o profissional de saúde, apoiado pela descoberta de informações provenientes dos artigos científicos, possa criar uma rotina que estabeleça as melhores condições de crescimento.

\subsection{Contribuições}

Considerando-se que doenças crônicas são, mundialmente, um problema sério de saúde e lideram as causas de mortalidade com $60 \%$ de todas as mortes (OMS, 2010c) e que que pesquisas em medicina genômica e bioinformática possuem um grande potencial para beneficiar a saúde pública, o presente trabalho provavelmente facilitará esse processo, possibilitando o uso direto dos resultados dessas pesquisas na saúde pública. Consequentemente, o trabalho aqui apresentado pode ser considerado um trabalho de bioinformática translacional, visto que realiza a "efetiva transformação dos resultados de pesquisas biomédicas em conhecimento possível de ser utilizado para melhorar a saúde pública" (BUTTE, 2008). 


\subsection{Dificuldades e Limitações}

Uma dificuldade encontrada no desenvolvimento do trabalho consistiu no estabelecimento de relacionamentos entre casos simulados e artigos científicos para a composição da coleção de referência. Esse é um trabalho árduo e necessita ser feito por especialistas do domínio, os quais possuem outras atividades para cumprir. Por esse motivo, conforme mencionado no Capítulo 6, a avaliação dos resultados de recuperação de artigos científicos relevantes para um registro clínico foi realizada para apenas seis dentre os trinta casos simulados.

A funcionalidade de classificação de pacientes em grupos de risco precisará de dados reais de pacientes para treinamento e testes dos classificadores.

\subsection{Trabalhos Futuros e em Andamento}

Para ampliar a coleção de referência entre registros clínicos e artigos científicos, o módulo do SisViDas que foi criado para que os profissionais da equipe de especialistas do ICr elaborassem a distância uma coleção de referência continuará em operação para que sejam estabelecidos todos os relacionamentos para os trinta casos simulados.

Como trabalho futuro, pode-se estender a Chronic Disease Ontology (CDO) com conhecimentos obtidos dos artigos científicos recuperados pelo SisViDas sobre mecanismos epigenéticos e fatores de risco epigenéticos para doenças crônicas. Para isso, os conhecimentos a serem inseridos na CDO podem ser sugeridos automaticamente por meio do processamento da linguagem natural dos artigos recuperados, por exemplo, com o auxílio da ferramenta SemRep (RINDFLESCH; FISZMAN, 2003). Outra possibilidade consiste na aplicação da área de text entailment ${ }^{1}$ para mapear fatores de risco em doenças crônicas. Esses conhecimentos adquiridos, entretanto, deverão ser confirmados por especialistas no domínio, antes de serem definitivamente inseridos na ontologia. Assim, o SisViDas poderá no futuro classificar pacientes em grupos de risco com o suporte de conhecimentos provenientes da ontologia CDO, após a extensão da mesma, e de tecnologias como Aprendizado de Máquina.

Outra coleção de referência está sendo elaborada para avaliar resultados para a subcoleção mais relacionada a fatores genéticos para o desenvolvimento de doenças crônicas.

\footnotetext{
${ }^{1}$ Análises com relação à vinculação de frases em dados textuais (e.g.: decidir se uma sentença implica em outra).
} 
Para isso, o presente trabalho será integrado ao trabalho de mestrado de Daniane Silva de Paula, orientado pela mesma orientadora do presente trabalho. Essa integração visa expandir a subconsulta 1 da consulta submetida pelo SisViDas ao PubMed para incluir, além dos símbolos de genes, os nomes dos mesmos, nomes e símbolos alias ${ }^{2}$, assim como nomes e símbolos prévios dos genes. Os relacionamentos dessa coleção deverão ser avaliados por outra equipe de especialistas do ICr, mais relacionada ao contexto dos fatores genéticos, como a equipe do Laboratório de Genômica Pediátrica. Com as duas coleções de referência completas em mãos, será possível avaliar e comparar os resultados de precisão e revocação de três maneiras distintas: considerando apenas a coleção com fatores epigenéticos para o desenvolvimento das doenças crônicas, apenas a coleção com fatores genéticos ou uma coleção com ambos os fatores, composta pela união das duas primeiras.

Outros trabalhos futuros interessantes consistem em: (i) utilizar SAPHIRE para mapeamento de registros clínicos para conceitos do Metathesaurus UMLS; (ii) implementar prontuário eletrônico para equipe do ICr e integrar com SisViDas; e (iii) trabalhar com consensos em pediatria. Para trabalhar com consensos em pediatria, é possível utilizar os documentos do projeto DIRETRIZES ${ }^{3}$ da Associação Médica Brasileira e Conselho Federal de Medicina para criar uma ontologia contendo todos os relacionamentos de causa, consequência e condutas recomendadas para doenças crônicas encontrados nos documentos de consensos em diagnóstico e terapia. Para o caso de uso de um pediatra na rotina clínica, utilizar a ontologia criada a partir das diretrizes para recomendar condutas e mostrar trecho da diretriz.

A possibilidade de criar uma ontologia com conhecimentos obtidos diretamente de artigos científicos foi estudada no início do projeto como uma das possibilidades para atingir o objetivo proposto. Entretanto, optou-se por desenvolver inicialmente a solução apresentada nesta dissertação, pois os artigos coletados pelo SisViDas deveriam subsidiar a criação da ontologia. Esses artigos coletados, além de subsidiar a criação da ontologia, podem ainda auxiliar a criação de novas diretrizes. Uma dificuldade de se utilizar somente as diretrizes consiste no fato de que elas não são atualizadas com a mesma frequência que a literatura científica. Outra dificuldade observada consiste em não ser adequado retornar ao profissional de saúde os documentos completos das diretrizes. Neste caso, seria necessário pesquisar outras maneiras de apresentação dos resultados ao profissional, com o objetivo de retornar apenas um trecho específico da diretriz, o qual se refere ao fator de risco em questão. Uma possibilidade vislumbrada para a apresentação de diretrizes selecionadas

\footnotetext{
${ }^{2}$ Outros nomes e símbolos não oficiais usados para designar um gene (pseudônimos)

${ }^{3} \mathrm{http}: / /$ www.projetodiretrizes.org.br/
} 
seria a sumarização automática desses documentos. 


\section{Referências}

AMIA. AMIA Strategic Plan. [S.1.], 2006. Accessed April 10, 2010.

ARFF. Disponível em: <http://www.cs.waikato.ac.nz/ ml/weka/arff.html>.

ARMANO, G.; MANCONI, A.; VARGIU, E. A multiagent system for retrieving bioinformatics publications from web sources. IEEE transactions on nanobioscience, v. 6, n. 2, p. 104-9, jun. 2007. ISSN 1536-1241. Disponível em: <http://www.ncbi.nlm.nih.gov/pubmed/17695743>.

ARONSON, A. Effective mapping of biomedical text to the umls metathesaurus: the metamap program. In: Proceedings of the AMIA Symposium. American Medical Informatics Association, 2001. pp, p. 17-21. Disponível em: <http://www.ncbi.nlm.nih.gov/pmc/articles/PMC2243666/>.

ARONSON, A. R.; LANG, F.-M. An overview of MetaMap: historical perspective and recent advances. Journal of the American Medical Informatics Association : JAMIA, v. 17, n. 3, p. 229-36, maio 2010. ISSN 1527-974X. Disponível em: $<$ http://www.pubmedcentral.nih.gov/articlerender.fcgi?artid=2995713\&tool=\% -pmcentrez\&rendertype $=$ abstract $>$.

BAEZA-YATES, R.; RIBEIRO-NETO, B. Modern Information Retrieval. New York, NY: Addison Wesley, 1999.

BARKER, D. J. P. Fetal and infant origins of adult disease. Monatsschrift Kinderheilkunde, Springer Berlin / Heidelberg, v. 149, p. S2-S6, 2001. ISSN 0026-9298. 10.1007/s001120170002. Disponível em: <http://dx.doi.org/10.1007/s001120170002>.

BELLMAN, R. E. An Introduction to Artificial Intelligence: Can Computers Think? San Francisco: Boyd \& Fraser Publishing Company, 1978.

BIRD, S.; KLEIN, E.; LOPER, E. Natural Language Processing with Python. 1. ed. O'Reilly Media, 2009. Paperback. ISBN 0596516495.

Disponível em: <http://www.amazon.com/exec/obidos/redirect?tag=citeulike0720\&path=ASIN $/ 0596516495>$.

BOURIGAULT, D.; JACQUEMIN, C.; L, M.-C. Recent Advances in Computational Terminology. Amsterdam: John Benjamins, 2001.

BUTTE, A. J. Translational bioinformatics: coming of age. Journal of the American Medical Informatics Association: JAMIA, v. 15, n. 6, p. 709-14, 2008. ISSN 1067-5027. Disponível em: <http://www.ncbi.nlm.nih.gov/pubmed/18755990>. 
CHEN, H.; FUlleR, S. S.; FRIEDMAN, C. P. Medical Informatics: Knowledge Management and Data Mining in Biomedicine (Integrated Series in Information Systems). Springer, 2005. Hardcover. ISBN 038724381X. Disponível em: <http://www.worldcat.org/isbn/038724381X>.

EBECKEN, N. F. F.; LOPES, M. C. S.; COSTA, M. C. A. Sistemas inteligentes: fundamentos e aplicações. In: Barueri-SP: Manole, 2003. cap. Mineração de Textos, p. 89-114.

EICHMANN, D.; RUIZ, M. E.; SRINIVASAN, P. Cross-language information retrieval with the umls metathesaurus. In: Proceedings of the 21st annual international ACM SIGIR conference on Research and development in information retrieval. New York, NY, USA: ACM, 1998. (SIGIR '98), p. 72-80. ISBN 1-58113-015-5. Disponível em: $<$ http://doi.acm.org/10.1145/290941.290959>.

FISZMAN, M.; DEMNER-FUSHMAN, D.; LANG, F. M.; GOETZ, P.; RINDFLESCH, T. C. Interpreting Comparative Constructions in Biomedical Text Lister Hill National Center for Biomedical Communications. Computational Linguistics, n. June, p. 137-144, 2007.

GILLMAN, M. W.; BARKER, D.; BIER, D.; CAGAMPANG, F.; CHALLIS, J.; FALL, C.; GODFREY, K.; GLUCKMAN, P.; HANSON, M.; KUH, D.; NATHANIELSZ, P.; NESTEL, P.; THORNBURG, K. L. Meeting report on the 3rd International Congress on Developmental Origins of Health and Disease (DOHaD). Pediatric research, v. 61, n. 5 Pt 1, p. 625-9, maio 2007. ISSN 0031-3998. Disponível em: <http://www.ncbi.nlm.nih.gov/pubmed/17413866>.

GRUBER, T. A translation approach to portable ontology specifications. Knowledge Acquisition, American Association for Artificial Intelligence, Menlo Park, CA, USA, v. 5, n. 2, p. 199-220, jun. 1993. ISSN 10428143. Disponível em: <http://dx.doi.org/10.1006/knac.1993.1008>.

GRUBER, T. Ontology. In: LIU, L.; OZSU, M. T. (Ed.). Encyclopedia of Database Systems. Springer US, 2009. p. 1963-1965. ISBN 978-0-387-39940-9. 10.1007/978-0-38739940-9_1318. Disponível em: <http://dx.doi.org/10.1007/978-0-387-39940-9_1318>.

GUARINO, N. Semantic matching: Formal ontological distinctions for information organization, extraction, and integration. In: PAZIENZA, M. (Ed.). Information Extraction A Multidisciplinary Approach to an Emerging Information Technology. Springer Berlin / Heidelberg, 1997, (Lecture Notes in Computer Science, v. 1299). p. 139-170. ISBN 978-3-540-63438-6. 10.1007/3-540-63438-X_8. Disponível em: $<$ http://dx.doi.org/10.1007/3-540-63438-X_8>.

GUDIVADA, R. C.; QU, X. a.; CHEN, J.; JEGGA, A. G.; NEUMANN, E. K.; ARONOW, B. J. Identifying disease-causal genes using Semantic Web-based representation of integrated genomic and phenomic knowledge. Journal of biomedical informatics, v. 41, n. 5, p. 717-29, out. 2008. ISSN 1532-0480. Disponível em: $<$ http://www.ncbi.nlm.nih.gov/pubmed/18755295>.

HAYKIN, S. Redes neurais: princípios e prática. 2a. ed. Porto Alegre-RS: Bookman, 2001. 27-74 p. 
HERSH, W. R. Information Retrieval: A Health and Biomedical Perspective. 2. ed. New York: Springer, 2003.

HERSH, W. R.; DONOHOE, L. C. SAPHIRE International: a tool for crosslanguage information retrieval. Proceedings / AMIA ... Annual Symposium. AMIA Symposium, p. 673-7, jan. 1998. ISSN 1531-605X. Disponível em: $<$ http:/ / www.pubmedcentral.nih.gov/articlerender.fcgi?artid=2232200\&tool $=\%$ -pmcentrez\&rendertype $=$ abstract $>$.

HOFFMANN, R.; VALENCIA, A. Implementing the ihop concept for navigation of biomedical literature. Bioinformatics (Oxford, England), v. 21 Suppl 2, n. Suppl 2, p. ii252-8, set. 2005. ISSN 1367-4811.

ISLES, A. R.; WILKINSON, L. S. Epigenetics: what is it and why is it important to mental disease? British medical bulletin, v. 85, n. 1, p. 35-45, jan. 2008. ISSN 1471-8391. Disponível em: <http://bmb.oxfordjournals.org/cgi/content/abstract/85/1/35>.

JANG, H.; LIM, J.; LIM, J.-H.; PARK, S.-J.; LEE, K.-C. BioProber: software system for biomedical relation discovery from PubMed. Conference proceedings : ... Annual International Conference of the IEEE Engineering in Medicine and Biology Society. IEEE Engineering in Medicine and Biology Society. Conference, v. 1, p. 5779-82, jan. 2006. ISSN 1557-170X. Disponível em: <http://www.ncbi.nlm.nih.gov/pubmed/17946334>.

KINGSBURY, P.; PALMER, M. From Treebank to PropBank. 2002. Disponível em: $<$ http://citeseerx.ist.psu.edu/viewdoc/summary?doi=10.1.1.13.7566>.

KORF, B. R. Principles of genetics: Overview of the paradigm of genetic contribution to health and disease. In: GOLDMAN, L.; AUSIELLO, D. (Ed.). Cecil Medicine. 23rd. ed. [S.l.]: Saunders Elsevier, 2008. cap. 37.

KRALLINGER, M.; VALENCIA, A. Text-mining and information-retrieval services for molecular biology. Genome biology, v. 6, n. 7, p. 224, jan. 2005. ISSN 1465-6914. Disponível em: <http://genomebiology.com/2005/6/7/224>.

LE, T.; CHEVALLET, J.-P.; LIM, J. Using bayesian network for conceptual indexing: Application to medical document indexing with umls metathesaurus. In: PETERS, C.; JIJKOUN, V.; MANDL, T.; MüLLER, H.; OARD, D.; PEñAS, A.; PETRAS, V.; SANTOS, D. (Ed.). Advances in Multilingual and Multimodal Information Retrieval. Springer Berlin / Heidelberg, 2008, (Lecture Notes in Computer Science, v. 5152). p. 631-636. ISBN 978-3-540-85759-4. 10.1007/978-3-540-85760-0_80. Disponível em: <http://dx.doi.org/10.1007/978-3-540-85760-0_80>.

LEE, C.-H.; WU, C.-H.; YANG, H.-C. Text mining of clinical records for cancer diagnosis. Second International Conference on Innovative Computing, Informatio and Control (ICICIC 2007), Ieee, p. 172-172, set. 2007.

MAOJO, V.; TSIKNAKIS, M. Biomedical informatics and healthGRIDs: a European perspective. IEEE engineering in medicine and biology magazine : the quarterly magazine of the Engineering in Medicine 8 Biology Society, v. 26, n. 3, p. 34-41, 2007. ISSN 0739-5175. Disponível em: <http://www.ncbi.nlm.nih.gov/pubmed/17549918>. 
MARGARITTE-JEANNIN, P.; CLERGET-DARPOUX, F.; HORS, J.; DESCHAMPS, I. Testing parental imprinting in insulin-dependent diabetes mellitus by the marker-association-segregation-chi 2 method. American journal of human genetics, v. 56, n. 5, p. 1080-7, maio 1995. ISSN 0002-9297. Disponível em: $<$ http://www.pubmedcentral.nih.gov/articlerender.fcgi?artid=1801436\&tool=\% -pmcentrez\&rendertype $=$ abstract $>$.

MATOS, P.; LOMBARDI, L.; PARDO, T.; CIFERRI, C.; VIEIRA, M.; CIFERRI, R. An environment for data analysis in biomedical domain: Information extraction for decision support systems. In: GARCíA-PEDRAJAS, N.; HERRERA, F.; FYFE, C.; BENíTEZ, J.; ALI, M. (Ed.). Trends in Applied Intelligent Systems. Springer Berlin / Heidelberg, 2010. (Lecture Notes in Computer Science, v. 6096), p. 306-316. ISBN 978-3-642-13021-2. 10.1007/978-3-642-13022-9_31. Disponível em: <http://dx.doi.org/10.1007/978-3-642-13022-9_31>.

MAtSubarA, E. T.; MARTINS, C. A.; MOnARD, M. C. PreTexT: uma ferramenta para pré-processamento de textos utilizando a abordagem bag-of-words. São Carlos, Agosto 2003.

MONARD, M. C.; BARANAUSKAS, J. A. Sistemas inteligentes: fundamentos e aplicações. In: __ Barueri-SP: Manole, 2003. cap. Cap. 3: Conceitos sobre Aprendizado de Máquina, p. 89-114.

MOURA, E. G. de; PASSOS, M. C. F. Neonatal programming of body weight regulation and energetic metabolism. Bioscience reports, v. 25, n. 3-4, p. 251-69, 2005. ISSN 0144-8463. Disponível em: <http://www.ncbi.nlm.nih.gov/pubmed/16283556>.

MUKHERJEA, S.; BAMBA, B.; KANKAR, P. Information retrieval and knowledge discovery utilizing a biomedical patent semantic Web. IEEE Transactions on Knowledge and Data Engineering, v. 17, n. 8, p. 1099-1110, ago. 2005. ISSN 1041-4347. Disponível em: <http://ieeexplore.ieee.org/lpdocs/epic03/wrapper.htm?arnumber $=1458703>$.

NICOLAS, F. P. Investigação sobre o Reconhecimento Automático de Conceitos do Domínio de Doenças Crônicas em Artigos Científicos. 66 p. Monografia (Trabalho de Conclusão de Curso) - Faculdade de Medicina de Ribeirão Preto e Faculdade de Filosofia Ciências e Letras de Ribeirão Preto, Universidade de São Paulo, Ribeirão Preto, 2010.

NLM. UMLS Reference Manual. National Library of Medicine (US), sep 2009. Disponível em: <http://www.ncbi.nlm.nih.gov/books/NBK9676/>.

OMS. Organização Mundial de Saúde: Cardiovascular diseases (CVDs). Updated September 2009. Availlable at: http://www.who.int/mediacentre/factsheets/fs317/en/index.html. Acessado em $15 / 12 / 2010$.

OMS. Organização Mundial de Saúde: Diabetes. November 2009. Availlable at: http://www.who.int/mediacentre/factsheets/fs312/en/index.html. Acessado em $15 / 12 / 2010$. 
OMS. Organização Mundial de Saúde: 10 Facts On Obesity. 2010. Availlable at: http://www.who.int/features/factfiles/obesity/facts/en/index.html. Acessado em 06/01/2011.

OMS. Organização Mundial de Saúde: Obesity and overweight. 2010. Availlable at: http://www.who.int/mediacentre/factsheets/fs311/en/index.html. Acessado em $15 / 01 / 2011$.

OMS. Organização Mundial de Saúde: Ten facts about chronic disease. 2010. Availlable at: http://www.who.int/features/factfiles/chp/en/index.html. Acessado em 15/12/2010.

PANICO, S. R. G.; CANZIANI, M. L.; GUERCHON, N. Indicadores nipe: Subsídios para políticas municipais de saúde. In: 1. ed. São Carlos-SP: NIPE, 1997. v. 1, n. 1, cap. Políticas Públicas Municipais.

PARAPAR, J.; FREIRE, A.; BARREIRO, l. Revisiting n-gram based models for retrieval in degraded large collections. In: BOUGHANEM, M.; BERRUT, C.; MOTHE, J.; SOUlE-DUPUY, C. (Ed.). Advances in Information Retrieval. Springer Berlin / Heidelberg, 2009, (Lecture Notes in Computer Science, v. 5478). p. 680-684. 10.1007/9783-642-00958-7_66. Disponível em: <http://dx.doi.org/10.1007/978-3-642-00958-7_66>.

PASTERNAK, J. J. Uma Introdução à Genética Molecular Humana: Mecanismos das Doenças Hereditárias. 2. ed. [S.l.]: Guanabara Koogan S.A., 2007. ISBN 978-85-277-1286-6.

PIKE, K. C.; HANSON, M. A.; GODFREY, K. M. Developmental mismatch: consequences for later cardiorespiratory health. BJOG : an international journal of obstetrics and gynaecology, v. 115, n. 2, p. 149-57, jan. 2008. ISSN 1471-0528. Disponível em: <http://www.ncbi.nlm.nih.gov/pubmed/18081597>.

POLIMENO, A. A puericultura personalizada do século 21. Revista Pesquisa Médica, p. 1-4, 2009. Disponível em:

$<$ http://www.revistapesquisamedica.com.brtextos.aspcodigo11572>.

POLlETTINI, J.; NICOLAS, F.; PANICO, S.; DANELUZZI, J.; TINOS, R.; BARANAUSKAS, J.; MACEDO, A. A software architecture-based framework supporting suggestion of medical surveillance level from classification of electronic patient records. In: Computational Science and Engineering, 2009. CSE '09. International Conference on. [S.l.: s.n.], 2009. v. 1, p. $166-173$.

POLLETTINI, J. T.

Definição automática de medidas que identificam pessoas requerendo diferentes graus de vigilância para atendimento em atenção básica à saúde: uma abordagem utilizando Relevance Feedback e a Classificação Internacional de Doenças — Universidade de São Paulo, 2008.

POlletTini, J. T.; TINóS, R.; PANICO, S.; DANElUZZI, J. C.; MACEDO, A. A. Classificação automática de pacientes para atendimento médico pediátrico multidisciplinar a partir do seu grau de vigilância. In: Anais do VIII Workshop de Informática Médica (Evento paralelo ao XXVIII Congresso da Sociedade Brasileira de Computação). Belém - Brasil: [s.n.], 2008. p. 10p. 
POLlETTINI, J. T.; TINóS, R.; PANICO, S.; DANELUZZI, J. C.; MACEDO, A. A. Vigilância em atenção básica à saúde a partir do uso de relevance feedback para classificação de pacientes em diferentes níveis de cuidado em saúde. In: Anais do CSBC (Congresso da Sociedade Brasileira de Computação) 2009 - Workshop de Informática Médica. Bento Gonçalves - RS: [s.n.], 2009. p. 10p.

RINDFLESCH, T.; FISZMAN, M.; LIBBUS, B. Semantic interpretation for the biomedical research literature. In: SHARDA, R.; VOB, S.; CHEN, H.; FULLER, S. S.; FRIEDMAN, C.; HERSH, W. (Ed.). Medical Informatics: Knowledge Mangement and Data Mining in Biomedicine. Springer US, 2005, (Integrated Series in Information Systems, v. 8). p. 399-422. ISBN 978-0-387-25739-6. 10.1007/0-387-25739-X_14. Disponível em: <http://dx.doi.org/10.1007/0-387-25739-X_14>.

RINDFLESCH, T. C.; FISZMAN, M. The interaction of domain knowledge and linguistic structure in natural language processing: interpreting hypernymic propositions in biomedical text. Journal of biomedical informatics, v. 36, n. 6, p. 462-77, dez. 2003. ISSN 1532-0464. Disponível em: <http://www.ncbi.nlm.nih.gov/pubmed/14759819>.

ROBERTS, D.; JOHNSON, R. Evolving Frameworks: A Pattern Language for Developing Object-Oriented Frameworks. In: Proceedings of the Third Conference on Pattern Languages and Programming. Addison-Wesley, 1996. v. 3. Disponível em: $<$ http://citeseerx.ist.psu.edu/viewdoc/summary?doi=10.1.1.46.8767>.

ROCCHIO, J. J. Relevance feedback in information retrieval. In: SALTON, G. (Ed.). The Smart Retrieval System - Experiments in Automatic Document Processing. [S.l.: s.n.], 1971.

RODRIGUEZ-ESTEBAN, R. Biomedical text mining and its applications. PLoS computational biology, v. 5, n. 12, p. e1000597, 2009. ISSN 1553-7358. Disponível em: $<$ http://www.ncbi.nlm.nih.gov/pubmed/20041219>.

RUSSELL, S. J.; NORVIG, P. Inteligência Artificial. 2. ed. [S.l.: s.n.], 2004.

SAIAS, J.; QUARESMA, P. A methodology to create ontology-based information retrieval systems. Progress in Artificial Intelligence, Springer, p. 424-434, 2003. Disponível em: <http://www.springerlink.com/index/NAUKB686AKDT14V6.pdf>.

SALLES, R. F. Análise de um Programa de intervenção com bebês e famílias atendidas em unidades básicas de saúde - SUS. Dissertação (Dissertação) - Universidade Federal de São Carlos, São Carlos/SP, 2001.

SCHALKOFF, R. J. Artificial Intelligence: An Engineering Approach (Schaums Outline Series in Computers). Mcgraw-Hill College. Hardcover. ISBN 0070550840. Disponível em: <http://www.worldcat.org/isbn/0070550840>.

SCHLINZIG, T.; JOHANSSON, S.; GUNNAR, A.; EKSTRöM, T. J.; NORMAN, M. Epigenetic modulation at birth - altered DNA-methylation in white blood cells after Caesarean section. Acta paediatrica (Oslo, Norway: 1992), v. 98, n. 7, p. 1096-9, jul. 2009. ISSN 1651-2227. Disponível em: <http://www.ncbi.nlm.nih.gov/pubmed/19638013>. 
SHAH, N. H.; JONQUET, C.; CHIANG, A. P.; BUTTE, A. J.; CHEN, R.; MUSEN, M. A. Ontology-driven indexing of public datasets for translational bioinformatics. $B M C$ bioinformatics, v. 10 Suppl 2, n. Suppl 2, p. S1, 2009. ISSN 1471-2105. Disponível em: $<$ http://www.biomedcentral.com/1471-2105/10/S2/S1>.

SMITH, L.; RINDFLESCH, T.; WILBUR, W. J. MedPost: a part-of-speech tagger for bioMedical text. Bioinformatics (Oxford, England), v. 20, n. 14, p. 2320-1, 2004. ISSN 1367-4803. Disponível em: <http://www.ncbi.nlm.nih.gov/pubmed/15073016>.

STRACHAN, T.; READ, A. P. Human Molecular Genetics. 2. ed. [S.1.]: Garland Science, 1999.

Strube de Lima, V. L.; NUNES, M. d. G. V.; VIEIRA, R. Desafios do Processamento de Línguas Naturais. In: Anais do XXVII Congresso da SBC - SEMISH (XXXIV) Seminário Integrado de Software e Hardware. Rio de Janeiro, RJ: [s.n.], 2007. p. 2202-2216. Disponível em: <http://www.inf.pucrs.br/ linatural/Docs/Desafios.pdf >.

SURE, Y.; ERDMANN, M.; ANGELE, J.; STAAB, S.; STUDER, R.; WENKE, D. OntoEdit: Collaborative Ontology Development for the Semantic Web. [s.n.], 2002. $221+$ p. Disponível em: <http://www.springerlink.com/content/drux1nwev5ghr695>.

SWANSON, D.; SMALHEISER, N. An interactive system for finding complementary literatures: a stimulus to scientific discovery. Artificial intelligence, Elsevier, v. 91, n. 2, p. 183-203, 1997. ISSN 0004-3702. Disponível em: <http://linkinghub.elsevier.com/retrieve/pii/S0004370297000088>.

TOSH, D. N.; FU, Q.; CALlAWAY, C. W.; MCKNIGHT, R. A.; MCMILlEN, I. C.; ROSS, M. G.; LANE, R. H.; DESAI, M. Epigenetics of programmed obesity: alteration in IUGR rat hepatic IGF1 mRNA expression and histone structure in rapid vs. delayed postnatal catch-up growth. American journal of physiology. Gastrointestinal and liver physiology, v. 299, n. 5, p. G1023-9, nov. 2010. ISSN 1522-1547. Disponível em: $<$ http://www.ncbi.nlm.nih.gov/pubmed/20813916>.

VERMA, A.; KASABOV, N.; RUSH, E.; SONG, Q. Ontology Based Personalized Modeling for Chronic Disease Risk Analysis: An Integrated Approach. In: Advances in Neuro-Information Processing. Berlin, Heidelberg: Springer Berlin Heidelberg, 2009. (Lecture Notes in Computer Science, v. 5506), p. 1204-1210. ISBN 978-3-642-02489-4. Disponível em: <http://www.springerlink.com/content/y1335173425n532g>.

VOLK, M.; VINTAR, S.; BUITELAAR, P. Ontologies in cross-language information retrieval. In: Wissensmanagement. [S.l.: s.n.], 2003. p. 43-50.

WADHWA, P. D.; BUSS, C.; ENTRINGER, S.; SWANSON, J. M. Developmental origins of health and disease: brief history of the approach and current focus on epigenetic mechanisms. Seminars in reproductive medicine, v. 27, n. 5, p. 358-68, set. 2009. ISSN 1526-4564. Disponível em: $<$ http://www.pubmedcentral.nih.gov/articlerender.fcgi?artid=2862635\&tool=\% -pmcentrez\&rendertype $=$ abstract $>$.

WITTEN, I. H.; FRANK, E. Data Mining: Practical machine learning tools and techniques. 2. ed. San Francisco: Morgan Kaufmann, 2005. 
ZHOU, X.; LIU, B.; WU, Z.; FENG, Y. Integrative mining of traditional Chinese medicine literature and MEDLINE for functional gene networks. Artificial intelligence in medicine, v. 41, n. 2, p. 87-104, 2007. ISSN 0933-3657. Disponível em: $<$ http://www.ncbi.nlm.nih.gov/pubmed/17804209>. 


\section{Produção Bibliográfica e Participações em eventos}

Resumos publicados em anais de congressos no período de desenvolvimento do presente projeto de mestrado:

1.POlletTini, J. T. ; MACEDO, A. A. . Poster: Chronic Disease Prevention: A Translational Bioinformatics Approach. In: 1st IEEE International Conference on Computational Advances in Bio and medical Sciences (ICCABS), 2011, Orlando, Florida. IEEE International Conference on Computational Advances in Bio and medical Sciences proceedings, 2011.

2.POlletTini, J. T. ; MACEDO, A. A. . Chronic Disease Prevention: An approach based on genetic and epigenetic scientific papers. In: 6th International Conference of Brasilian Association for Bioinformatics and Computational Biology, 2010, Ouro Preto - MG. X-Meeting Eletronic Abstracts Book, 2010.

3.POLlETTINI, J. T. ; MACEDO, A. A. . Perspectives on the use of Bioinformatics Information to Help Healthcare Professionals on Chronic Diseases Prevention. In: 5th International Conference of the Brazilian Association for Bioinformatics and Computational Biology, 2009, Angra dos Reis, RJ. X-Meeting Eletronic Abstracts Book 2009, 2009.

Trabalhos completos publicados em anais de congressos:

1.NICOLAS, F. P. ; POLlETtini, J. T. ; PANICO, S. ; DANELUZZI, J. C. ; MACEDO, A. A. . O uso de UMLS para aprimorar a recomendação de graus de vigilância para pacientes do setor primário. In: XXX Congresso da Sociedade Brasileira de Computação - X Workshop de Informática Médica, 2010, Belo Horizonte. Anais do X Workshop de Informática Médica (WIM 2010), 2010. p. 10p.

2.POLlETtini, J. T. ; MiRANDA, G. H. B. ; Goularte, R. ; PANICO, S. ; DANELUZZI, J. C. ; MACEDO, A. A. . Sistema de Informação Geográfica: uma Abordagem 
Integrada a Sistemas de Informação em Saúde. In: XII Congresso Brasileiro de Informática em Saúde (CBIS), 2010, Porto de Galinhas - PE. Anais do XII Congresso Brasileiro de Informática em Saúde, 2010. p. 6p.

3.NICOLAS, F. P. ; POlletTini, J. T. ; PANICO, S. ; DANELUZZI, J. C. ; RUIZ, E. E. S. ; MACEDO, A. A. . Determinação e Análise de Tipos Semânticos usando UMLS e Árvores de Decisão para aprimorar a Determinação Automática do Grau de Vigilância de Pacientes. In: XII Congresso Brasileiro de Informática em Saúde (CBIS), 2010, Porto de Galinhas - PE. Anais do XII Congresso Brasileiro de Informática em Saúde, 2010. p. 6p.

4.POlletTini, J. T. ; TINOS, R. ; PANICO, S. ; DANELUZZI, J. C. ; MACEDO, A. A. . Vigilância em atenção básica à saúde a partir do uso de relevance feedback para classificação de pacientes em diferentes níveis de cuidado em saúde. In: Congresso da Sociedade Brasileira de Computação - IX Workshop de Informática Médica, 2009, Bento Gonçalves - RS. Anais do CSBC 2009 - Workshop de Informática Médica, 2009. p. 1945-1954.

5.POLlETTINI, J. T. ; NICOLAS, F. P. ; PANICO, S. ; DANELUZZI, J. C. ; TINOS, R. ; BARANAUSKAS, J. A. ; MACEDO, A. A. . A software architecture-based framework supporting suggestion of medical surveillance level from classification of electronic patient records. In: International Conference on Computational Science and Engineering, 2009, Vancouver, Canada. The 12th IEEE International Conference on Computational Science and Engineering, 2009. p. 166-173.

\section{Trabalho completo submetido para congresso internacional:}

1.POlletTini, J. T.; RUIZ, E. E. S.; MACEDO, A. A. . A Language Resources Framework supporting Conceptual Relationships among Biomedical Information to Chronic Disease Surveillance. In: Eighth International Conference on Language Resources and Evaluation (LREC), 2012, Istanbul, 2012.

\section{Artigo submetido para periódico internacional:}

1.POlletTINI, J. T. ; PANICO, S. ; DANELUZZI, J. C. ; TINOS, R. ; BARANAUSKAS, J. A. ; MACEDO, A. A. . Using machine learning classifiers to assist healthcarerelated decisions: classification of electronic patient records. Journal of Medical Systems, Springer. 


\section{Apresentação de Trabalho:}

1.POLLETTINI, J. T. . Sistema de Vigilância baseado no relacionamento entre fatores epigenéticos e doenças crônicas. Apresentação de Trabalho no I Workshop de Bioinformática da Universidade de São Paulo. 2010.

\section{Participações em Eventos Científicos}

1.6th International Conference of Brazilian Association for Bioinformatics and Computational Biology (X-Meeting 2010) - realizado no período de 15 a 18/11/2010, em Ouro Preto, MG.

2.I Workshop de Bioinformática da Universidade de São Paulo - realizado no período de 09 a 10/09/2010, em São Paulo, SP.

3.1st Sao Paulo School of Translational Science - curso da modalidade ESPCA (Escola São Paulo de Ciência Avançada), realizado no período de 19 a 30/04/2010, no Hospital A.C. Camargo, São Paulo, SP.

4.5th International Conference of the Brazilian Association for Bioinformatics and Computational Biology (X-Meeting 2009) - realizado no período de 18 a 22/10/2009, em Angra dos Reis, RJ.

5.Seminário em Ciência Translacional - ministrado no Laboratório de Telemedicina - LAT/Unifesp, pelos Profs. Drs Eneida Abrantes Mendonça (Assistant Professor, University of Chicago) e Dr. Umberto Tachinardi Andrade Silva (Director of Informatics, University of Chicago Cancer Research Center - UCCRC) no período de 14 a 16/09/2009. Participação via RUTE (Rede Universitária de Telemedicina).

6.XXIX Congresso da Sociedade Brasileira de Computação (CSBC-2009) - realizado no período de 20 a 24/07/09, em Bento Gonçalves, RS.

\section{Participações em Bancas Examinadoras}

1.AlveS, D.; SABBATINI, R. M. E.; POlletTini, J. T.. Participação em banca de Gustavo Bertoldo da Silva. Desenvolvimento de um Sistema de Dicionário de Dados para Prontuário Eletrônico do Paciente Web para Atendimento de Crianças com Diabetes Tipo 1. 2010. Trabalho de Conclusão de Curso (Graduação em Informática Biomédica) - Universidade de São Paulo. 
2.AlVES, D.; MARqueS, P. M. A.; POlletTini, J. T.. Participação em banca de Danubia Midori Berto Fujita. A Telemedicina na Estratégia de Saúde da Família: uma Avaliação de Aplicabilidade e Resolubilidade. 2010. Trabalho de Conclusão de Curso (Graduação em Informática Biomédica) - Universidade de São Paulo.

\section{Supervisões e Orientações Concluídas}

1.Flávia Pena Nicolas. Sistema para Reconhecimento Automático de Conceitos do Domínio de Doenças Crônicas em Artigos Científicos. 2010. Trabalho de Conclusão de Curso. (Graduação em Informática Biomédica) - Universidade de São Paulo. Co-orientação (Orientador principal: Alessandra Alaniz Macedo). 


\section{APÊNDICE A - Mecanismos Epigenéticos}

Lista de mecanismos epigenéticos obtida a partir da análise de vocabulários controlados da área de saúde presentes no Sistema Unificado de Linguagem Médica (UMLS) e analisada por equipe de especialistas no domínio pertencentes ao Laboratório de Genômica Pediátrica da FMUSP:

\author{
Epigenomics \\ Epigenesis, Genetic \\ Epigenetic Process \\ Genomic Imprinting \\ Chromosomal Position Effects \\ Dosage Compensation, Genetic \\ $\mathrm{X}$ Chromosome Inactivation \\ regulation of gene expression, epigenetic \\ dosage compensation \\ dosage compensation, by inactivation of $\mathrm{X}$ chromo- \\ some \\ dosage compensation, by hyperactivation of $\mathrm{X}$ chro- \\ mosome \\ dosage compensation, by hypoactivation of $\mathrm{X}$ chro- \\ mosome \\ $\mathrm{X}$ Chromosome Inactivation \\ DNA methylation \\ DNA methylation during embryonic development \\ DNA methylation during gametogenesis \\ DNA methylation on adenine \\ DNA methylation on cytosine \\ Hypermethylation \\ DNA Methylation Increase
}

\author{
DNA Methylation Decrease \\ genetic imprinting \\ negative regulation of gene expression, epigenetic \\ chromatin silencing \\ positive regulation of gene expression, epigenetic \\ chromatin-mediated maintenance of transcription \\ negative regulation of chromatin silencing \\ long-term maintenance of gene activation \\ posttranscriptional gene silencing \\ posttranscriptional gene silencing by RNA \\ gene silencing by miRNA \\ RNA interference \\ long-distance posttranscriptional gene silencing \\ host gene silencing in virus induced gene silencing \\ viral gene silencing in virus induced gene silencing \\ gene silencing \\ posttranscriptional gene silencing \\ chromatin silencing \\ gene silencing by RNA \\ RNA Interference \\ negative regulation of rhodopsin gene expression \\ negative regulation of survival gene product expression
}




\section{APÊEDICE B - Consulta PubMed}

A consulta utilizada pelo ChronDiseaSSys para buscar artigos científicos do domínio é composta por quatro sub-consultas, as quais são apresentadas a seguir.

Subconsulta 1: Genes ligados a doenças crônicas como doenças cardiovasculares, diabetes e obesidade extraídos da CDO.

'ACE[All Fields] OR ADD1[All Fields] OR ADIPOQ[All Fields] OR ("receptors, adrenergic, beta-2"[MeSH Terms] OR ("receptors"[All Fields] AND "adrenergic"[All Fields] AND "beta-2" [All Fields]) OR "beta-2 adrenergic receptors"[All Fields] OR "adrb2"[All Fields]) OR AGT[All Fields] OR AGTR1[All Fields] OR AHSG[All Fields] OR ANGPT4[All Fields] OR ANGPTL3[All Fields] OR APOA4[All Fields] OR ("apolipoproteins b" [MeSH Terms] OR "apolipoproteins b"[All Fields] OR "apob"[All Fields]) OR APOC3[All Fields] OR ("apolipoproteins e" [MeSH Terms] OR "apolipoproteins e" [All Fields] OR "apoe"[All Fields]) OR BBS4[All Fields] OR CAPN10[All Fields] OR CAPN5[All Fields] OR CCL2[All Fields] OR CD36[All Fields] OR ("ccaat-enhancer-binding protein-alpha" [MeSH Terms] OR ("ccaat-enhancer-binding" [All Fields] AND "protein-alpha" [All Fields]) OR "ccaat-enhancer-binding protein-alpha" [All Fields] OR "cebpa"[All Fields]) OR CETP[All Fields] OR CHGA[All Fields] OR CRP[All Fields] OR ENPP1[All Fields] OR FABP2[All Fields] OR FABP4[All Fields] OR FGB[All Fields] OR ("fibroblast growth factor 1" [MeSH Terms] OR "fibroblast growth factor 1"[All Fields] OR "fgf1"[All Fields]) OR FLT1[All Fields] OR GHRL[All Fields] OR GNB3[All Fields] OR ("hypoxia-inducible factor 1, alpha subunit" [MeSH Terms] OR "alpha subunit hypoxia-inducible factor 1"[All Fields] OR "hif1a"[All Fields]) OR HNF4A[All Fields] OR ("intercellular adhesion molecule-1"[MeSH Terms] OR ("intercellular"[All Fields] AND "adhesion"[All Fields] AND "molecule-1"[All Fields]) OR "intercellular adhesion molecule-1"[All Fields] OR "icam1"[All Fields]) OR IGF1[All Fields] OR ("insulin-like growth factor binding protein 1"[MeSH Terms] OR "insulin-like growth factor binding protein 1"[All Fields] OR "igfbp1"[All Fields]) OR ("interleukin 1 receptor antagonist protein"[MeSH Terms] OR "interleukin 1 receptor antagonist protein"[All Fields] OR "il1rn"[All Fields]) OR IL6[All Fields] OR IL8[All Fields] OR INS[All Fields] OR INSR[All Fields] OR IRS1[All Fields] OR IRS2[All Fields] OR ITLN1[All Fields] OR KCNJ11[All Fields] OR LEP[All Fields] OR LIPC[All Fields] OR LIPE[All Fields] OR LIPG[All Fields] OR LMNA[All Fields] OR LPL[All Fields] OR MMP2[All Fields] OR ("methylenetetrahydrofolate reductase (nadph2)"[MeSH Terms] OR ("methylenetetrahydrofolate"[All Fields] AND "reductase"[All Fields] AND "(nadph2)"[All Fields]) OR "methylenetetrahydrofolate reductase (nadph2)"[All Fields] OR "mthfr"[All Fields]) OR NAIP[All Fields] OR NOS3[All Fields] OR PLTP[All Fields] OR ("ppar gamma"[MeSH Terms] OR ("ppar"[All Fields] AND "gamma"[All Fields]) OR "ppar gamma"[All Fields] OR "pparg"[All Fields]) OR PRKAA2[All Fields] OR PRKAG1[All Fields] OR RBP4[All Fields] OR RETN[All Fields] OR ("Spec Care Dentist" [Journal] OR "scd"[All Fields]) OR SELE[All Fields] OR ("plasminogen activator inhibitor 1"[MeSH Terms] OR "plasminogen activator inhibitor 1"[All Fields] OR "serpine1"[All Fields]) OR SOD3[All Fields] OR TCF7L2[All Fields] OR ("transforming growth factor beta1"[MeSH Terms] OR ("transforming"[All Fields] AND "growth"[All Fields] AND "factor"[All Fields] AND "beta1"[All Fields]) OR "transforming growth factor beta1"[All Fields] OR "tgfb1"[All Fields]) OR TNF[All Fields] OR TNFRSF1B[All Fields] OR ("vascular endothelial growth factor a" [MeSH Terms] OR "vascular endothelial growth factor a"[All Fields] OR "vegf" [All Fields]) OR WFS1[All Fields]'

\section{Subconsulta 2: Mutações.}

'(Complex[All Fields] AND rearrangements[All Fields] AND including[All Fields] AND inversions[All Fields]) OR ("sequence deletion" [MeSH Terms]) OR ("dinucleotide repeats"[MeSH Terms]) OR ("dinucleotide repeats"[All Fields] OR "dinucleotide repeat"[All Fields]) OR ("frameshift mutation" [MeSH Terms]) OR (Gross[All Fields] AND deletions[All Fields]) OR (Gross[All Fields] AND insertions[All Fields] AND duplications[All Fields]) OR ("mutagenesis, insertional" [MeSH Terms]) OR ("chromosome inversion" [MeSH Terms]) OR (Missense/nonsense[All Fields] AND ("mutation" [MeSH Terms])) OR (mononucleotide[All Fields] AND repeat[All Fields]) OR (Point[All Fields] AND Variation[All Fields]) OR (Regulatory[All Fields] AND ("mutation"[MeSH Terms])) OR (Repeat[All Fields] AND variations[All Fields]) OR ("polymorphism, restriction fragment length"[MeSH Terms]) OR ("polymorphism, single nucleotide"[MeSH Terms]) OR ("small"[All Fields] AND deletions[All Fields]) OR ("small"[All Fields] AND indels[All Fields]) OR ("small"[All Fields] AND insertions[All Fields]) OR (("rna splicing"[MeSH Terms] OR "rna splicing"[All Fields] OR "splicing"[All Fields]) AND ("mutation"[MeSH Terms] OR "mutation"[All Fields] OR "mutations"[All Fields])) OR Substitution[All Fields] OR ("microsatellite repeats" [MeSH Terms] OR "tetranucleotide repeat"[All Fields]) OR ("trinucleotide repeats" [MeSH Terms]) OR ("minisatellite repeats"[MeSH Terms] OR "variable number of tandem repeats"[All Fields])' 
Subconsulta 3: Mecanismos epigenéticos extraídos do UMLS e expandidos através da expansão de consultas do PubMed.

'("epigenomics"[MeSH Terms]) OR ("epigenomics"[All Fields]) OR ("epigenesis, genetic"[MH]) OR ("genomic imprinting"[MH]) OR ("chromosomal position effects" [MH]) OR ("dosage compensation, genetic" [MH]) OR ("x chromosome inactivation" [MH]) OR (("gene expression regulation" $[\mathrm{MH}])$ AND "epigenetic"[All Fields]) OR (("dosage compensation, genetic" [MH]) AND ("hyperactivation"[All Fields]) AND ("x chromosome" $[\mathrm{MH}]$ OR "x chromosome"[All Fields])) OR (("dosage compensation, genetic"[MH]) AND ("hypoactivation"[All Fields]) AND ("x chromosome" $[\mathrm{MH}]$ OR "x chromosome"[All Fields])) OR ("dna methylation" $[\mathrm{MH}])$ OR (("dna methylation"[MH]) AND (("embryonic development" $[\mathrm{MH}])$ OR ("embryonic development" [All Fields]))) OR (("dna methylation" [MH]) AND (("gametogenesis" [MH]) OR "gametogenesis"[All Fields])) OR (("dna methylation" [MH]) AND ("adenine" [MH]) OR ("adenine"[All Fields]))) OR (("dna methylation" [MH]) AND (("cytosine" $[\mathrm{MH}])$ OR ("cytosine"[All Fields]))) OR (("dna methylation" [MH]) AND ("Increase" [All Fields])) OR (("dna methylation" [MH]) AND ("Decrease"[All Fields])) OR (("negative"[All Fields]) AND ("gene expression regulation"[MH]) AND ("epigenetic"[All Fields])) OR (("chromatin"[MH]) AND ("silencing"[All Fields])) OR (("positive"[All Fields]) AND ("gene expression regulation"[MH]) AND ("epigenetic"[All Fields])) OR (("chromatin-mediated"[All Fields]) AND ("maintenance" [MH]) AND ("transcription, genetic"[MH])) OR (("negative"[All Fields]) AND ("social control, formal" [MH]) AND ("chromatin"[MH]) AND ("silencing"[All Fields])) OR (("long-term"[All Fields]) AND ("maintenance" $[\mathrm{MH}]$ ) AND ("transcriptional activation" $[\mathrm{MH}])$ ) OR ("rna interference" $[\mathrm{MH}])$ OR (("gene silencing" $[\mathrm{MH}])$ AND (("micrornas" [MH]) OR ("micrornas"[All Fields]) OR ("mirna"[All Fields]))) OR (("long-distance"[All Fields]) AND ("rna interference"[MH])) OR (("host"[All Fields]) AND ("gene silencing" [MH]) AND ("viruses"[MH]) AND ("induced"[All Fields])) OR (("genes, viral" [MH]) AND ("silencing" [All Fields]) AND ("viruses" [MH]) AND ("induced"[All Fields]) AND ("gene silencing" [MH])) OR ("gene silencing" [MH]) OR ("rna interference" $[\mathrm{MH}])$ OR (("chromatin" $[\mathrm{MH}])$ AND ("silencing"[All Fields])) OR (("gene silencing" [MH]) AND (("rna" [MH]) OR ("rna" $[\mathrm{All}$ Fields])) ) OR (("negative" [All Fields]) AND (("social control, formal" [MH]) OR ("formal social control" [All Fields])) AND (("rhodopsin" [MH]) OR ("rhodopsin" [All Fields])) AND (("gene expression"[MH]) OR ("gene expression" [All Fields]))) OR ((" negative" [All Fields]) AND (("social control, formal" [MH]) OR ("formal social control"[All Fields])) AND (("survival" [MH]) OR ("mortality" [All Fields])) AND (("proteins"[MH]) OR ("gene product"[All Fields])) AND (("gene expression" [MH]) OR ("gene expression"[All Fields]))),

Subconsulta 4: Termos para especificar conteúdo para o domínio dos fatores de risco incidentes da concepção ao final da adolescência para as três doenças crônicas de interesse.

'(("child"[MeSH Terms] OR "child"[All Fields]) OR ("infant"[MeSH Terms] OR "infant"[All Fields]) OR kid[All Fields] OR youngster[All Fields] OR ("adolescent" [MeSH Terms] OR "adolescent" [All Fields] OR "teenager"[All Fields]) OR ("adolescent"[MeSH Terms] OR "adolescent"[All Fields] OR "teen"[All Fields]) OR ("adolescent"[MeSH Terms] OR "adolescent"[All Fields]) OR ("infant, newborn"[MeSH Terms] OR ("infant"[All Fields] AND "newborn"[All Fields]) OR "newborn infant"[All Fields] OR "baby"[All Fields] OR "infant"[MeSH Terms] OR "infant"[All Fields]) OR ("child"[MeSH Terms] OR "child"[All Fields] OR "children"[All Fields]) OR kids[All Fields] OR offspring[All Fields]) AND (("obesity" [MeSH Terms] OR "obesity" [All Fields]) OR ("diabetes mellitus"[MeSH Terms] OR ("diabetes" [All Fields] AND "mellitus"[All Fields]) OR "diabetes mellitus" [All Fields] OR "diabetes" [All Fields]) OR ("cardiovascular diseases" [MeSH Terms] OR ("cardiovascular"[All Fields] AND "diseases"[All Fields]) OR "cardiovascular diseases"[All Fields] OR ("cardiovascular"[All Fields] AND "disease"[All Fields]) OR "cardiovascular disease" [All Fields])), 